\title{
Putative role of palmitate and Akt signaling in attenuating skeletal muscle growth in the obese zucker rat
}

Jonathan Michael Peterson

West Virginia University

Follow this and additional works at: https://researchrepository.wvu.edu/etd

\section{Recommended Citation}

Peterson, Jonathan Michael, "Putative role of palmitate and Akt signaling in attenuating skeletal muscle growth in the obese zucker rat" (2008). Graduate Theses, Dissertations, and Problem Reports. 2713. https://researchrepository.wvu.edu/etd/2713

This Dissertation is protected by copyright and/or related rights. It has been brought to you by the The Research Repository @ WVU with permission from the rights-holder(s). You are free to use this Dissertation in any way that is permitted by the copyright and related rights legislation that applies to your use. For other uses you must obtain permission from the rights-holder(s) directly, unless additional rights are indicated by a Creative Commons license in the record and/ or on the work itself. This Dissertation has been accepted for inclusion in WVU Graduate Theses, Dissertations, and Problem Reports collection by an authorized administrator of The Research Repository @ WVU.

For more information, please contact researchrepository@mail.wvu.edu. 
Putative Role of Palmitate and Akt signaling in Attenuating Skeletal Muscle Growth in the Obese Zucker Rat

Jonathan Michael Peterson, BS, MS

Dissertation Submitted to the

School of Medicine

At West Virginia University

in Partial Fulfillment of the Requirements

for the Degree of

Doctor of Philosophy

in

Exercise Physiology

Randall W. Bryner, Ph.D., Chair

Stephen E. Always, Ph.D.

Guyton W. Hornsby, Ph.D.

Robert G. Cutlip, Ph.D

Stanely M. Hileman, Ph.D.

Morgantown, West Virginia

2008 


\begin{abstract}
Putative Role of Palmitate and Akt signaling in Attenuating Skeletal Muscle Growth in the Obese Zucker Rat

Jonathan Michael Peterson, BS, MS
\end{abstract}

The Obese zucker rat (OZR) is a model of obesity and metabolic syndrome, with a reduced skeletal muscle mass compared with the lean zucker rat (LZR). Growth and hypertrophy of muscle fibers critically depend on activation and differentiation of satellite cells into new myonuclei, as well as the prevention of myonuclear apoptosis. Akt is known to regulate satellite cell activation and differentiation and inhibit apoptotic signaling. Akt activity is also reduced in the OZR compared to the LZR. The present study had two primary purposes; first, to observe, in vitro, the effects of the saturated free fatty acid palmitate on C2C12 mouse myoblast proliferation and differentiation, Akt signaling and apoptosis in myotubes, and second, to examine if there was reduced Akt signaling, satellite cell proliferation and differentiation, and/or increased satellite death in the OZR compared to the LZR. Akt signaling was significantly reduced both in vitro following palmitate treatment and in vivo in the OZR. Furthermore, myoblast proliferation and differentiation were reduced after palmitate treatment, in vitro, and satellite cell activation was reduced in the OZR compared to the LZR. Although palmitate treatment was sufficient to induce apoptotic signaling in C2C12 myotubes, there was no increase in apoptotic signaling in muscles of the OZR. Together, these data indicate that although disruptions in Akt signaling in muscles of the OZR may be responsible for the decrease in muscle mass through attenuated satellite cell activation and proliferation, increased apoptotic signaling does not appear to be a factor to explain the decrease muscle mass in the OZR compared to the LZR. 
CHAPTER 5: "Mitochondrial Apoptotic Signaling is Elevated in Cardiac but not Skeletal Muscle in the Obese Zucker Rat and is Reduced with Aerobic Exercise"

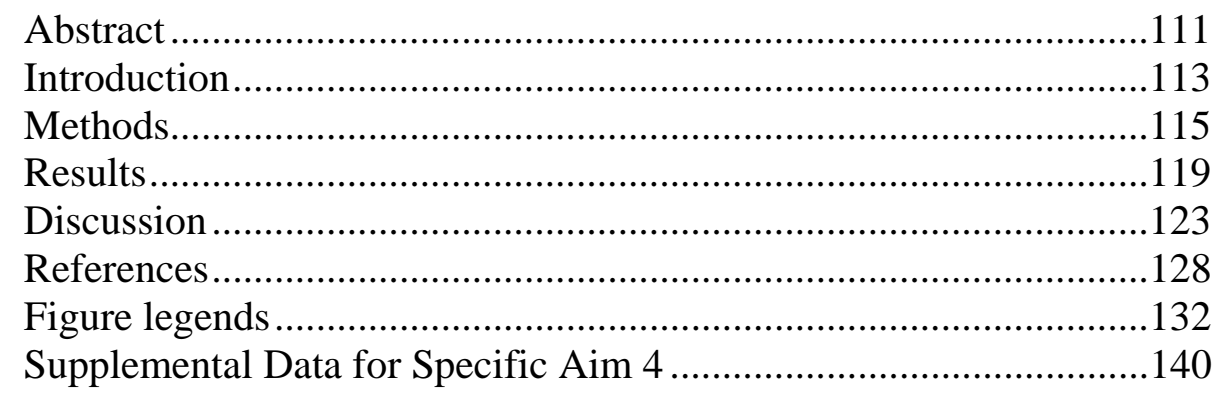

CHAPTER 6:

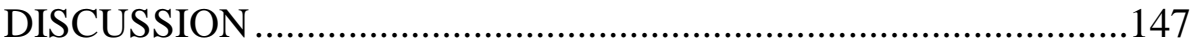

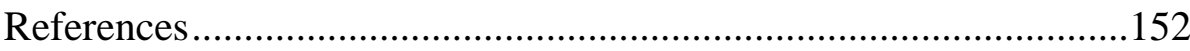

APENDIX

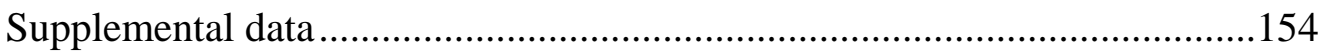

Supplemental publication: "Effects of exercise and obesity on UCP3 content in Rat hindlimb Muscles

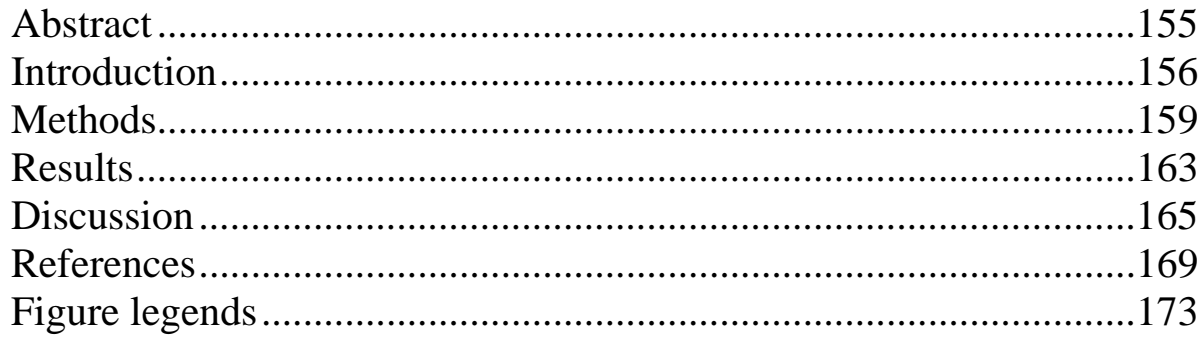

Methods. 


\section{LIST OF FIGURES}

\section{CHAPTER 1}

Figure 1: “Akt action on cell cycle control”......................................5

Figure 2: “Akt action and Myoblast Differentiation”........................

Figure 3: “Akt action on apoptotic signaling” .................................9

CHAPTER 2:

Figure 1: “Myoblast proliferation CFSE” ........................................42

Figure 2: "Myoblast proliferation BrdU” ......................................43

Figure 3: "Cell cycle" ..................................................................44

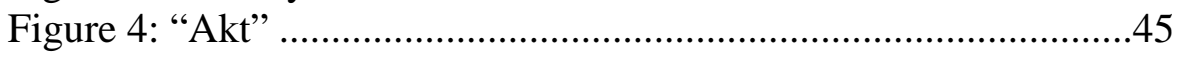

Figure 5: "Cell cycle proteins" ......................................................46

Figure 6: "Myoblast Differentiation”.............................................47

CHAPTER 3:

Table 1: "Animal Characteristics”....................................................75

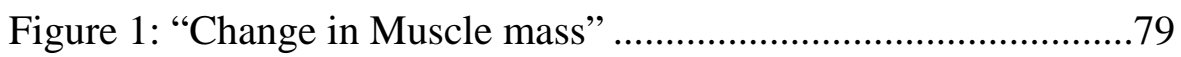

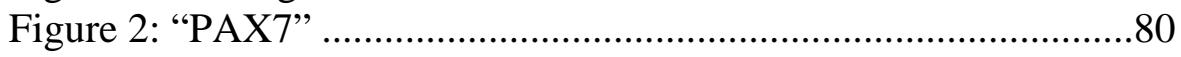

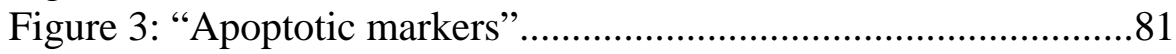

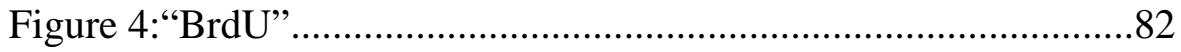

Figure 5: "Myogenic Regulatory Factors”........................................83

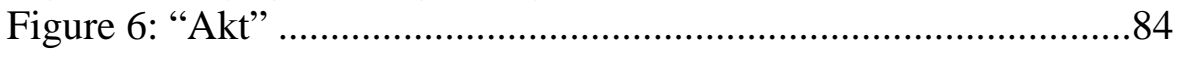

CHAPTER 4:

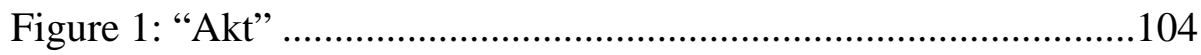

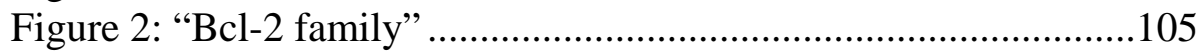

Figure 3: "Mitochondrial Apoptotic protein” ....................................106

Figure 4: "Caspase Activation” ......................................................107

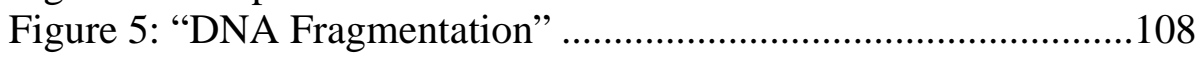

Figure 6: “Immunoprecipitation”................................................109

Figure 7: "Bax siRNA”.................................................................110

\section{CHAPTER 5:}

Table1: "Muscle Wet weights”..................................................131

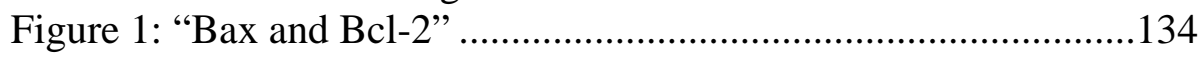

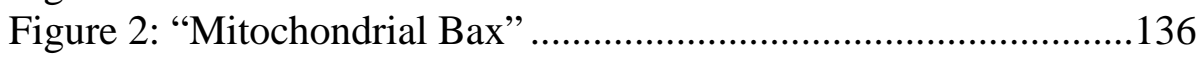

Figure 3: "Mitochondrial Apoptotic protein” .................................137

Figure 4: "Caspase Activation” ...................................................138

Figure 5: "DNA Fragmentation” .................................................139

Supplemental 1: "Bax and Bcl-2”................................................144

Supplemental 2: “Caspase Activation”...........................................145 
Supplemental 3: "DNA fragmentation”

SUPPLEMENTAL DATA

Figure 1: “UCP3 protein expression” .............................................175

Figure 2: "Mitochondrial protein expression” ................................177

Figure 3: "Citrate synthase activity”..............................................178 


\section{SPECIFIC AIMS}

Metabolic syndrome is a clinically important problem, which affect more than 50 million Americans (11). Metabolic syndrome is defined as a cluster of risk factors for heart disease and type 2 diabetes mellitus including: (i) obesity, (ii) insulin resistance (with or without glucose intolerance), (iii) hypertension, (iv) dyslipidemia, (v) a prothrombotic state (e.g., high fibrinogen or plasminogen activator inhibitor-1 in the blood), and (vi) a proinflammatory state (e.g., elevated C-reactive protein in the blood). Disruptions of glucose or fatty acid oxidation are major contributors to the complications associated with obesity and metabolic syndrome. Because skeletal muscles are the primary tissue responsible for glucose and fatty acid oxidation (2; $3 ; 23)$, any reduced skeletal muscle mass would be an unfavorable outcome in metabolic syndrome.

The obese Zucker ( $f a / f a)$ rat (OZR) is a rodent model of severe obesity and metabolic syndrome. The OZR has a dysfunctional leptin receptor which leads to chronic hyperphagia, resulting in a rapid onset of obesity, skeletal muscle insulin resistance, hyperglycemia, mild hypertension, and high circulating levels of free fatty acids (12; 26; 27; 30). Although OZRs are significantly less active than the LZRs (5), OZRs have a greater body mass, and therefore should have a greater stimulus for muscle growth on the weight bearing muscles. However, there is a significant (10-25\%) reduction in the skeletal muscle mass of the OZR compared to the lean Zucker rat (LZR) phenotype (10). We have found that increasing the activity of the OZR through daily treadmill running, fails to increase the size of skeletal muscles (12). This raises the

possibility that a metabolic syndrome induced defect in skeletal muscle may account for the reduction in skeletal muscle mass in the OZR.

Hypertrophy of muscle fibers critically depends on the activation and differentiation of satellite cells into new myonuclei, as well as the preservation of mature myonuclei $(1 ; 17 ; 21 ; 22$; 
24). It is possible that disruptions in the regulation of myonuclear number may account for the reduced muscle mass in the OZR compared to the LZR, as muscle fiber size is critically dependent on myonuclear content $(1 ; 24)$. This idea is consistent with the observation that nucleic acid content is less in the OZR, (10) which could be explained if there was a decreased myonuclear number, in the skeletal muscles of OZRs compared to the LZRs.

One potential mechanism that might account for reduced nuclei is lower Akt activity in muscles of the OZR (20). This is because Akt regulates at least in part, satellite cell activation and differentiation, and inhibits myonuclear apoptosis (4; 8; 9; 13-15; 18; 19; 25; 28; 29). Akt activity might be inhibited by high intramuscular lipid levels in muscles of animals with metabolic syndrome, such as palmitate (6;7), which is the most common saturated fatty acid found in the muscle tissue (16). Our central hypothesis is that increased palmitate decreases satellite cell proliferation and differentiation and sensitizes differentiated myonuclei to apoptosis through disruptions in Akt signaling. This central hypothesis was tested by the following four specific aims.

Specific aim 1: To determine if the addition of palmitate attenuates proliferation and differentiation of myoblasts in vitro.

Hypothesis 1.1: Palmitate treatment of $\mathrm{C} 2 \mathrm{C} 12$ myoblasts will decrease myoblast proliferation in vitro.

Hypothesis 1.2: Palmitate treatment will reduce myoblast fusion/ differentiation in vitro. 
Specific aim 2: To determine if reduced proliferation and differentiation of satellite cells contributes to a decreased muscle fiber size and muscle wet weight in the OZR model of obesity and metabolic syndrome.

Hypothesis 2.1: The number of activated satellite cells incorporated into myofibers in vivo will be lower in muscles of OZR rats compared to LZR.

Hypothesis 2.2: Impaired satellite cell proliferation cannot be restored by increased loading in skeletal muscles of OZR compared to the LZR.

Specific aim 3: To determine if palmitate treatment increases the susceptibly of myoblasts or myotubes to mitochondrial-associated apoptosis in vitro.

Hypothesis 3.1: Palmitate treatment will increase nuclear apoptosis of C2C12 myoblasts and myotubes through mitochondrial-associated (intrinsic) pathways including an elevation of the Bax to Bcl2 ratio.

Specific aim 4: To determine if metabolic syndrome increases the susceptibly of myonuclei to apoptosis during muscle wasting induced by denervation.

Hypothesis 4.1: Mitochondrial associated apoptotic signaling and nuclear apoptosis will be elevated in denervated skeletal muscles of OZR compared to the LZR. 
Reference List

1. Allen DL, Roy RR and Edgerton VR. Myonuclear domains in muscle adaptation and disease. Muscle Nerve 22: 1350-1360, 1999.

2. Basu A, Basu R, Shah P, Vella A, Johnson CM, Nair KS, Jensen MD, Schwenk WF and Rizza RA. Effects of type 2 diabetes on the ability of insulin and glucose to regulate splanchnic and muscle glucose metabolism: evidence for a defect in hepatic glucokinase activity. Diabetes 49: 272-283, 2000.

3. Bjornholm $\mathbf{M}$ and Zierath JR. Insulin signal transduction in human skeletal muscle: identifying the defects in Type II diabetes. Biochem Soc Trans 33: 354-357, 2005.

4. Bouzakri K, Zachrisson A, Al Khalili L, Zhang BB, Koistinen HA, Krook A and Zierath JR. siRNA-based gene silencing reveals specialized roles of IRS-1/Akt2 and IRS2/Akt1 in glucose and lipid metabolism in human skeletal muscle. Cell Metab 4: 89-96, 2006.

5. Bray GA. The Zucker-fatty rat: a review. Fed Proc 36: 148-153, 1977.

6. Chavez JA, Knotts TA, Wang LP, Li G, Dobrowsky RT, Florant GL and Summers SA. A role for ceramide, but not diacylglycerol, in the antagonism of insulin signal transduction by saturated fatty acids. J Biol Chem 278: 10297-10303, 2003. 
7. Chavez JA and Summers SA. Characterizing the effects of saturated fatty acids on insulin signaling and ceramide and diacylglycerol accumulation in 3T3-L1 adipocytes and C2C12 myotubes. Arch Biochem Biophys 419: 101-109, 2003.

8. Cho H, Thorvaldsen JL, Chu Q, Feng F and Birnbaum MJ. Akt1/PKBalpha is required for normal growth but dispensable for maintenance of glucose homeostasis in mice. J Biol Chem 276: 38349-38352, 2001.

9. Downward J. PI 3-kinase, Akt and cell survival. Semin Cell Dev Biol 15: 177-182, 2004.

10. Durschlag RP and Layman DK. Skeletal muscle growth in lean and obese Zucker rats. Growth 47: 282-291, 1983.

11. Ford ES, Giles WH and Dietz WH. Prevalence of the metabolic syndrome among US adults: findings from the third National Health and Nutrition Examination Survey. JAMA 287: 356-359, 2002.

12. Frisbee JC, Samora JB, Peterson $\mathbf{J}$ and Bryner R. Exercise training blunts microvascular rarefaction in the metabolic syndrome. Am J Physiol Heart Circ Physiol 291: H2483-H2492, 2006.

13. Frost RA and Lang $\mathbf{C H}$. Protein kinase B/Akt: a nexus of growth factor and cytokine signaling in determining muscle mass. J Appl Physiol 103: 378-387, 2007. 
14. Furukawa-Hibi Y, Kobayashi Y, Chen C and Motoyama N. FOXO transcription factors in cell-cycle regulation and the response to oxidative stress. Antioxid Redox Signal 7: 752$760,2005$.

15. Gardai SJ, Hildeman DA, Frankel SK, Whitlock BB, Frasch SC, Borregaard N, Marrack P, Bratton DL and Henson PM. Phosphorylation of Bax Ser184 by Akt regulates its activity and apoptosis in neutrophils. J Biol Chem 279: 21085-21095, 2004.

16. Gorski J, Nawrocki A and Murthy M. Characterization of free and glyceride-esterified long chain fatty acids in different skeletal muscle types of the rat. Mol Cell Biochem 178: 113-118, 1998.

17. Harridge SD. Plasticity of human skeletal muscle: gene expression to in vivo function. Exp Physiol 92: 783-797, 2007.

18. Heron-Milhavet L, Franckhauser C, Rana V, Berthenet C, Fisher D, Hemmings BA, Fernandez A and Lamb NJ. Only Akt1 is required for proliferation, while Akt2 promotes cell cycle exit through p21 binding. Mol Cell Biol 26: 8267-8280, 2006.

19. Heron-Milhavet L, Mamaeva D, Rochat A, Lamb NJ and Fernandez A. Akt2 is implicated in skeletal muscle differentiation and specifically binds Prohibitin2/REA. J Cell Physiol 214: 158-165, 2008. 
20. Kim YB, Peroni OD, Franke TF and Kahn BB. Divergent regulation of Akt1 and Akt2 isoforms in insulin target tissues of obese Zucker rats. Diabetes 49: 847-856, 2000.

21. McCall GE, Allen DL, Linderman JK, Grindeland RE, Roy RR, Mukku VR and Edgerton VR. Maintenance of myonuclear domain size in rat soleus after overload and growth hormone/IGF-I treatment. J Appl Physiol 84: 1407-1412, 1998.

22. Ohira Y, Yoshinaga T, Nomura T, Kawano F, Ishihara A, Nonaka I, Roy RR and Edgerton VR. Gravitational unloading effects on muscle fiber size, phenotype and myonuclear number. Adv Space Res 30: 777-781, 2002.

23. Olsen DB, Sacchetti M, Dela F, Ploug T and Saltin B. Glucose clearance is higher in arm than leg muscle in type 2 diabetes. J Physiol 565: 555-562, 2005.

24. Roy RR, Monke SR, Allen DL and Edgerton VR. Modulation of myonuclear number in functionally overloaded and exercised rat plantaris fibers. J Appl Physiol 87: 634-642, 1999.

25. Stambolic V, Suzuki A, de la Pompa JL, Brothers GM, Mirtsos C, Sasaki T, Ruland J, Penninger JM, Siderovski DP and Mak TW. Negative regulation of PKB/Akt-dependent cell survival by the tumor suppressor PTEN. Cell 95: 29-39, 1998.

26. Takaya K, Ogawa Y, Masuzaki H, Matsuoka N, Hosoda K and Nakao K. [Leptin Receptor]. Nippon Rinsho 56: 1925-1930, 1998. 
27. Turner N, Bruce CR, Beale SM, Hoehn KL, So T, Rolph MS and Cooney GJ. Excess lipid availability increases mitochondrial fatty acid oxidative capacity in muscle: evidence against a role for reduced fatty acid oxidation in lipid-induced insulin resistance in rodents. Diabetes 2007.

28. Vincent AM and Feldman EL. Control of cell survival by IGF signaling pathways. Growth Horm IGF Res 12: 193-197, 2002.

29. Xu Q and Wu Z. The insulin-like growth factor-phosphatidylinositol 3-kinase-Akt signaling pathway regulates myogenin expression in normal myogenic cells but not in rhabdomyosarcoma-derived RD cells. J Biol Chem 275: 36750-36757, 2000.

30. Zucker LM. Fat mobilization in vitro and in vivo in the genetically obese Zucker rat "fatty". J Lipid Res 13: 234-243, 1972. 


\section{BACKGROUND AND SIGNIFICANCE}

\section{Clinical significance of metabolic syndrome and obesity.}

The results of the National Health and Nutrition Examination Survey 2003-2004 indicate that an estimated two-thirds of U.S. adults are either overweight or obese, and the prevalence of obesity is increasing, especially in young people, affecting approximately $17 \%$ of Americans 219 years of age $(18 ; 60 ; 61)$. With increased obesity there is an elevation of lipids in the bloodstream, termed lipidemia, which is a major risk factor for the development of metabolic syndrome and heart disease, the number one cause of death in the U.S. (59). Metabolic syndrome is defined as a cluster of risk factors for heart disease and type 2 diabetes mellitus including: (i) obesity, (ii) insulin resistance (with or without glucose intolerance), (iii) hypertension, (iv) dyslipidemia, (v) a prothrombotic state (e.g., high fibrinogen or plasminogen activator inhibitor1 in the blood), and (vi) a proinflammatory state (e.g., elevated C-reactive protein in the blood). Muscle strength negatively correlates with the development of metabolic syndrome regardless of age or BMI (39). Moreover, the quality of muscle (strength normalized to cross sectional area) is significantly reduced in skeletal muscle of persons with obesity and metabolic syndrome (13; 64). Combined, these data indicated that there may be an interaction between obesity and metabolic syndrome and skeletal muscle regulation.

\section{Importance of skeletal muscle in metabolic syndrome and obesity.}

Fasting and postprandial free fatty acid concentrations are elevated in individuals who are obese or who have metabolic syndrome (31). Thus, insulin target tissues, such as skeletal muscle, 
are constantly exposed to high levels of FFAs. Skeletal muscle is the primary tissue for glucose and lipid utilization and has become an important target tissue in the study of metabolic syndrome as it accounts for $55-100 \%$ of glucose intolerance $(5 ; 6 ; 63)$. Attenuated muscle mass associated with obesity and metabolic syndrome could be particularly detrimental as blood glucose and lipid levels increase and the ability to utilize each is diminished. For example, the obese zucker rat (OZR) is a model of obesity and metabolic syndrome based on chronic hyperphagia (8), which results in the rapid development of obesity, insulin resistance, and hyperlipidemia $(4 ; 8 ; 11 ; 41)$. Within the OZR, there is a significant $(10-25 \%)$ reduction in the skeletal muscle mass compared to the Lean Zucker rat (LZR) phenotype (25).

\section{Nuclear regulation of muscle mass.}

Each myonucleus controls a relatively fixed cytoplasmic area, so growth or hypertrophy of a muscle fiber is critically dependent on adding new nuclei (1; 34). Muscle satellite cells are quiescent myogenic precursor cells found between the basal lamina and the sarcolema of a muscle fiber (34) and they provide the only important means of adding new nuclei to adult muscle $(1 ; 33 ; 55 ; 62 ; 67)$. In contrast, apoptosis, or programmed cell death, can selectively eliminate myonuclei and satellite cells, and can lead to skeletal muscle atrophy $(1 ; 2 ; 24 ; 50)$.

\section{AKT regulation of muscle in obesity and metabolic syndrome.}

Protein Kinase B/Akt (Akt) is a family of serine/threonine-specific protein kinases. Two Akt isoforms are highly expressed in skeletal muscle (Akt1 and Akt2). When Akt is constitutively activated there is an increase in muscle hypertrophy and a corresponding decrease in the amount of free fatty acids and adipose tissue (46). On the other hand, when Akt activity is 
reduced there is a corresponding reduction in free fatty acid metabolism and muscle mass (7). Paradoxically, Akt activity can be inhibited by chronic exposure to certain free fatty acids, such as palmitate $(14 ; 15)$, and has been shown to be attenuated with obesity and metabolic syndrome (16; 43; 45; 75). Additionally, in the OZR, Akt activity is reduced and there is a decreased nucleic acid content in the skeletal muscles, compared to the LZR (25; 43), further demonstrating that decreased Akt activity with obesity and metabolic syndrome may be involved with attenuated skeletal muscle of these animals.

\section{Akt regulation of cell cycle progression and satellite cell proliferation.}

Disrupted Akt signaling with obesity and metabolic syndrome may impair satellite cell proliferation. Akt signaling is integrally involved in the regulation of satellite cell proliferation and differentiation by controlling cell cycle progression $(7 ; 17 ; 23 ; 26 ; 27 ; 29 ; 36 ; 37 ; 74 ; 78$; 80). The progression of the cell cycle is as follows: (i) First the cell begins in the $G_{1}$ phase of the cell cycle, containing one copy of DNA, (ii) next, DNA replication begins, the S-phase, (iii) thirdly, the $\mathrm{G}_{2}$ phase in which the cell has two copies of DNA but has not yet divided, (iv) the final stage of the cell cycle is the M-phase in which the cell begin mitosis, (v) and the cell cycle is completed with the formation of two new 'daughter' cells and begins again in $\mathrm{G}_{1}(44)$. Akt is a key regulator of cell cycle progression by exerting control at check points $G_{1}$ and $G_{2}$ in the cell cycle.

Akt may control satellite cell progression through cell cycle progression via the cyclindependent kinase inhibitor p21 in $(3 ; 36 ; 56 ; 70 ; 71)$. As diagramed in figure 1 , when in the nucleus, p21 inhibits cell proliferation, however when phosphorylated by Akt, p21 protein leaves the nucleus and is no longer able to interfere with cell cycle progression $(32 ; 47 ; 48 ; 72)$. 
Additionally, Akt signaling can enhance proliferation of satellite cells by down-regulating the negative inhibition of forkhead (FoxO) transcription factor FoxO3a (3; 28; 52). When phosphorylated by Akt, FoxO3a leaves the nucleus and removes the inhibition of FoxO3a on myogenic regulatory factors, like MyoD, and other cell cycle proteins (3; 27; 28; 38; 54). Akt can also enhance cell cycle progression of satellite cells through regulation of the activity of cyclin $\mathrm{D}$ in the $\mathrm{G}_{1}$-phase and cyclin $\mathrm{B} 1$ during the $\mathrm{G}_{2} / \mathrm{M}$ phase transition (38; 65; 71). 


\section{Akt and cell cycle.}

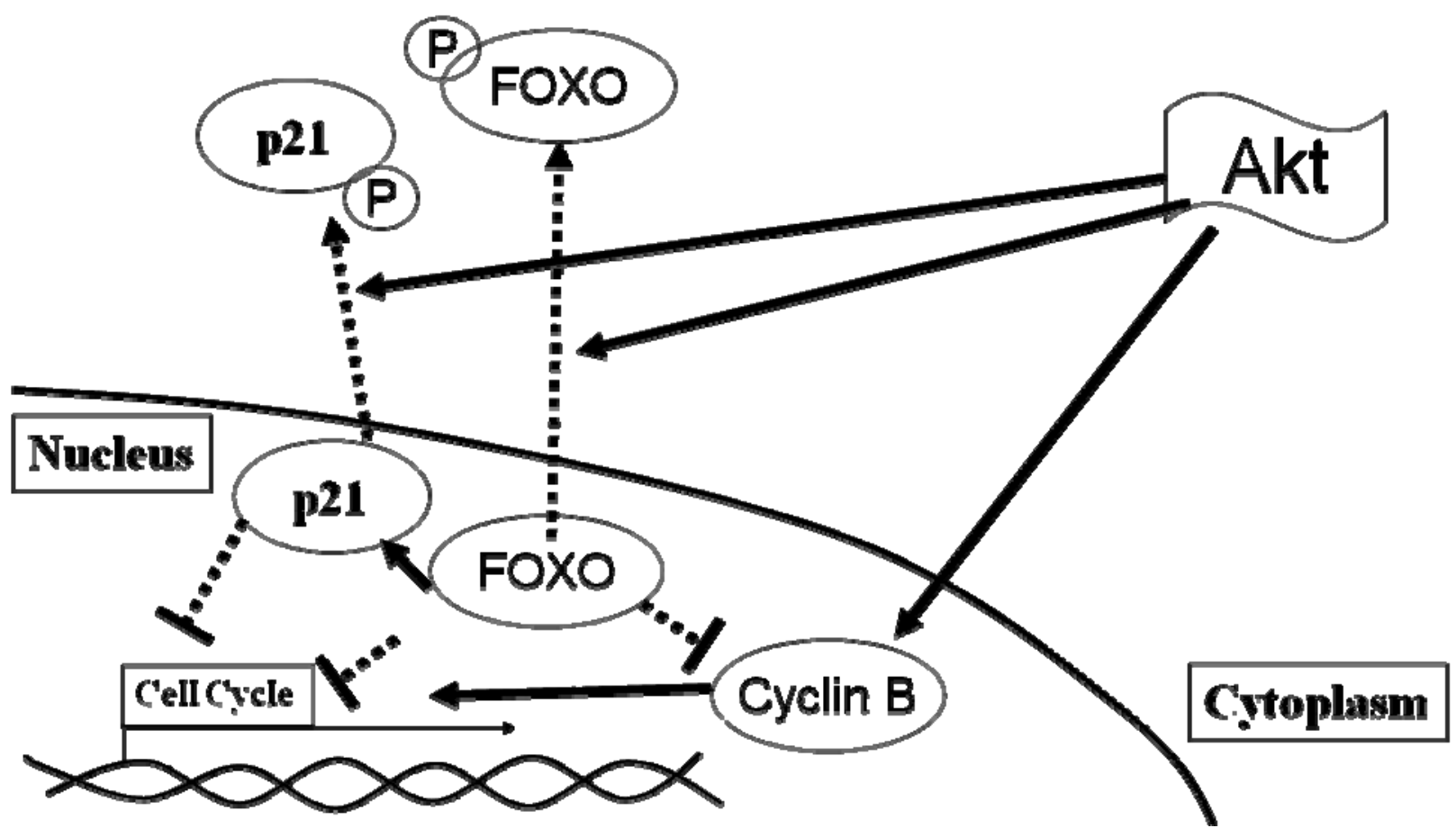

Figure 1. A schematic representation of Akt action on cell cycle control. 


\section{AKT regulation of satellite cell differentiation.}

After proliferation, satellite cells must differentiate and become incorporated into existing muscle fibers. Satellite cell differentiation is a highly controlled process (49) that is dependent on the myogenic regulatory factors, MyoD and myognein, and Akt activity. MyoD and myogenin are muscle-specific helix-loop-helix transcription factors which regulate muscle specific genes $(9 ; 34 ; 53 ; 58)$. As diagramed in figure 2 it appears that Akt is transcriptionally regulated by MyoD, and provides a positive feedback to enhance the actions of MyoD to further increase its own transcription $(19 ; 37 ; 40)$. Furthermore, Akt also works in conjunction with MyoD to promote the transcription of myogenin (40), a necessary step for the progression of muscle cell differentiation (7). Akt, particularly the Akt2 isoform, is essential for differentiation to occur. When the expression of Akt2 is inhibited in C2C12 myoblasts, an in vitro model of muscle satellite cells, there is complete abolishment of differentiation (7; 40). Additionally, Akt knockout mouse have much smaller muscles than their wildtype counterparts $(16 ; 17)$, whereas, over-expression of active Akt induces skeletal muscle hypertrophy (46). 


\section{Akt and Differentiation.}

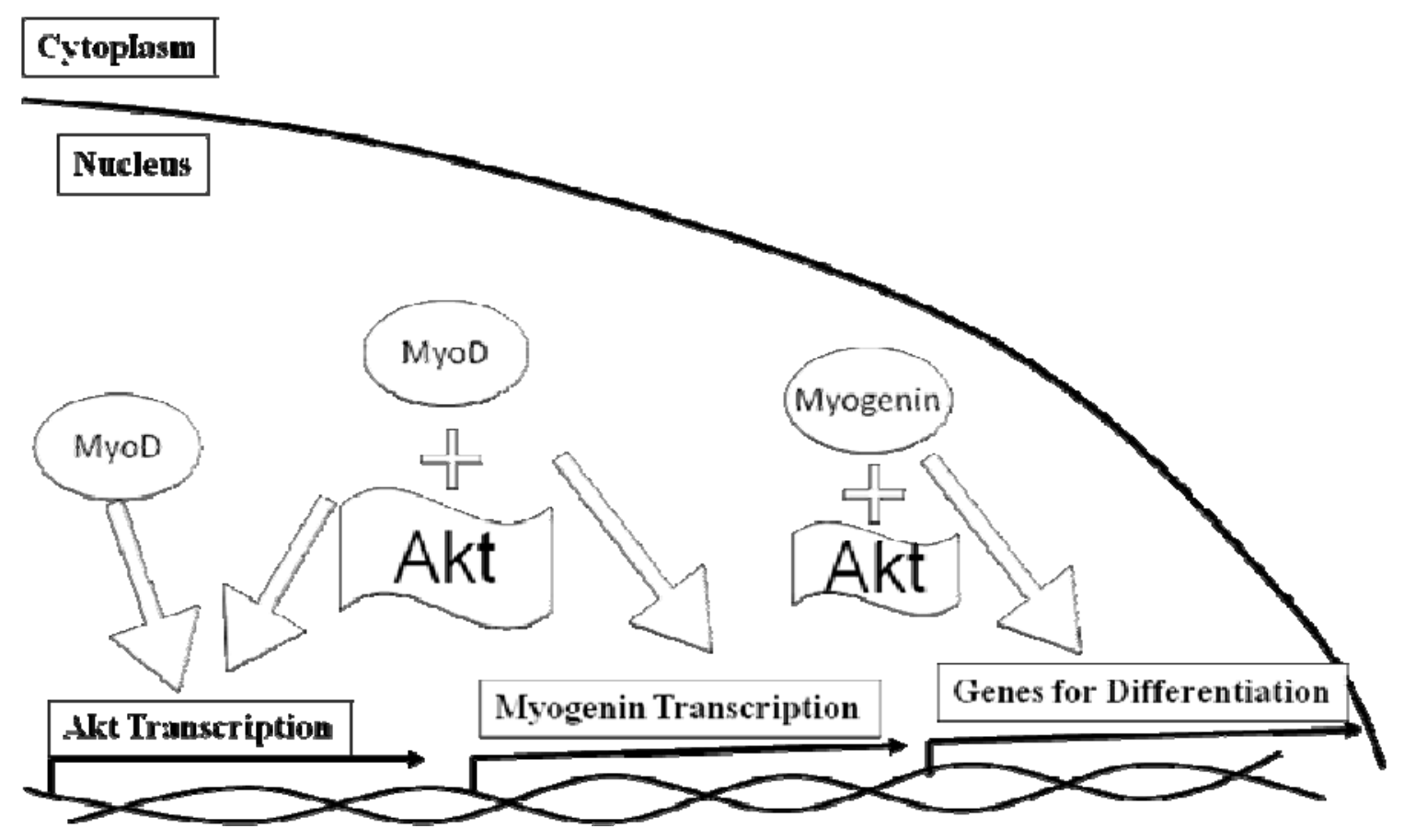

Figure 2: A schematic representation of Akt action and Myoblast differentiation. 


\section{Akt and myonuclear apoptosis.}

Loss of myonuclei via apoptosis is a potential mechanism that could contribute to lower muscle mass in obesity and metabolic syndrome. As diagramed in figure 3, Akt has been shown to inhibit apoptosis through a number of pathways (23; 81). Activated Akt inhibits the activity of the Bcl-associated death promoter (BAD) protein (20). BAD is a proapoptotic member of the B-cell leukemia/lymphoma-2 (Bcl-2) family that disrupts the binding of Bcl-2 associated $\mathrm{X}$ protein (Bax) from Bcl-2. Once Bax is released from $\mathrm{Bcl}-2$ there is a Bax-Bax-oligomerization, this Bax-Bax protein complex then inserts into the mitochondrial membrane, causing mitochondrial permeabilization (82). When the mitochondrial membrane is permeablized there is a release of proapoptotic factors, such as apoptosis inducing factor (AIF) and cytochrome $c$, which begin the apoptotic signaling pathway $(10 ; 42)$. When released from the mitochondria, cytochrome $c$ and Apaf-1 activate Caspase-9. Active Caspase-9 activates Caspase-3, an apoptotic effector that leads to DNA fragmentation and cell death $(10 ; 51)$. In addition to inhibiting apoptosis through BAD phosphorylation, Akt also phosphorylates and inhibits the activity of procaspase-9, thus inhibiting the ability of cytochrome $c$ and Apaf-1 to activate this pathway (12). It has also been shown in our lab that recently activated satellite cells are more susceptible to apoptosis, and correlates with changes in Bax and Bcl-2 protein levels (69). Therefore, it seems reasonable to conclude that there may be increased apoptosis in myoblast or satellite cells in which the anti-apoptotic effect of Akt will diminish, such as that occurring in obesity and metabolic syndrome. 


\section{Akt and Apoptotic Signaling}

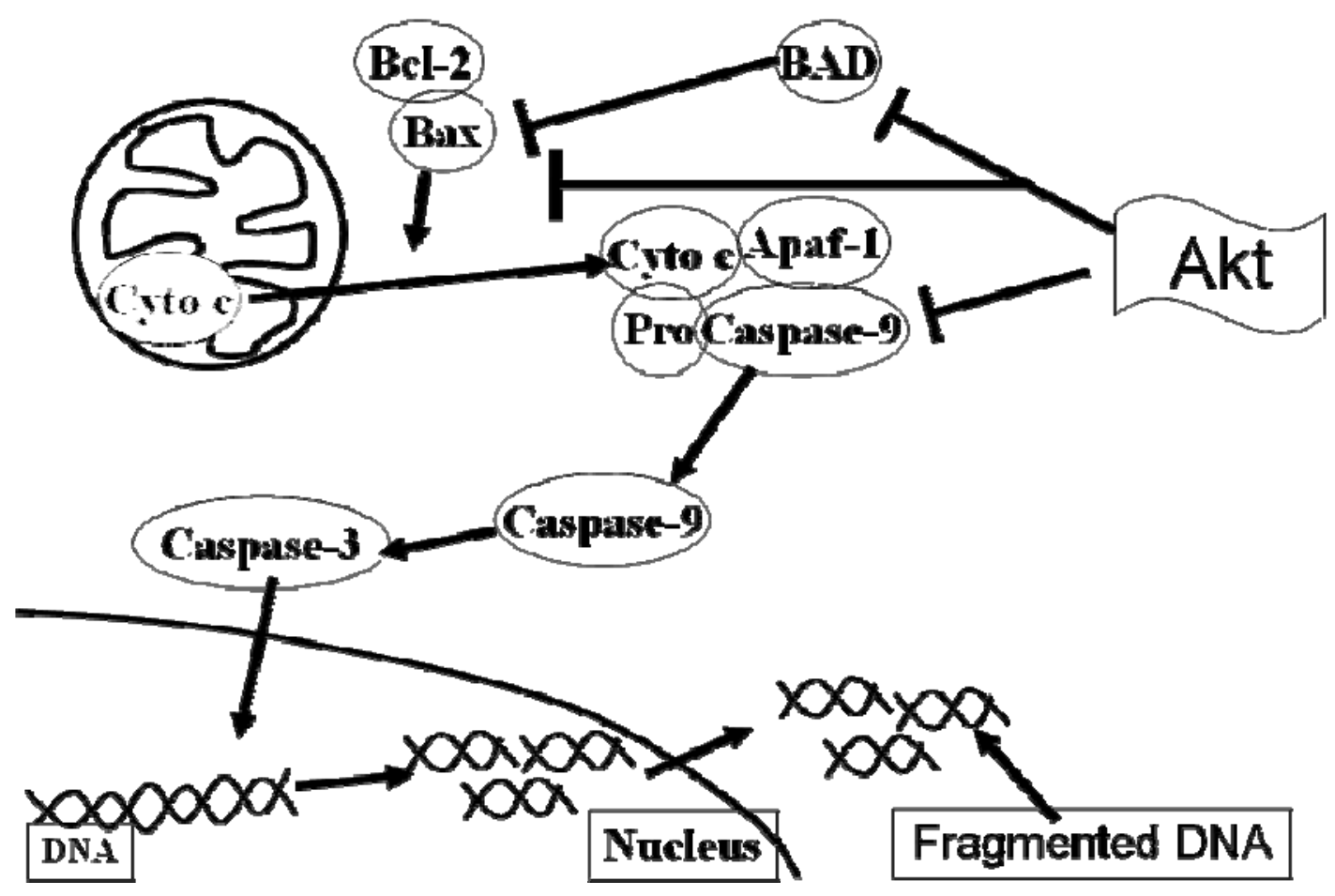

Figure 3: Schematic representation of Akt action on apoptotic signaling. 


\section{Overview: Akt and the Myonuclear Domain Hypothesis}

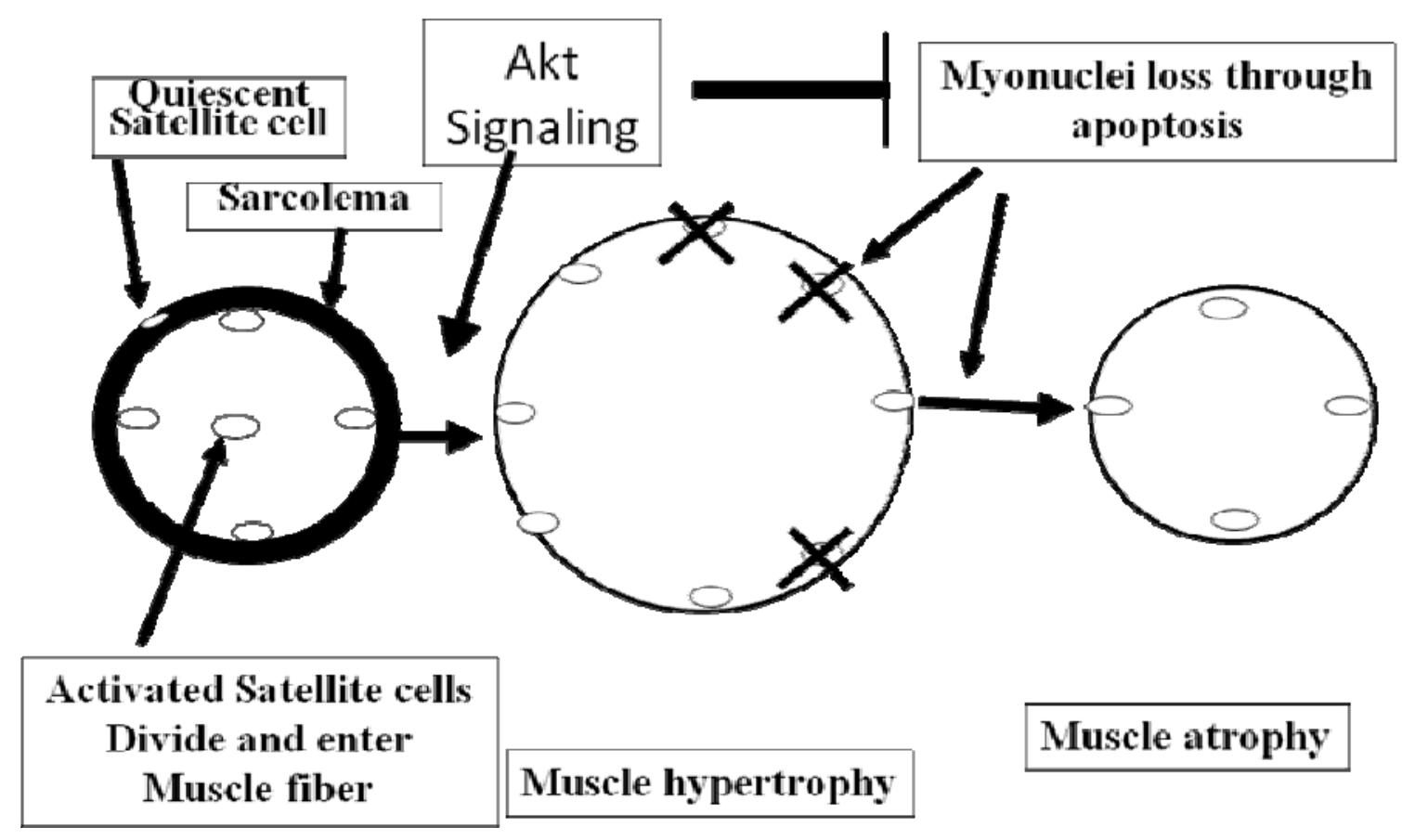

Figure 4 
OZR as a mode of metabolic syndrome in which to study satellite cell proliferation.

Skeletal muscles of the obese Zucker rat (OZR), a commonly used animal model of metabolic syndrome, are considerably smaller than the skeletal muscles of the control lean Zucker rat (LZR) of similar ages (25). The OZR has a homozygous missense mutation of the leptin receptor gene resulting in chronic hyperphagia (8) and this causes rapid development of obesity, insulin resistance, and hyperlipidemia as early as 6 weeks of age $(4 ; 8 ; 11 ; 41)$. These animals also develop hypertriglyceridemia, hypertention, and the genesis of a prothrombotic and proinflammatory state and therefore, the OZR is considered a good model of metabolicsyndrome (8; 35). In addition, Akt activity is significantly reduced in the skeletal muscles of the OZR (43), and defective Akt signaling is a possible mechanism responsible for the attenuated muscle size. Therefore the OZR provides a good model of metabolic syndrome and obesity in which to evaluate the potential role of inhibition of satellite cell proliferation resulting in lower muscle mass. In this project we examined the proliferation of satellite cells in control muscles of the OZR model of metabolic syndrome and determined if satellite cell activation and proliferation can be rescued by muscle loading in the OZR. Furthermore, we examined the role of Akt signaling in control and loaded muscles of the OZR.

\section{Putative role of palmitate in metabolic syndrome and loss of muscle nuclei.}

Palmitate is the most abundant systemic saturated fatty acid in muscle and is elevated in cases of obesity and metabolic syndrome $(30 ; 76)$ and therefore it has been studied in various tissues to better understand the effects of saturated fatty acids in dyslipidemia $(15 ; 22 ; 57 ; 73$; 79). Palmitate treatment has been shown to induce apoptosis in multiple cell types in vitro (21; 
57; 66; 77). Furthermore, palmitate has been found to inhibit Akt/Protein kinase B (Akt) activity in response to insulin $(14 ; 15 ; 68)$. Shorter carbon chained saturated fatty acids, (i.e. laurate), do not to interfere with Akt signaling $(14 ; 15)$; however, their impact on apoptosis has not been examined. In this project we have examined the putative role for palmitate to reduce Akt activity, leading to apoptosis and loss of nuclei in muscle cells using an in vitro model. 
. Reference List

1. Allen DL, Roy RR and Edgerton VR. Myonuclear domains in muscle adaptation and disease. Muscle Nerve 22: 1350-1360, 1999.

2. Alway SE, Degens H, Krishnamurthy G and Chaudhrai A. Denervation stimulates apoptosis but not Id2 expression in hindlimb muscles of aged rats. J Gerontol A Biol Sci Med Sci 58: 687-697, 2003.

3. Arden KC. FoxO: linking new signaling pathways. Mol Cell 14: 416-418, 2004.

4. Argiles JM. The obese Zucker rat: a choice for fat metabolism 1968-1988: twenty years of research on the insights of the Zucker mutation. Prog Lipid Res 28: 53-66, 1989.

\section{Basu A, Basu R, Shah P, Vella A, Johnson CM, Nair KS, Jensen MD, Schwenk WF} and Rizza RA. Effects of type 2 diabetes on the ability of insulin and glucose to regulate splanchnic and muscle glucose metabolism: evidence for a defect in hepatic glucokinase activity. Diabetes 49: 272-283, 2000.

6. Bjornholm $\mathbf{M}$ and Zierath JR. Insulin signal transduction in human skeletal muscle: identifying the defects in Type II diabetes. Biochem Soc Trans 33: 354-357, 2005. 
7. Bouzakri K, Zachrisson A, Al Khalili L, Zhang BB, Koistinen HA, Krook A and Zierath JR. siRNA-based gene silencing reveals specialized roles of IRS-1/Akt2 and IRS-2/Akt1 in glucose and lipid metabolism in human skeletal muscle. Cell Metab 4: 8996, 2006.

8. Bray GA. The Zucker-fatty rat: a review. Fed Proc 36: 148-153, 1977.

9. Buckingham M. Skeletal muscle formation in vertebrates. Curr Opin Genet Dev 11: 440-448, 2001.

10. Cai L, Li W, Wang G, Guo L, Jiang Y and Kang YJ. Hyperglycemia-induced apoptosis in mouse myocardium: mitochondrial cytochrome C-mediated caspase-3 activation pathway. Diabetes 51: 1938-1948, 2002.

11. Campion DR, Shapira JF, Allen CE, Hausman GJ and Martin RJ. Metabolic characteristics of skeletal muscle from lean and obese Zucker rats. Growth 51: 397-410, 1987.

12. Cardone MH, Roy N, Stennicke HR, Salvesen GS, Franke TF, Stanbridge E, Frisch S and Reed JC. Regulation of cell death protease caspase-9 by phosphorylation. Science 282: 1318-1321, 1998.

13. Cetinus E, Buyukbese MA, Uzel M, Ekerbicer $\mathbf{H}$ and Karaoguz A. Hand grip strength in patients with type 2 diabetes mellitus. Diabetes Res Clin Pract 70: 278-286, 2005. 
14. Chavez JA, Knotts TA, Wang LP, Li G, Dobrowsky RT, Florant GL and Summers SA. A role for ceramide, but not diacylglycerol, in the antagonism of insulin signal transduction by saturated fatty acids. J Biol Chem 278: 10297-10303, 2003.

15. Chavez JA and Summers SA. Characterizing the effects of saturated fatty acids on insulin signaling and ceramide and diacylglycerol accumulation in 3T3-L1 adipocytes and C2C12 myotubes. Arch Biochem Biophys 419: 101-109, 2003.

16. Cho H, Mu J, Kim JK, Thorvaldsen JL, Chu Q, Crenshaw EB, III, Kaestner KH, Bartolomei MS, Shulman GI and Birnbaum MJ. Insulin resistance and a diabetes mellitus-like syndrome in mice lacking the protein kinase Akt2 (PKB beta). Science 292: 1728-1731, 2001.

17. Cho H, Thorvaldsen JL, Chu Q, Feng F and Birnbaum MJ. Akt1/PKBalpha is required for normal growth but dispensable for maintenance of glucose homeostasis in mice. J Biol Chem 276: 38349-38352, 2001.

18. Cole TJ, Flegal KM, Nicholls D and Jackson AA. Body mass index cut offs to define thinness in children and adolescents: international survey. BMJ 335: 194, 2007.

19. Cornelison DD, Olwin BB, Rudnicki MA and Wold BJ. MyoD(-/-) satellite cells in single-fiber culture are differentiation defective and MRF4 deficient. Dev Biol 224: 122137, 2000. 
20. Datta SR, Dudek H, Tao X, Masters S, Fu H, Gotoh Y and Greenberg ME. Akt phosphorylation of BAD couples survival signals to the cell-intrinsic death machinery. Cell 91: 231-241, 1997.

21. de Pablo MA, Susin SA, Jacotot E, Larochette N, Costantini P, Ravagnan L, Zamzami N and Kroemer G. Palmitate induces apoptosis via a direct effect on mitochondria. Apoptosis 4: 81-87, 1999.

22. de Vries JE, Vork MM, Roemen TH, de Jong YF, Cleutjens JP, van der Vusse GJ and Van Bilsen M. Saturated but not mono-unsaturated fatty acids induce apoptotic cell death in neonatal rat ventricular myocytes. J Lipid Res 38: 1384-1394, 1997.

23. Downward J. PI 3-kinase, Akt and cell survival. Semin Cell Dev Biol 15: 177-182, 2004.

24. Dupont-Versteegden EE. Apoptosis in muscle atrophy: relevance to sarcopenia. Exp Gerontol 40: 473-481, 2005.

25. Durschlag RP and Layman DK. Skeletal muscle growth in lean and obese Zucker rats. Growth 47: 282-291, 1983.

26. Frost RA and Lang CH. Protein kinase B/Akt: a nexus of growth factor and cytokine signaling in determining muscle mass. J Appl Physiol 103: 378-387, 2007. 
27. Furukawa-Hibi Y, Kobayashi Y, Chen C and Motoyama N. FOXO transcription factors in cell-cycle regulation and the response to oxidative stress. Antioxid Redox Signal 7: 752-760, 2005.

28. Furukawa-Hibi Y, Yoshida-Araki K, Ohta T, Ikeda K and Motoyama N. FOXO forkhead transcription factors induce G(2)-M checkpoint in response to oxidative stress. $J$ Biol Chem 277: 26729-26732, 2002.

29. Gardai SJ, Hildeman DA, Frankel SK, Whitlock BB, Frasch SC, Borregaard N, Marrack P, Bratton DL and Henson PM. Phosphorylation of Bax Ser184 by Akt regulates its activity and apoptosis in neutrophils. J Biol Chem 279: 21085-21095, 2004.

30. Gorski J, Nawrocki A and Murthy M. Characterization of free and glyceride-esterified long chain fatty acids in different skeletal muscle types of the rat. Mol Cell Biochem 178: 113-118, 1998.

31. Groop LC, Saloranta C, Shank M, Bonadonna RC, Ferrannini E and DeFronzo RA. The role of free fatty acid metabolism in the pathogenesis of insulin resistance in obesity and noninsulin-dependent diabetes mellitus. J Clin Endocrinol Metab 72: 96-107, 1991.

32. Halevy O, Novitch BG, Spicer DB, Skapek SX, Rhee J, Hannon GJ, Beach D and Lassar AB. Correlation of terminal cell cycle arrest of skeletal muscle with induction of p21 by MyoD. Science 267: 1018-1021, 1995. 
33. Harridge SD. Plasticity of human skeletal muscle: gene expression to in vivo function. Exp Physiol 92: 783-797, 2007.

34. Hawke TJ and Garry DJ. Myogenic satellite cells: physiology to molecular biology. $J$ Appl Physiol 91: 534-551, 2001.

35. Herbert JM, Bernat A and Chatenet-Duchene L. Effect of ciprofibrate on fibrinogen synthesis in vitro on hepatoma cells and in vivo in genetically obese Zucker rats. Blood Coagul Fibrinolysis 10: 239-244, 1999.

36. Heron-Milhavet L, Franckhauser C, Rana V, Berthenet C, Fisher D, Hemmings BA, Fernandez A and Lamb NJ. Only Akt1 is required for proliferation, while Akt2 promotes cell cycle exit through p21 binding. Mol Cell Biol 26: 8267-8280, 2006.

37. Heron-Milhavet L, Mamaeva D, Rochat A, Lamb NJ and Fernandez A. Akt2 is implicated in skeletal muscle differentiation and specifically binds Prohibitin2/REA. $J$ Cell Physiol 214: 158-165, 2008.

38. Johnson DG and Walker CL. Cyclins and cell cycle checkpoints. Annu Rev Pharmacol Toxicol 39: 295-312, 1999.

39. Jurca R, Lamonte MJ, Barlow CE, Kampert JB, Church TS and Blair SN. Association of muscular strength with incidence of metabolic syndrome in men. Med Sci Sports Exerc 37: 1849-1855, 2005. 
40. Kaneko S, Feldman RI, Yu L, Wu Z, Gritsko T, Shelley SA, Nicosia SV, Nobori T and Cheng JQ. Positive feedback regulation between Akt2 and MyoD during muscle differentiation. Cloning of Akt2 promoter. J Biol Chem 277: 23230-23235, 2002.

41. Kasiske BL, O'Donnell MP and Keane WF. The Zucker rat model of obesity, insulin resistance, hyperlipidemia, and renal injury. Hypertension 19: I110-I115, 1992.

42. Kim R, Emi M and Tanabe K. Role of mitochondria as the gardens of cell death. Cancer Chemother Pharmacol 1-9, 2005.

43. Kim YB, Peroni OD, Franke TF and Kahn BB. Divergent regulation of Akt1 and Akt2 isoforms in insulin target tissues of obese Zucker rats. Diabetes 49: 847-856, 2000.

44. Kitzmann M and Fernandez A. Crosstalk between cell cycle regulators and the myogenic factor MyoD in skeletal myoblasts. Cell Mol Life Sci 58: 571-579, 2001.

45. Krook A, Roth RA, Jiang XJ, Zierath JR and Wallberg-Henriksson H. Insulinstimulated Akt kinase activity is reduced in skeletal muscle from NIDDM subjects. Diabetes 47: 1281-1286, 1998.

46. Lai KM, Gonzalez M, Poueymirou WT, Kline WO, Na E, Zlotchenko E, Stitt TN, Economides AN, Yancopoulos GD and Glass DJ. Conditional activation of akt in adult skeletal muscle induces rapid hypertrophy. Mol Cell Biol 24: 9295-9304, 2004. 
47. Lawlor MA, Feng X, Everding DR, Sieger K, Stewart CE and Rotwein P. Dual control of muscle cell survival by distinct growth factor-regulated signaling pathways. Mol Cell Biol 20: 3256-3265, 2000.

48. Lawlor MA and Rotwein P. Insulin-like growth factor-mediated muscle cell survival: central roles for Akt and cyclin-dependent kinase inhibitor p21. Mol Cell Biol 20: 89838995, 2000.

49. Le Grand F and Rudnicki MA. Skeletal muscle satellite cells and adult myogenesis. Curr Opin Cell Biol 19: 628-633, 2007.

50. Leeuwenburgh C. Role of apoptosis in sarcopenia. J Gerontol A Biol Sci Med Sci 58: 999-1001, 2003.

\section{Li P, Nijhawan D, Budihardjo I, Srinivasula SM, Ahmad M, Alnemri ES and Wang} X. Cytochrome c and dATP-dependent formation of Apaf-1/caspase-9 complex initiates an apoptotic protease cascade. Cell 91: 479-489, 1997.

52. Liang $\mathbf{J}$ and Slingerland $\mathbf{J M}$. Multiple roles of the PI3K/PKB (Akt) pathway in cell cycle progression. Cell Cycle 2: 339-345, 2003.

53. Lowe DA and Alway SE. Stretch-induced myogenin, MyoD, and MRF4 expression and acute hypertrophy in quail slow-tonic muscle are not dependent upon satellite cell proliferation. Cell Tissue Res 296: 531-539, 1999. 
54. Machida S, Spangenburg EE and Booth FW. Forkhead transcription factor FoxO1 transduces insulin-like growth factor's signal to p27Kip1 in primary skeletal muscle satellite cells. J Cell Physiol 196: 523-531, 2003.

55. McCall GE, Allen DL, Linderman JK, Grindeland RE, Roy RR, Mukku VR and Edgerton VR. Maintenance of myonuclear domain size in rat soleus after overload and growth hormone/IGF-I treatment. J Appl Physiol 84: 1407-1412, 1998.

56. Medema RH, Klompmaker R, Smits VA and Rijksen G. p21waf1 can block cells at two points in the cell cycle, but does not interfere with processive DNA-replication or stress-activated kinases. Oncogene 16: 431-441, 1998.

57. Mishra R and Simonson MS. Saturated free fatty acids and apoptosis in microvascular mesangial cells: palmitate activates pro-apoptotic signaling involving caspase 9 and mitochondrial release of endonuclease G. Cardiovasc Diabetol 4: 2, 2005.

58. Muscat GE, Emery J and Collie ES. Tissue-specific expression of the skeletal alphaactin gene involves sequences that can function independently of MyoD and Id. Gene Expr 2: 241-257, 1992.

59. National Institute of Diabetes and Digestive and Kidney Diseases. National Diabetes Statistics fact sheet: general information and national estimates on diabetes in the United States, 2005. National Institute of Health, 20052005. 
60. Ogden CL, Carroll MD, Curtin LR, McDowell MA, Tabak CJ and Flegal KM. Prevalence of overweight and obesity in the United States, 1999-2004. JAMA 295: 15491555, 2006.

61. Ogden CL, Yanovski SZ, Carroll MD and Flegal KM. The epidemiology of obesity. Gastroenterology 132: 2087-2102, 2007.

62. Ohira Y, Yoshinaga T, Nomura T, Kawano F, Ishihara A, Nonaka I, Roy RR and Edgerton VR. Gravitational unloading effects on muscle fiber size, phenotype and myonuclear number. Adv Space Res 30: 777-781, 2002.

63. Olsen DB, Sacchetti M, Dela F, Ploug T and Saltin B. Glucose clearance is higher in arm than leg muscle in type 2 diabetes. J Physiol 565: 555-562, 2005.

64. Park SW, Goodpaster BH, Strotmeyer ES, de Rekeneire N, Harris TB, Schwartz AV, Tylavsky FA and Newman AB. Decreased muscle strength and quality in older adults with type 2 diabetes: the health, aging, and body composition study. Diabetes 55: 1813-1818, 2006.

65. Plesca D, Crosby ME, Gupta D and Almasan A. E2F4 function in G2: maintaining G2-arrest to prevent mitotic entry with damaged DNA. Cell Cycle 6: 1147-1152, 2007. 
66. Rachek LI, Musiyenko SI, LeDoux SP and Wilson GL. Palmitate induced mitochondrial deoxyribonucleic acid damage and apoptosis in 16 rat skeletal muscle cells. Endocrinology 148: 293-299, 2007.

67. Roy RR, Monke SR, Allen DL and Edgerton VR. Modulation of myonuclear number in functionally overloaded and exercised rat plantaris fibers. J Appl Physiol 87: 634-642, 1999.

68. Schmitz-Peiffer C, Craig DL and Biden TJ. Ceramide generation is sufficient to account for the inhibition of the insulin-stimulated PKB pathway in C2C12 skeletal muscle cells pretreated with palmitate. J Biol Chem 274: 24202-24210, 1999.

69. Siu PM, Pistilli EE, Butler DC and Alway SE. Aging influences cellular and molecular responses of apoptosis to skeletal muscle unloading. Am J Physiol Cell Physiol 288: C338-C349, 2005.

70. Smits VA, Klompmaker R, Vallenius T, Rijksen G, Makela TP and Medema RH. p21 inhibits Thr161 phosphorylation of Cdc2 to enforce the G2 DNA damage checkpoint. J Biol Chem 275: 30638-30643, 2000.

71. Smits VA and Medema RH. Checking out the G(2)/M transition. Biochim Biophys Acta 1519: 1-12, 2001. 
72. Spangenburg EE, Chakravarthy MV and Booth FW. p27Kip1: a key regulator of skeletal muscle satellite cell proliferation. Clin Orthop Relat Res S221-S227, 2002.

73. Staiger K, Staiger H, Weigert C, Haas C, Haring HU and Kellerer M. Saturated, but not unsaturated, fatty acids induce apoptosis of human coronary artery endothelial cells via nuclear factor-kappaB activation. Diabetes 55: 3121-3126, 2006.

74. Stambolic V, Suzuki A, de la Pompa JL, Brothers GM, Mirtsos C, Sasaki T, Ruland J, Penninger JM, Siderovski DP and Mak TW. Negative regulation of PKB/Aktdependent cell survival by the tumor suppressor PTEN. Cell 95: 29-39, 1998.

75. Storgaard H, Song XM, Jensen CB, Madsbad S, Bjornholm M, Vaag A and Zierath JR. Insulin signal transduction in skeletal muscle from glucose-intolerant relatives of type 2 diabetic patients [corrected]. Diabetes 50: 2770-2778, 2001.

76. Turcotte LP, Swenberger JR, Zavitz TM and Yee AJ. Increased fatty acid uptake and altered fatty acid metabolism in insulin-resistant muscle of obese Zucker rats. Diabetes 50: 1389-1396, 2001.

77. Turpin SM, Lancaster GI, Darby I, Febbraio MA and Watt MJ. Apoptosis in skeletal muscle myotubes is induced by ceramides and is positively related to insulin resistance. Am J Physiol Endocrinol Metab 291: E1341-E1350, 2006. 
78. Vincent AM and Feldman EL. Control of cell survival by IGF signaling pathways. Growth Horm IGF Res 12: 193-197, 2002.

79. Welters HJ, Tadayyon M, Scarpello JH, Smith SA and Morgan NG. Monounsaturated fatty acids protect against beta-cell apoptosis induced by saturated fatty acids, serum withdrawal or cytokine exposure. FEBS Lett 560: 103-108, 2004.

80. Xu Q and Wu Z. The insulin-like growth factor-phosphatidylinositol 3-kinase-Akt signaling pathway regulates myogenin expression in normal myogenic cells but not in rhabdomyosarcoma-derived RD cells. J Biol Chem 275: 36750-36757, 2000.

81. Yue TL, Bao W, Gu JL, Cui J, Tao L, Ma XL, Ohlstein EH and Jucker BM. Rosiglitazone treatment in Zucker diabetic Fatty rats is associated with ameliorated cardiac insulin resistance and protection from ischemia/reperfusion-induced myocardial injury. Diabetes 54: 554-562, 2005.

82. Zha H, Aime-Sempe C, Sato T and Reed JC. Proapoptotic protein Bax heterodimerizes with Bcl-2 and homodimerizes with Bax via a novel domain (BH3) distinct from BH1 and BH2. J Biol Chem 271: 7440-7444, 1996. 


\section{Palmitate treatment inhibits C2C12 myoblast proliferation and differentiation Jonathan M. Peterson, Randall W. Bryner, and Stephen E. Alway}

\section{ABSTRACT}

Myoblast proliferation and differention are highly controlled processes that involve the coordination of a variety of cell signaling pathways. This progression includes cyclins, Akt, myogenic regulatory factors, as well as others. The purpose of this study was to determine whether palmitate interfered with myoblast proliferation and or differentiation. For these series of experiments $\mathrm{C} 2 \mathrm{C} 12$ myoblasts were grown to approximately 60 percent confluence and then treated with or without $0.25 \mathrm{mM}$ palmitate for 12 hours. The effect of palmitate on myoblast proliferation was determined in two separate experiments through either pre-staining carboxyfluorescein diacetate, succinimidyl ester (CFSE) or with post-treatment incubation with 5-bromo-2-deoxyuridine (BrdU). Both of these techniques revealed that there was a significant decrease in the rate of proliferation in the palmitate treated myoblasts. Furthermore, when the cell cycle was analyzed through Propidium Iodide staining there was a significant accumulation of cells in the G2/M phase of the cell cycle. Immunoblot analysis of palmitate treated myoblast showed a significant decrease in p21, Akt2, myoD, and a significant increase in Foxo3a protein expression. Furthermore, the treatment of myoblasts with palmitate completely abolished the formation of myotubes. The absence of myotube formation corresponded with the attenuation of many of the proteins which are normally rapidly expressed at the onset of myoblast differentiation, including Akt2, myogenin, and MF20. These data demonstrate 
that palmitate treatment not only inhibits the proliferation of myoblast, but palmitate also inhibits the formation of new myotubes. 


\section{INTRODUCTION}

The transition of mono-nucleated myoblast into fully differentiated multinucleated myotubes is a step-by-step process characterized by cell cycle withdrawal, expression of muscle-specific proteins, and formation and maturation of myofibers (22). A large portion of the control process for these process is regulated by the musclespecific helix-loop-helix transcription factors, myoD and myogenin, which are able to

promote the transcription of muscle specific genes $(3,18,19)$. In addition, to the myogenic regulatory factors, forkhead transcriptions factors and cell cycle proteins also contribute to the regulation of myoblast differentiation $(6,8)$.

Recently, it has been demonstrated that Akt1 and Akt2 play distinct roles in cell cycle progression with Akt1 being required for proliferation while Akt2 promotes cell cycle exit and is necessary for myoblast differentiation $(2,10,11)$. For, example Akt indirectly, through GSK3- $\beta$ inhibition, increases the activity of cyclin-D $(7,13)$. Cyclin D is a necessary protein for cell cycle progression from the $G_{1}$ phase of the cell cycle, whereas in the absence of cyclin D the cell will be unable to progress through the cell cycle $(12,16)$. Additionally, Akt signaling can enhance proliferation through the forkhead (FoxO) transcription factors. The FoxO family proteins increase the nuclear expression of negative cell cycle proteins, whereas phosphorylation of the FoxO family of proteins by Akt negates this effect. Additionally, the inhibition of the FoxO family of proteins results in their nuclear export thus removing the inhibition of the FoxO proteins on myogenic regulatory factors $(1,15)$. On the other hand, it has been postulated that Akt2 may activate MyoD induced myogenin expression, a necessary step for differentiation (11). Combining the aforementioned roles of Akt signaling on the FoxO 
family proteins as well as the cell cycle proteins it seems reasonable to assume that disrupted Akt signaling with metabolic syndrome may not only reduce myoblast/satellite cell proliferation, but also reduce myoblast/satellite cell differentiation. However, the effects of metabolic syndrome on muscle cell cycle and differentiation have not been studied.

The purpose of this study was to determine if the addition of the saturated free fatty acid (FFA) palmitate inhibits either $\mathrm{C} 2 \mathrm{C} 12$ myoblast proliferation and/or differentiation. Palmitate has been previously demonstrated to inhibit Akt activity in myotubes but its effects on myoblast proliferation and differentiation are unknown. Furthermore, a secondary purpose of this study was to investigate some of the specific signaling that is altered with palmitate treatment that may account for the decreases in myoblast proliferation and/or differentiation.

\section{METHODS}

C2C12 Culture. Mouse C2C12 myoblasts were purchased from American Type Culture Collection (ATCC). Cells were cultured in $50 \mathrm{~mm}$ polystyrene culture dishes in Dulbecco Modified Eagle's Medium (DMEM) supplemented with 10\% fetal bovine serum, and $1 \%$ antibiotic antimycotic mixture. Cells were passaged by trypsinization using $0.25 \%$ trypsin. Cells were maintained in a humidified incubator under an atmosphere of $5 \% \mathrm{CO} 2$ at $37^{\circ} \mathrm{C}$. Fresh medium was supplied every $24-36$ hours.

Palmitate (Sigma Chemicals; St. Louis, MO) was administered to cells as described by Chavez and Summers $(4,5)$ with dodecanoic acid (Lauric acid) used as a free fatty acid (FFA) control, with an additional control group receiving media only. Lauric acid was chosen as a FFA control because it has been shown not to interfere with 
Akt activity (5). However, a BSA only group was also used to determine if the FFAs affected the measured variables independent of Akt activity. Briefly, palmitate was dissolved in ethanol and diluted DMEM containing 2\% BSA. C2C12 myotubes were incubated with the FFAs (0.25 mM final concentration) in 10\% FBS-DMEM in 2\% BSA for $12 \mathrm{~h}$ prior to analysis.

Myoblast proliferation. The first experiment performed was to determine if palmitate treatment inhibited myoblast proliferation. For this experiment $\mathrm{C} 2 \mathrm{C} 12$ myoblasts were suspended in trypsin, centrifuged at $20^{\circ} \mathrm{C}$ for 5 minutes at $1500 \mathrm{rpm}$ and then resuspended in PBS. Next $10 \mu \mathrm{M}$ Carboxyfluorescein Diacetate, Succinimidyl Ester (CFSE) was added to the cells and then the staining was immediately quenched with the addition of an equal volume of $10 \%$ FBS. An aliquot was fixed in $1 \%$ paraformaldehyde, to determine initial staining intensity. The cells were then plated into $35 \mathrm{~mm}$ plates in $10 \%$ FBS and allowed to grow for 24 hours. At this point the myoblasts were treated with palmitate, Lauric acid, Akt-inhibitor (124005, Calbiochem, Germany) or BSA only and allowed to grow for an additional 24 hours. Next, the myoblasts were washed twice with PBS, harvested in $0.25 \%$ trypsin, and fixed with $1 \%$ paraformaldehyde, and examined using the FACSCalibur ${ }^{\mathrm{TM}}$ Flow Cytometer.

An additional proliferation assay was performed in a separated experiment in which the $\mathrm{C} 2 \mathrm{C} 12$ myoblasts were grown to $\sim 50$ percent confluency, pulsed for $20 \mathrm{~min}$ with $30 \mu \mathrm{g} / \mathrm{ml}$ BrdU (550891, BD Biosciences Pharmingen, USA), harvested in trypsin, and fixed in ice cold 70\% EOTH for 24 hours. The myoblast were then resuspended in $0.1 \%$ triton-X/0.1 M HCL for $1 \mathrm{~min}$, centrifuged at $2000 \mathrm{rpm}$ for $5 \mathrm{~min}$, then resuspended 
in DNA Denaturing Buffer $\left(0.15 \mu \mathrm{M} \mathrm{NaCl}, 15 \mu \mathrm{M}\right.$ Trissodium citrate dihydrate) at $95^{\circ} \mathrm{C}$ for $5 \mathrm{~min}$, followed by incubation at $4^{\circ} \mathrm{C}$ for $5 \mathrm{~min}$, and centrifuged $2000 \mathrm{rpm} 5 \mathrm{~min}$. Next the pellet was washed in 1\% BSA in PBS and then resuspended in Mouse anti-BrdU (1:50; 555627; BD Pharmingen ${ }^{\mathrm{TM}}$, USA) for $30 \mathrm{~min}$ at room temperature. The cells were then washed twice in PBS and incubated with Anti-mouse Alexa-488 secondary antibody (1:400; A11029; Invitrogen, USA). Lastly, the myoblasts were wash twice with PBS and then resuspended in Propidium Iodide (10 $\mu \mathrm{g} / \mathrm{ml}$; P3566, Invitrogen, USA), RNAse (100 $\mu \mathrm{g} / \mathrm{ml}$; 10109169001; Roche, USA) in PBS and analyzed using the FACSCalibur ${ }^{\mathrm{TM}}$ Flow Cytometer.

Flow Cytometry Analysis. The samples were transferred to $5 \mathrm{ml}$ polstytrene round bottom tubes for data acquisition and analysis on a FACSCalibur ${ }^{\mathrm{TM}}$ Flow Cytometer using CellQuest Pro software (BD Biosciences). All data are represented as mean fluorescence intensity (MFI). Additional cell cycle modeling was performed using Modfit LT software (Verity Software house, Inc).

Myoblast differentiation. For differentiation into myotubes, the myoblasts were grown to $70 \%$ confluency and then treated for 12 hours with FFAs $(0.25 \mathrm{mM}$ final concentration) or BSA only for 12 hours. After treatment the cells were washed three times with DHANKs and then transferred to DMEM containing ITS liquid media (Sigma-Aldrich, St. Louis, MO). All experiments were performed in triplicate. 
Immunoblot analysis. The protein contents of the solublized extracts were quantified in duplicate by using bicinchoninic acid reagents (Pierce, Rockford, IL, USA) and bovine serum albumin (BSA) standards. $60 \mu \mathrm{g}$ of soluble protein was boiled for 4 min at $100^{\circ} \mathrm{C}$ in Laemmli buffer and loaded on each lane of a $12 \%$ polyacrylamide gel. The proteins were separated by routine SDS-PAGE for 1.5 hours at $20^{\circ} \mathrm{C}$. The gels were blotted to nitrocellulose membranes (Bio-Rad, Hercules, CA, USA) and stained with Ponceau S red (Sigma Chemical Co, St Louis, MO, USA) to confirm equal loading and transferring of proteins to the membrane in each lane.

The membranes were then blocked in 5\% non-fat milk in Tris buffered saline with $0.05 \%$ Tween 20 (TBS-T) and probed with appropriate primary antibodies (see table 1). Secondary antibodies were conjugated to horseradish peroxidase (HRP) (Chemicon, CA, USA) and the signals were developed by chemiluminescence (Pierce, Rockford, IL, USA). The signals were visualized by exposing the membranes to X-ray films (BioMax MS-1, Eastman Kodak, Rochester, NY, USA), and digital records of the films were captured with a Kodak 290 camera. The resulting bands were quantified as optical density (OD) x band area by a one-dimensional (1-D) image analysis system (Eastman Kodak, Rochester, NY, USA) and expressed in arbitrary units. The sizes of the proteins were verified by using standard molecular-weight markers (Bio-Rad, Hercules, CA, USA). To reduce the day-to-day variability between blots all comparisons were performed on samples run on the same membrane.

Statistical analyses. Statistical analyses were performed using the SPSS 10.0 software package. A one-way ANOVA was performed on the difference between each 
variable among treatments. Statistical significance was accepted at $P<0.05$. All data are given as means $\underline{ \pm} \mathrm{SE}$.

\section{RESULTS}

Myoblast proliferation. The first part of this study design was to determine if palmitate treatment attenuated myoblast proliferation. CFSE is a fluorescent dye that stains all the protein in the cell. A subset of the cells was preserved as the parent generation (figure 1A), each time the myoblast divide the intensity of the stain is reduced by approximately one-half. The myoblast were obtained from one set of parent cells and allowed to grow for 24 hours under control treatment. Our pilot data demonstrated that after 24 hours the myoblasts divided approximately three times in the first 24 hours (Data not shown). After 24 hours of control treatment the myoblasts were incubated with FFAs, BSA only control, or Akt-inhibitor for an additional 24 hours (48 hours total). The proliferation index is an estimation of the number of times the myoblast divided based on the change of CFSE fluorescence intensity of the treated myoblasts compared to the parent generation (Sample histograms are shown figure 1A and 1B). This experiment showed that both palmitate and the Akt-inhibitor both significantly reduced myoblast proliferation (Figure 1C).

$\mathrm{BrdU}$ is incorporated into proliferating myoblasts as they transition through the Sphase of the cell cycle. Figure 2 shows that with both palmitate treatment and Akt Inhibitor significantly reduced the incorporation of BrdU into the myoblasts. Combining the CFSE data and the BrdU data it is clear that palmitate treatment significantly reduces 
myoblast proliferation. Furthermore, when the cell cycle was analyzed through examination of the PI staining it clearly demonstrated that there was a G2 cell cycle shift in the palmitate treated myoblasts (figure 3). This was different then the Akt inhibitor treated myoblast which had an increase accumulation in both G1 and G2 cell cycle phases. It has been previously demonstrated that Akt activity is involved with both the G1 and G2 cell cycle check points $(8,9,14)$, however it is unclear why there is a G2 cell cycle shift in the palmitate treated myoblasts.

Akt protein Expression. To determine the putative impact of Akt signaling in accounting for the decrease proliferation in palmitate treated myoblasts the protein expression of Akt was determined. After palmitate treatment there was no change in the protein expression of total Akt or Akt1. However, there was a significant absence of Akt2 protein expression in palmitate treated myoblasts (Figure 4A). It should be noted that in $\mathrm{C} 2 \mathrm{C} 12$ myoblasts the protein expression of Akt2 is extremely small compared to the expression of Akt1 isoform. In this study the exposure time for Akt1 was approximately 30 seconds compared to 5 minutes for Akt 2 with all steps besides primary antibody being equal. This would explain why there is no difference observed in either total Akt or Akt1 protein expression even though Akt2 protein expression is significantly reduced.

To determine whether Akt activity was reduced with the palmitate treatment the myoblasts were treated as above, and then incubated in serum free media (with or without FFAs) for 2 hours before serum was reintroduced to the samples for 10 minutes before harvest. There was a significant reduction in pAkt (Serine 473) protein expression after 
the reintroduction of serum in the palmitate treated myoblasts (Figure 4B). This indicates that although palmitate did not alter total Akt protein expression it did attenuate the Akt activity, as determined through decreased protein expression of pAkt.

Cell cycle regulatory proteins. To further evaluate the mechanism for palmitate induced G2 cell cycle phase shift the expression levels of other G2 regulatory proteins were investigated. The protein expression of the myogenic regulatory factor MyoD and the cyclin-dependent kinase inhibitor p21 were both reduced in the palmitate treatment myoblasts. On the other hand there was an approximately 2 -fold increase in the protein expression of forkhead transcription factor Foxo3A (figure 5A). These data are consistent with the previous finding of a G2 cell cycle shift and may be part of mechanism accounting for the G2 shift. Other proteins that were examined include p27, p53, Foxo1, and Foxo4 however, no differences were observed in the protein expression of these proteins with palmitate treatment (data not shown). On the other hand, a small decrease in the protein expression of the cell cycle regulatory protein Cyclin B1 with palmitate treatment was observed. However, a band was also observed at $\sim 60 \mathrm{kDa}$ which corresponds with a hyper-phosphorylated form of Cyclin B1 in both control treatments, but was absent in the palmitate treated myoblasts (figure 5B). Furthermore, when either the BSA or Lauric acid control groups were treated with an Akt inhibitor the $60 \mathrm{kDa}$ band of Cyclin B1 was no longer present.

Differentiation. The last part of this study was to determine whether palmitate treatment interfered with the ability for the myoblast to differentiate. For this series of experiments 
the myoblasts were treated for 12 hours with or without the FFAs and then washed and transferred to differentiation media. The myoblasts were trypsin harvested at 6,12 , and 24 hours after being the start of differentiation and stained for Annexin V. Annexin V is an early marker for cells that are undergoing apoptosis, as there is a translocation of the membrane phosphatidylserine (PS) from the inner face of the plasma membrane to the cell surface, or have become necrotic and the membrane integrity is diminished. Although there was no increase in Annexin $\mathrm{V}$ positive myoblasts in the palmitate pretreated myoblasts after 6 hours in differentiation media, there was an approximately 2fold increase in the percent of cells that were Annexin V positive at both 12 and 24 hours after the initiation of differentiation.

Furthermore, cells were harvested 48 hours after the beginning of differentiation and the expression of proteins that are expressed during differentiation were examined. The data clearly demonstrates the absence of the proteins that are normally expressed during differentiation (figure 6B). Combined these data demonstrate that the treatment on myoblast with palmitate attenuates myotube formation.

\section{Discussion}

The novel findings of this study are that palmitate treatment significantly reduces myoblast proliferation and differentiation. Furthermore, these data demonstrated that with palmitate treatment there is a significant G2 cell cycle shift, indicating that with palmitate treatment the myoblasts are unable to pass the G2-check point $(17,21)$. Although palmitate treatment resulted in a reduction in pAkt protein expression and this may partially account for the decreased proliferation, and the Akt inhibitor also decreased proliferation, the reduction in pAkt protein expression is not sufficient to explain the G2 
cell cycle shift. The G2 cell cycle shift may be explained by some of the other proteins whose expression levels were alter with the palmitate treatment. There was a significant reduction in protein expression of $\mathrm{p} 21$ and $\mathrm{MyoD}$ and an increase in the protein expression of Foxo3A. Additionally, there was a significant attenuation of a hyperphosphorylated Cyclin B1, with palmitate and with Akt inhibitor. Combined these data shed light on a possible mechanism for the G2 cell cycle shift in the palmitate treated myotubes $(8,17,20,21)$.

On the other hand the absence of Akt2 in palmitate treated myoblast most likely does not contribute to the attenuated proliferation, but may be a mechanism responsible for the attenuation of myoblast differentiation $(2,10,11)$. It has been previously shown that when Akt2 is reduced with siRNA treatment in $\mathrm{C} 2 \mathrm{C} 12$ myoblast there is complete abolishment of myotube formation, whereas Akt1 siRNA transfection had no effect on differentiation (2). It has been proposed that myoD and Akt2 work in conjunction to induce the expression of myogenin, a necessary step for myotube formation to occur. Combined these data demonstrate that palmitate treatment of $\mathrm{C} 2 \mathrm{C} 12$ myoblast significantly attenuates proliferation and abolishes myotube formation. 
Reference List

1. Arden KC. FoxO: linking new signaling pathways. Mol Cell 14: 416-418, 2004.

2. Bouzakri K, Zachrisson A, Al Khalili L, Zhang BB, Koistinen HA, Krook A and Zierath JR. siRNA-based gene silencing reveals specialized roles of IRS1/Akt2 and IRS-2/Akt1 in glucose and lipid metabolism in human skeletal muscle. Cell Metab 4: 89-96, 2006.

3. Buckingham M. Skeletal muscle formation in vertebrates. Curr Opin Genet Dev 11: 440-448, 2001.

4. Chavez JA, Knotts TA, Wang LP, Li G, Dobrowsky RT, Florant GL and Summers SA. A role for ceramide, but not diacylglycerol, in the antagonism of insulin signal transduction by saturated fatty acids. J Biol Chem 278: $10297-$ 10303, 2003.

5. Chavez JA and Summers SA. Characterizing the effects of saturated fatty acids on insulin signaling and ceramide and diacylglycerol accumulation in 3T3-L1 adipocytes and C2C12 myotubes. Arch Biochem Biophys 419: 101-109, 2003.

6. Delgado I, Huang X, Jones S, Zhang L, Hatcher R, Gao B and Zhang $\mathbf{P}$. Dynamic gene expression during the onset of myoblast differentiation in vitro. Genomics 82: 109-121, 2003.

7. Diehl JA, Cheng M, Roussel MF and Sherr CJ. Glycogen synthase kinase3 beta regulates cyclin D1 proteolysis and subcellular localization. Genes Dev 12: 3499-3511, 1998.

8. Furukawa-Hibi Y, Yoshida-Araki K, Ohta T, Ikeda K and Motoyama N. FOXO forkhead transcription factors induce G(2)-M checkpoint in response to oxidative stress. J Biol Chem 277: 26729-26732, 2002.

9. Heron-Milhavet L, Franckhauser C, Rana V, Berthenet C, Fisher D, Hemmings BA, Fernandez A and Lamb NJ. Only Akt1 is required for proliferation, while Akt2 promotes cell cycle exit through p21 binding. Mol Cell Biol 26: 8267-8280, 2006.

10. Heron-Milhavet L, Mamaeva D, Rochat A, Lamb NJ and Fernandez A. Akt2 is implicated in skeletal muscle differentiation and specifically binds Prohibitin2/REA. J Cell Physiol 214: 158-165, 2008. 
11. Kaneko S, Feldman RI, Yu L, Wu Z, Gritsko T, Shelley SA, Nicosia SV, Nobori T and Cheng JQ. Positive feedback regulation between Akt 2 and MyoD during muscle differentiation. Cloning of Akt2 promoter. J Biol Chem 277: 23230-23235, 2002.

12. Lawlor MA and Rotwein $\mathbf{P}$. Insulin-like growth factor-mediated muscle cell survival: central roles for Akt and cyclin-dependent kinase inhibitor p21. Mol Cell Biol 20: 8983-8995, 2000.

13. Leger B, Cartoni R, Praz M, Lamon S, Deriaz O, Crettenand A, Gobelet C, Rohmer P, Konzelmann M, Luthi F and Russell AP. Akt signalling through GSK-3 beta\}, mTOR and Foxo1 is involved in human skeletal muscle hypertrophy and atrophy. J Physiol 2006.

14. Liang $\mathbf{J}$ and Slingerland $\mathbf{J M}$. Multiple roles of the PI3K/PKB (Akt) pathway in cell cycle progression. Cell Cycle 2: 339-345, 2003.

15. Machida S, Spangenburg EE and Booth FW. Forkhead transcription factor FoxO1 transduces insulin-like growth factor's signal to $\mathrm{p} 27 \mathrm{Kip} 1$ in primary skeletal muscle satellite cells. J Cell Physiol 196: 523-531, 2003.

16. Matsushime H, Roussel MF, Ashmun RA and Sherr CJ. Colony-stimulating factor 1 regulates novel cyclins during the G1 phase of the cell cycle. Cell 65: 701-713, 1991.

17. Medema RH, Klompmaker R, Smits VA and Rijksen G. p21waf1 can block cells at two points in the cell cycle, but does not interfere with processive DNAreplication or stress-activated kinases. Oncogene 16: 431-441, 1998.

18. Molkentin JD, Black BL, Martin JF and Olson EN. Cooperative activation of muscle gene expression by MEF2 and myogenic bHLH proteins. Cell 83: 1125$1136,1995$.

19. Olson EN and Klein WH. bHLH factors in muscle development: dead lines and commitments, what to leave in and what to leave out. Genes Dev 8: 1-8, 1994.

20. Smits VA, Klompmaker R, Vallenius T, Rijksen G, Makela TP and Medema RH. p21 inhibits Thr161 phosphorylation of Cdc2 to enforce the G2 DNA damage checkpoint. J Biol Chem 275: 30638-30643, 2000.

21. Smits VA and Medema RH. Checking out the $\mathrm{G}(2) / \mathrm{M}$ transition. Biochim Biophys Acta 1519: 1-12, 2001.

22. Zammit PS, Partridge TA and Yablonka-Reuveni Z. The skeletal muscle satellite cell: the stem cell that came in from the cold. J Histochem Cytochem 54: 1177-1191, 2006. 


\section{FIGURE LEGENDS}

Figure 1. CFSE is a fluorescent dye that stains all the protein in the cell. After initial treatment with CFSE dye a subset of the cells was preserved as the parent generation, a histogram with the mean fluorescent intensity in a log scale on the $\mathrm{x}$-axes and cell count on the why axis is shown (A). After 24 hours of control treatment the myoblasts were incubated with FFAs, BSA only control, or Akt-inhibitor for an additional 24 hours before trypsin harvest. Representative histogram of control myoblasts grown in $10 \%$ FBS for 48 hours after initial CFSE treatment is shown (B). Each time the myoblast divide the intensity of the stain is reduced by approximately one-half. The proliferation index is an estimation of the number of times the myoblast divided based on the change of CFSE fluorescence intensity of the treated myoblasts compared to the parent generation (C). This experiment showed that both palmitate and $10 \mu \mathrm{M}$ Akt-inhibitor both significantly reduced myoblast proliferation. The data are displayed as mean $\pm \mathrm{SE}$. $* \mathrm{p}<0.05$ vs. control samples. Abbreviation: Con $=$ BSA only control; Laur $=$ Lauric acid free fatty acid control; Pal $=$ Palmitic acid treated AktI $=$ Treated with $10 \mu \mathrm{M}$ Akt Inhibitor; CFSE = Carboxyfluorescein Diacetate, Succinimidyl Ester.

Figure 2. BrdU is incorporated into proliferating myoblasts as they transition through the S-phase of the cell cycle. Figure 2A shows a representative graph displaying Flow Cytometry data with the mean fluorescent intensity (MFI) of BrdU-alexa 488 on the yaxis and MFI of propidium Iodide on the x-axis. Figure 2B displays the number of cells for each treatment that are BrdU positive. The data are displayed as mean $\pm \mathrm{SE} . *_{\mathrm{p}}<$ 
0.05 vs. control samples. Abbreviations: Con $=$ BSA only control; Laur $=$ Lauric acid free fatty acid control; Pal $=$ Palmitic acid treated; AktI $=$ Treated with $10 \mu \mathrm{M}$ Akt Inhibitor; BrdU = Bromodeoxyuridine (5-bromo-2-deoxyuridine).

Figure 3. Cell cycle was analyzed through examination of the PI staining. A) Representative histogram is demonstrated cell number in is each phase of the cell cycle based on the staining intensity of Propidium Iodide. B) Palmitate and AktI treated myoblasts had significantly decreased number of myoblasts in the S-phase of cell cycle. Palmitate treatment resulted in a significant accumulation of myoblasts in the $G 2 / \mathrm{M}$ phase of the cell cycle. The data are displayed as mean \pm SE. $* p<0.05$ vs. control samples. Abbreviations: Con $=$ BSA only control; Laur $=$ Lauric acid free fatty acid control; Pal $=$ Palmitic acid treated; AktI $=$ Treated with $10 \mu \mathrm{M}$ Akt Inhibitor. 
Figure 1
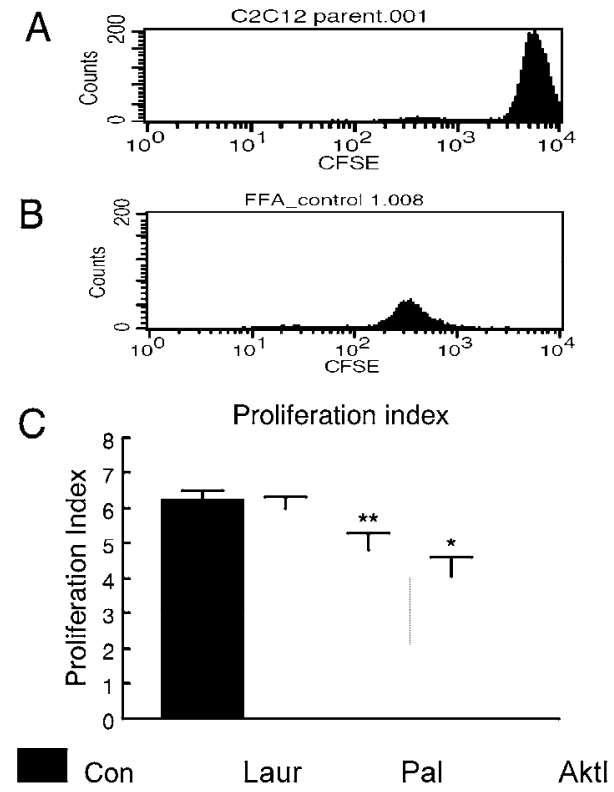
Figure 2

A

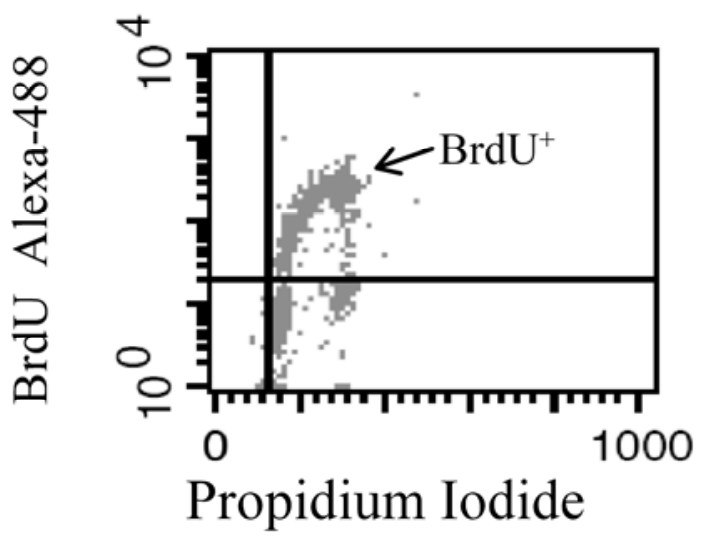

B

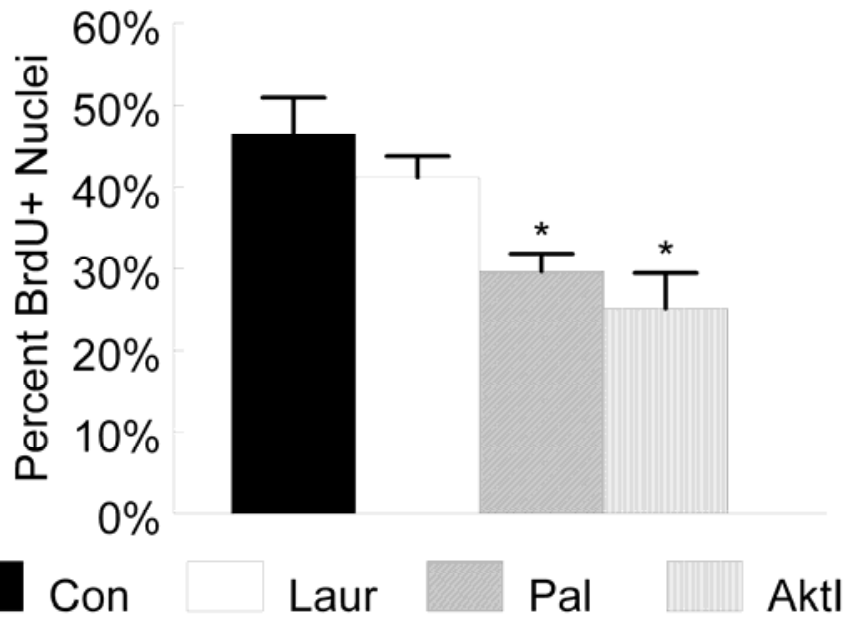


Figure 3
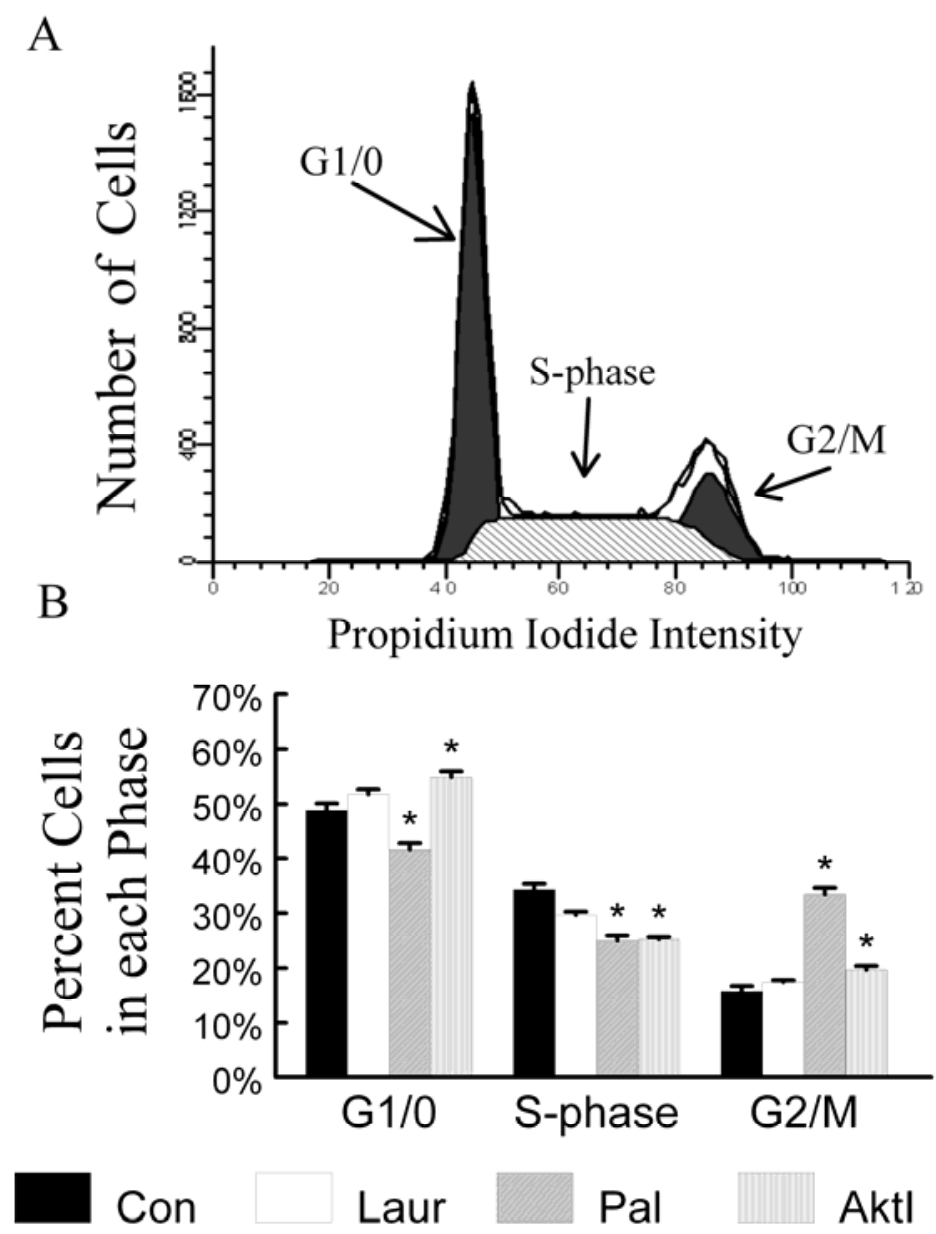
Figure 4

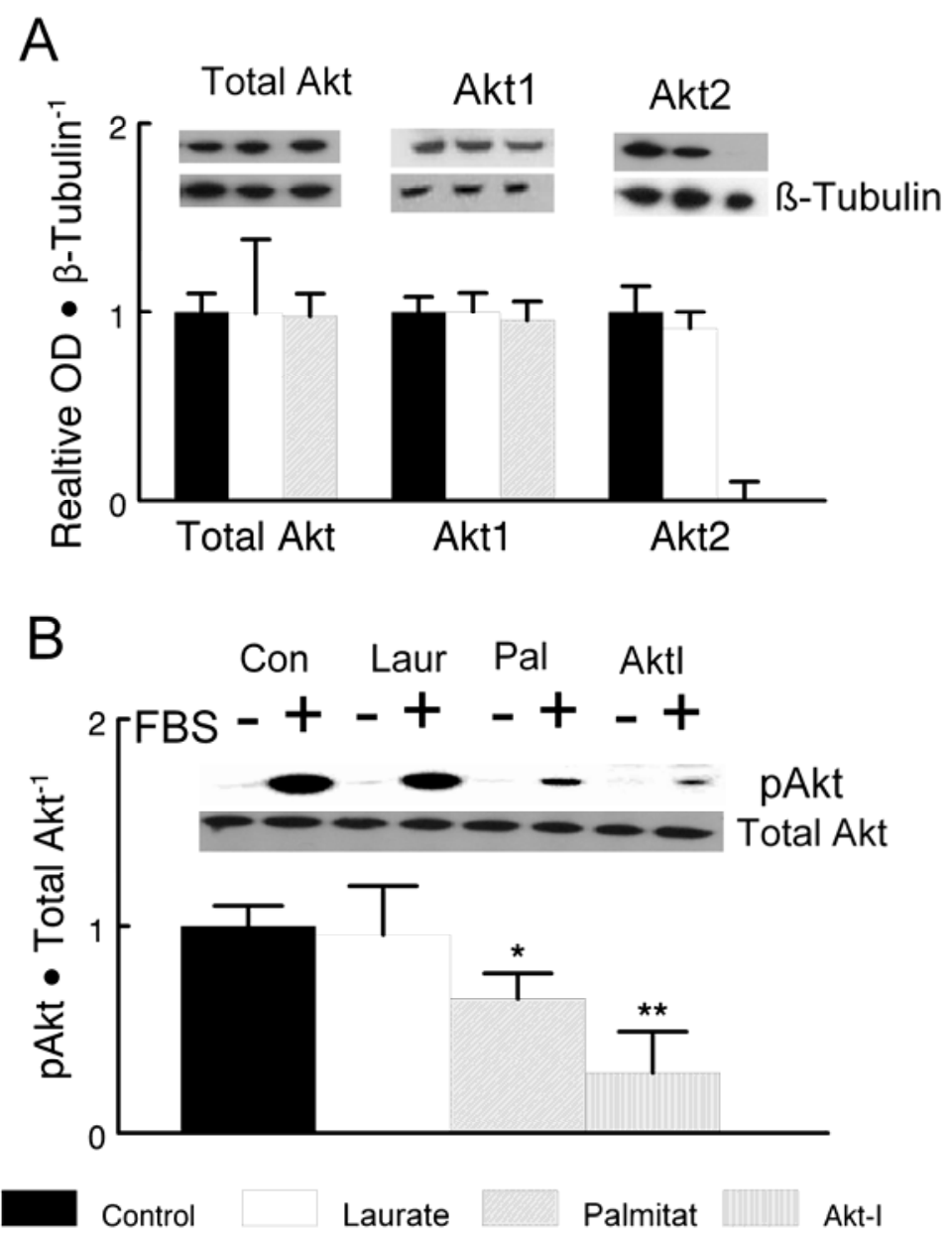


Figure 5

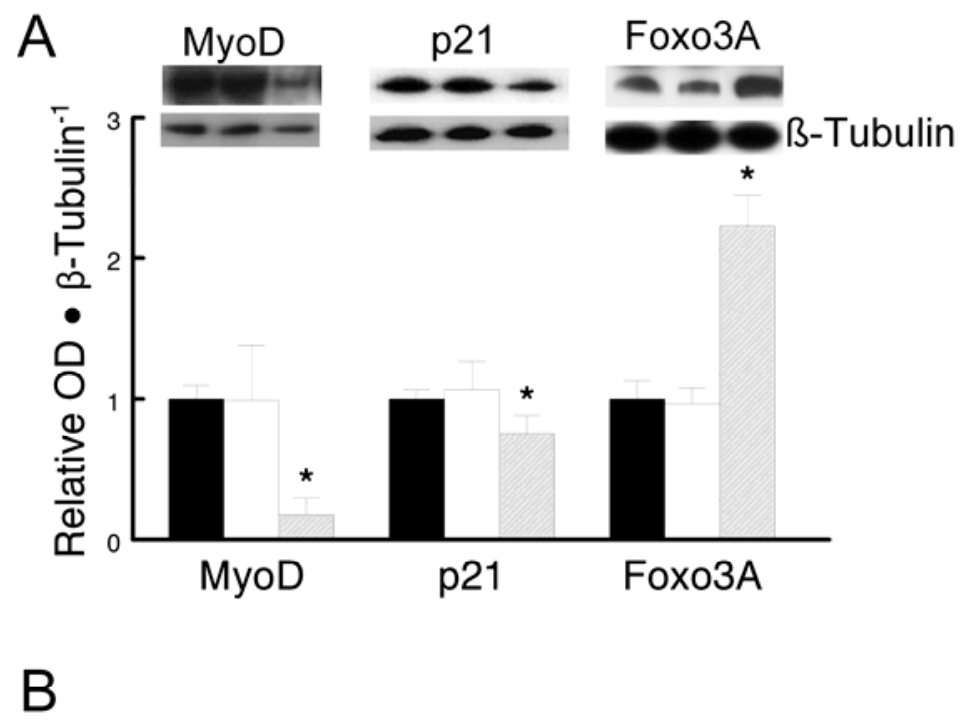

Cyclin B1

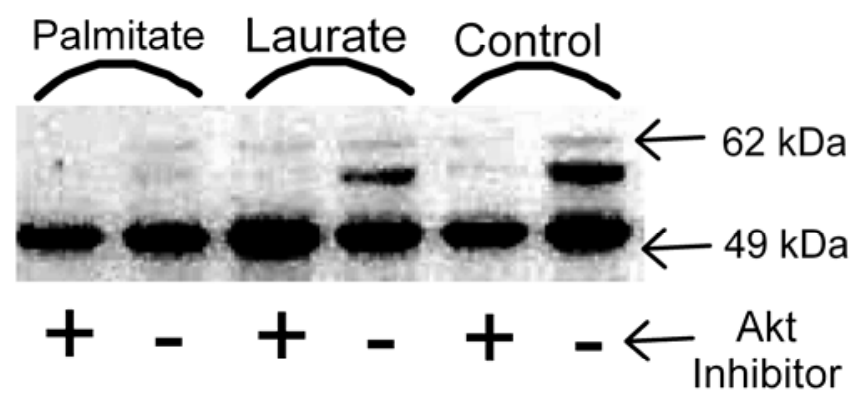


Figure 6

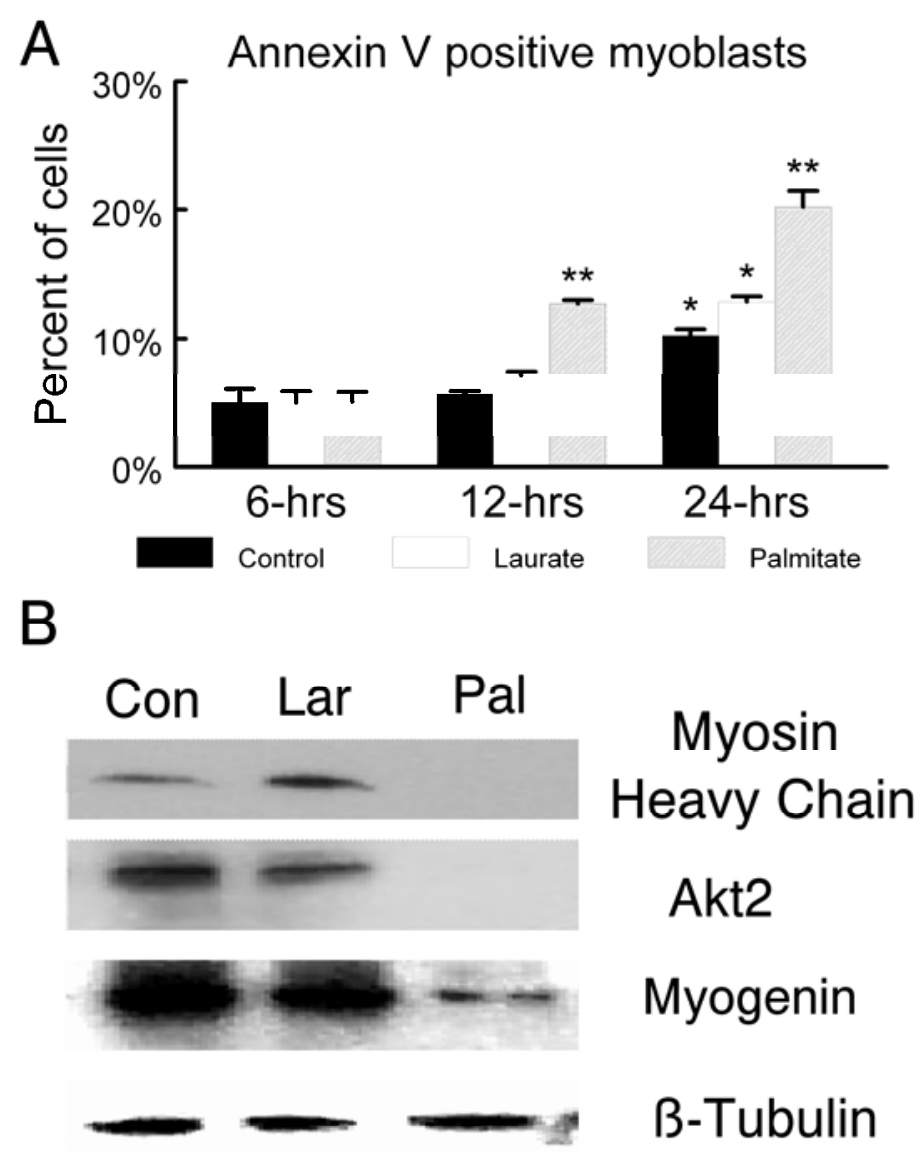




\section{Satellite cell proliferation is reduced in muscles of obese Zucker rats, but restored with loading}

JONATHAN M. PETERSON, RANDALL W. BRYNER, AND STEPHEN E. ALWAY

Laboratory of Muscle Biology and Sarcopenia, Division of Exercise Physiology, West Virginia University School of Medicine, Morgantown,

West Virginia 26506

Abbreviated title: Satellite cells proliferation in metabolic syndrome

\section{Send correspondence and reprint requests to:}

Stephen E Alway, Ph.D.

Professor and Chair

Exercise Physiology, School of Medicine,

Robert C. Byrd Health Science Center, West Virginia University, Morgantown WV 26506-9227, USA

Phone: 304-293-0772

Fax: 304-293-7105

Email: salway@hsc.wvu.edu 


\begin{abstract}
The obese Zucker rat (OZR) is a model of the metabolic syndrome, which has lower skeletal muscle size compared to the lean Zucker rat (LZR). Because satellite cells are essential for postnatal muscle growth, this study was designed to determine if reduced satellite cell proliferation contributes to the reduction of skeletal mass in the OZR compared with the LZR. Satellite cell proliferation was determined by a constant release 5-bromo-2-deoxyuridine (BrdU) pellet that was placed subcutaneously in each animal. Satellite cell proliferation, as determined by incorporation of BrdU, was significantly attenuated in control soleus and plantaris muscles of the OZR compared to the LZR. To determine whether this attenuation of satellite cell activity could be rescued in OZR muscles, the soleus and the gastrocnemius muscles were denervated, placing a compensatory load on the plantaris muscle. There was a $\sim 25 \%$ and $\sim 30 \%$ increase in the plantaris muscle wet weight compared to the contra-lateral control muscle in the LZR and the OZR, respectively after 21-days of loading. The number of BrdU positive nuclei increased similarly in loaded plantaris muscles from LZR and OZR. Myogenin, MyoD and Akt protein expression, were lower in the control muscles of OZR compared to LZR, but they were all elevated to similar levels in the loaded plantaris muscles of OZR and LZR. These data indicate that metabolic syndrome may reduce satellite cell proliferation and this may be a factor that contributes to the reduced mass in control muscles of OZR; however, satellite cell proliferation can be restored with compensatory loading in OZR.
\end{abstract}

Key Words: muscle stem cells, muscle hypertrophy, metabolic syndrome, myogenic transcription factors 


\section{Introduction}

The obese Zucker rat (OZR) is a widely accepted model of the metabolic syndrome, which occurs as a result of a homozygous missense mutation of the leptin receptor gene (9) leading to chronic hyperphagia $(9,21)$. As a result, the OZR rapidly becomes obese and develops extreme insulin resistance and hypertriglyceridemia, which is accompanied by a clinically relevant hypertension and a prothrombotic and proinflammatory state $(5,16,20,22,28,36)$. Skeletal muscles are considerably smaller in the OZR than in the control lean Zucker rat (LZR) of similar ages. This is important because skeletal muscle, is the primary site of glucose and fat oxidation, both of which are in excess with metabolic syndrome $(6,27)$. Therefore, a reduction of skeletal muscle mass would further compromise clinical outcomes in metabolic syndrome.

The lower skeletal muscle mass in the OZR appears to be partly accounted for by an altered balance between protein synthesis and degradation in this model of metabolic syndrome $(4,16)$. However, it has also been observed that there is a decrease in nucleic acid content in the muscles of the OZR compared to the LZR (16). Replacing nuclei that are lost during normal turnover and maintaining nuclear content in adult muscle, is a primary responsibility of muscle satellite cells. Muscle satellite cells are normally quiescent myogenic precursor cells found between the basal lamina and the sarcolemma of a muscle fiber (1). However, these cells can proliferate in response to a variety of stimuli, and they are responsible for maintenance of the nuclear to cytoplasmic relationship in muscle. Furthermore, postnatal muscle growth and hypertrophy of skeletal muscle, critically depend on the proliferation and differentiation of muscle satellite cells $(1,25)$. It is possible that a decrease in satellite cell proliferation could contribute to the decrease in nucleic acid content and skeletal muscle mass observed in the OZR. 
Mechanisms that may contribute to lower satellite cell proliferation and differentiation in muscles of the OZR could include decreases in the expression levels of myogenic regulatory factor proteins. Myogenic regulatory factors are muscle-specific helix-loop-helix transcription factors which regulate muscle specific genes (12,25). MyoD and myogenin are myogenic regulatory factors which are expressed in activated satellite cells and they are necessary for satellite cell proliferation and differentiation $(12,37)$. MyoD and myogenin are reduced during muscle atrophy, and in models of diabetes $(3,13)$, although it has not been determined if this corresponds to reduced satellite cell proliferation or differentiation in models of the metabolic syndrome. We hypothesized that a decrease in the protein expression of MyoD and myogenin might result in lower satellite cell proliferation and/or differentiation and lead to lower muscle mass in the OZR model of metabolic syndrome, as compared to the lean phenotype.

Another possible mechanism for disrupted satellite cell proliferation is deregulated protein kinase B/Akt (Akt) signaling. Control of the Akt signaling pathway is essential for muscle growth and hypertrophy (reviewed $(7,19)$ ). Furthermore, a lower level of activated Akt is associated with attenuated increases in muscle hypertrophy under conditions such as aging $(7,19)$. Akt, and specifically Akt2, is essential for proliferation and differentiation of skeletal muscle satellite cells $(7,8)$. In the OZR there is a reduced protein expression of Akt2 and reduced activity levels of both Akt1 and Akt2 compared to the LZR (24). These findings underscore the possibility that Akt signaling may play an important role in the control of satellite cell proliferation and differentiation in muscles of the OZR.

Although the skeletal muscles of the OZR are smaller compared to the LZR, to the best of our knowledge, no study has evaluated whether muscles in the OZR have attenuated hypertrophy 
in response to loading. While the OZR is significantly less active than the LZR (9), the OZR have much greater body mass, and this should provide a greater stimulus for muscle growth on the weight bearing muscles. Nevertheless, a previous study from our lab in which the daily activity of the OZR was increased through daily treadmill running, demonstrated no increase in the size of the skeletal muscles (18). These findings suggest that there may be an underlying deficit in the ability of skeletal muscle to respond to increased loading in the OZR model of metabolic syndrome.

The purposes of this study were to determine (i) if there was a decrease in the number of satellite cells in the skeletal muscles of the OZR compared to the LZR (ii) whether satellite cell proliferation is attenuated in OZR compared to the LZR in control muscle; (iii) whether satellite cell proliferation is attenuated in OZR compared to the LZR in loaded muscle; and, (iv) whether the skeletal muscles of the OZR are able to hypertrophy in response to loading. Furthermore, as muscle loading directly activates Akt (31) and MRF signaling (2,26), Akt, MyoD, and myogenin protein expression were measured. We hypothesized that Akt and MRF protein expression would be rescued with compensatory hypertrophy in the OZR, and enable a restoration of satellite cell proliferation to levels similar to lean animals. 


\section{METHODS}

Animal Care. Male LZR $(+/ f a)$ and OZR $(f a / f a)$ rats were purchased from Harlan labs (Harlan, Indianapolis, IN). The OZR are homozygous for a recessive missense mutation of the leptin receptor gene which results chronic hyperphagia. The LZR are heterozygous for this mutation but do not shown eating abnormalities $(9,29)$. Twelve animals of each phenotype were used in this study. All animals were 12 weeks of age at completion of this study. The animals were housed in pathogen-free conditions, at $20-22^{\circ} \mathrm{C}$, and fed rat chow and water ad libitum throughout the study period. The animal care standards were followed by adhering to the recommendations for the care of laboratory animals, as advocated by the American Association for Accreditation of Laboratory Animal Care, which fully conformed to the Animal Welfare Act of the US Department of Health and Human Services. All animal procedures were conducted in accordance with institutional guidelines and ethical approval was obtained from the Animal Care and Use Committee at the West Virginia University prior to carrying out tests.

Compensatory loading protocol. To achieve compensatory hypertrophy of the plantaris muscle, synergist denervation of the soleus and gastrocnemius muscles was used as previously described in our (14). Briefly, the distal branches of the tibial nerve were transected, therefore, removing the innervation to the soleus muscle and both heads of the gastrocnemius muscle. The severed nerved endings were sutured onto the biceps femoris muscle to prevent reinnervation back to the original muscles (14). This placed a compensatory load on the plantaris muscle. The contralateral limb received a sham surgery, in which the branches of the tibial nerve were identified but not severed, and this served as an internal control for each animal. All procedures were performed under aseptic conditions. The animals recovered quickly and were alert and walking within $\sim 15$ min after surgery. Loading occurred for 7 or 21 days. 
Bromodeoxyuridine (BrdU) implantation. A time-released 5-bromo-2-deoxyuridine (BrdU) pellet (21-day release, $0.22 \mu \mathrm{g} \mathrm{BrdU} \cdot \mathrm{g}$ body $\operatorname{mass}^{-1} \cdot$ day $^{-1}$; Innovative Research, Sarasota, FL) was placed subcutaneously on the dorsum of the back of each animal. BrdU is a thymidine analog and is incorporated in nuclei during DNA synthesis. Skeletal muscle nuclei are postmitotic and cannot incorporate BrdU into their DNA. In contrast, satellite cells can incorporate BrdU during proliferation. Therefore, BrdU positive nuclei located under the basal lamina can be identified as satellite cells that have proliferated, migrated and become incorporated into a muscle fiber (1). Therefore, BrdU was used to identify satellite cells/muscle precursor cells that had proliferated during the 7- or 21-day period of muscle loading-induced hypertrophy. Only the BrdU positive nuclei within the basal lamina were quantified. The BrdU labeling index was calculated as the number of BrdU labeled myonuclei $\cdot$ total myonuclei ${ }^{-1} \cdot 100$. This provided an index of satellite cell proliferation.

Tissue Collection. The plantaris muscles were collected 7 days ( $n=6$ LZR-7 and $n=6$ OZR-7) or 21 days ( $n=6$ LZR-21 and $n=6$ OZR-21) after the surgical denervation of the synergists. The animals were 12 weeks old at time of tissue collection. The rats were

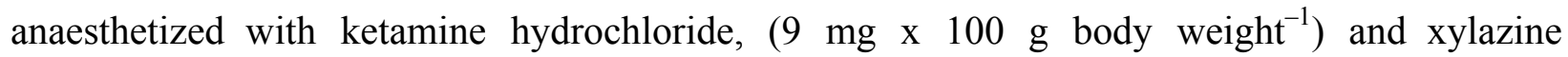
hydrochloride ( $1 \mathrm{mg}$ x $100 \mathrm{~g}$ body weight $^{-1}$ ), I.P. and the plantaris muscles from each limb were removed and frozen in isopentane, cooled to the temperature of liquid nitrogen, and stored at $80^{\circ} \mathrm{C}$ until further analysis. Additionally, a mid-belly section of each muscle was fixed in $10 \%$ formalin and was embedded in paraffin.

Immunoblot protein analysis. Total protein homogenates were prepared in lysis buffer (20 mM Tris pH 7.5, $150 \mathrm{mM} \mathrm{NaCl,} \mathrm{1 \%} \mathrm{Nonidet} \mathrm{P-40,} \mathrm{0.5 \%} \mathrm{Sodium} \mathrm{Deoxycholate,} 1 \mathrm{mM}$ 
EDTA, 0.1\% SDS) with the addition of a protease inhibitor (Sigma Chemical Co, St Louis, MO, USA). The protein contents of muscle homogenates were quantified in duplicate by using bicinchoninic acid reagents (Pierce, Rockford, IL, USA) and bovine serum albumin (BSA) standards. The mitochondria-free cytosolic protein fraction was isolated as previously described (33) and used for immunoblotting for apoptosis inducing factor (AIF). AIF was used as an index of mitochondria permeability and release of pro-apoptotic factors to the cytosolic protein fraction. $50 \mu \mathrm{g}$ of soluble protein was boiled for $4 \mathrm{~min}$ at $100^{\circ} \mathrm{C}$ in Laemmli buffer and separated on a 4-12\% gradient polyacrylamide gel (Invitrogen, USA). The gels were blotted to nitrocellulose membranes (Bio-Rad, Hercules, CA, USA) and stained with Ponceau red (Sigma Chemical Co, St Louis, MO, USA) to confirm equal loading and transfer of proteins to the membrane.

The membranes were then blocked in 5\% non-fat milk in Tris buffered saline containing 0.05\% Tween 20 (TBS-T) and probed with antibodies to Akt, Akt1, Akt2 (Cell Signaling Technology, MA, USA), MyoD or myogenin (Santa Cruz, CA, USA). To determine if apoptotic signaling was enhanced in control muscles of OZR animals, the membranes were probed with antibodies to: AIF, apoptotic protease activating factor 1 (Apaf-1), apoptosis repressor with a caspase recruitment domain (ARC), and Bcl-xL/Bcl-2 associated death promoter (BAD), (Santa Cruz, CA, USA). As a further confirmation of equal loading and blotting of the proteins, the membranes were also probed for ß-tubulin or GapDH (Abcam, MA, USA). Secondary antibodies were conjugated to horseradish peroxidase (Chemicon, CA, USA) and the signals were developed by chemiluminescence (ECL advance, Amersham Biosciences). The signals were visualized by exposing the membranes to X-ray films (BioMax MS-1, Eastman Kodak, Rochester, NY, USA), and digital records of the films were captured with a Kodak 290 camera. 
The resulting bands were quantified as optical density (OD) $\mathrm{x}$ band area by a one-dimensional (1-D) image analysis system (Eastman Kodak, Rochester, NY, USA) and expressed in arbitrary units normalized to ß-tubulin or glyceraldehyde 3-phosphate dehydrogenase (GapDH; Abcam Inc. Cambridge, MA).

Immunofluorescent staining. Paraffin embedded, 7- $\mu$ m-thick, muscle-cross sections from loaded and control plantaris muscles were de-paraffinized in xylene, followed by rehydration in graded ethanol washes, and then rinsed in distilled water. The tissues sections were incubated in an antigen retrieval buffer $(10 \mathrm{mM}$ sodium citrate, $0.05 \%$ Tween-20, $\mathrm{pH} 6.0)$ for 30 minutes at $95^{\circ} \mathrm{C}$, washed in phosphate buffered saline (PBS) and then blocked in $1.5 \%$ goat serum in PBS at $37^{\circ} \mathrm{C}$ for $30 \mathrm{~min}$. Sections were then incubated with an anti-BrdU mouse monoclonal antibody (BD Pharmingen, San Diego, CA) followed by an anti-mouse Alexa 488 (Invitrogen, CA). Negative control experiments were done by omitting the BrdU antibody from the tissue sections. The basal lamina was identified with a primary antibody to anti-laminin (D18; Hybridoma Bank) followed by a rhodamine conjugated secondary antibody (Santa Cruz Biotechnology, CA). Only the BrdU positive nuclei within the basal lamina were quantified. The BrdU labeling index was calculated as the number of BrdU labeled nuclei total nuclei ${ }^{-1} \cdot 100$. This provided an index of satellite cell proliferation.

Pax7 antibody (PAX7; Developmental Studies, Hybridoma Bank, U. Iowa) was used to determine the number of satellite cells in the control muscles (40). Since the formalin fixation interfered with the $\operatorname{Pax} 7$ antibody, $7 \mu \mathrm{m}$ cross-sections were obtained from frozen mid-belly sections of the muscle as previously performed in our laboratory (34). Briefly, the sections were air dried at room temperature, fixed in ice-cold methanol-acetone (1:1) for 10 minutes, rinsed in 
PBS, and permeabilized in $0.2 \%$ triton- $\mathrm{X}$ in $0.1 \%$ sodium citrate. The sections were incubated for 30 minutes in $1.5 \%$ goat serum at $37^{\circ} \mathrm{C}$ then incubated-with a primary antibody to $\operatorname{Pax} 7$ followed by Alexa 488. The tissue sections were then probed with anti-Laminin mouse IgG2a (2E8; Hybridoma Bank) followed by a rhodamine conjugated secondary antibody (Santa Cruz Biotechnology, CA).

Immunoblot analysis was completed on 6 non-overlapping tissue cross-sections (40x magnification). Three cross- sections were examined in each muscle. Myonuclei were only counted for analysis if they resided within the basal lamina. Pax7 positive nuclei were identified as quiescent satellite cells, because neither myonuclei nor activated/differentiated satellite cells express Pax7 (40). Additionally, skeletal muscle nuclei are post-mitotic, and therefore any nuclei residing under the basal lamina that were BrdU positive were identified as proliferated satellite cells (1). The BrdU labeling index was calculated as the number of BrdU labeled myonuclei $\cdot$ total myonuclei ${ }^{-1} \cdot 100$ and this was used as an index of satellite cell proliferation.

In situ TdT-mediated dUTP nick end labeling (TUNEL) staining. Apoptotic nuclei were assessed from muscle cross-sections via a TUNEL assay. $10-\mu \mathrm{m}$-thick frozen sections were cut in a freezing cryostat at $-20^{\circ} \mathrm{C}$ from plantaris muscle cross-sections. Apoptotic nuclei were identified by a fluorometric TUNEL detection kit (Roche Applied Science, Indianapolis, IN) according to the manufacturer's instructions for both $\mathrm{C} 2 \mathrm{C} 12$ myoblasts and muscle cross sections. Briefly, tissue sections were fixed in $4 \%$ paraformaldehyde in $\mathrm{PBS}, \mathrm{pH} 7.4$, at room temperature for $20 \mathrm{~min}$, permeabilized with $0.2 \%$ Triton $\mathrm{X}-100$ in $0.1 \%$ sodium citrate at $4^{\circ} \mathrm{C}$ for $2 \mathrm{~min}$, and incubated with fluorescein-conjugated TUNEL reaction. Negative control experiments were done by omitting the TdT enzyme in the TUNEL reaction mixture on the 
tissue sections. After TUNEL labeling, the muscle sections were incubated with an anti-laminin monoclonal antibody (2E8; Hybridoma Bank, Iowa) followed by an anti-mouse (Cy3 Conjugate, C2181) and mounted with 4',6-Diamidino-2-phenylindole (DAPI; Vectashield ${ }^{\circledR}$ mounting medium). TUNEL- and DAPI-positive nuclei and laminin staining were examined under a fluorescence microscope, and the captured images were stacked using a SPOT RT camera (Diagnostic Instruments, Sterling Heights, MI), and SPOT RT software (Universal Imaging, Downingtown, PA). The number of TUNEL and DAPI-positive nuclei was counted from six random, non-overlapping fields at an objective magnification of $\mathrm{x} 40$. Only the labeled nuclei that were under the laminin staining were counted, to exclude any non-muscle nuclei in the sections. Data were expressed as number of TUNEL-positive nuclei per 100 nuclei counted.

Statistical analyses. Statistical analyses were performed using the SYSTAT 11.0 software package. A one way Analysis of variance (ANOVA) was performed on the difference in all measured variables. The effect of loading on muscle wet-weight was determined by comparing muscle wet-weights from control and loaded limbs with a paired T-test. The percent change in muscle wet weight was calculated for each individual animal and the means from these data for each animal group ( $n=6 /$ group) are presented in Figure 1. Satellite cell proliferation index, body weight, control or loaded soleus muscle weight, control or loaded plantaris muscle weight, Pax7 positive nuclei, BrdU positive nuclei, protein expression levels, and nuclei number per muscle fiber were analyzed using a 2 way ANOVA (phenotype x treatment; control or loaded).The satellite cell proliferation index, and protein expression were not compared between 7 days post 
surgery and 21 days post surgery. Statistical significance was accepted at $P<0.05$. All data are presented as means \pm standard error. 


\section{RESULTS}

Muscle characteristics. The OZR had significantly more body weight than the LZR. The control plantaris and soleus muscles of the OZR were significantly smaller than the LZR after 7or 21 days of compensatory loading. 7-days of loading did not significantly increase muscle wet weight in either LZR or OZR. However, 21 days of loading increased the mass of the plantaris muscles by $23 \pm 12.8 \%$ in the LZR-21 and $32 \pm 13 \%$ in the OZR-21 (Figure 1). These data indicate that the compensatory loading protocol used in this study was sufficient to induce hypertrophy in both the obese and lean phenotype over a 21-day time point.

Quiescent satellite cells. Pax 7 was used as a marker to identify quiescent satellite cells (40) in tissue cross-sections from soleus and plantaris muscles. The number of quiescent satellite cells was expressed as a percentage of total myonuclei (DAPI-positive nuclei within the muscle fiber, as determined by staining of the basal lamina). The percentage of Pax 7 positive nuclei to total myonuclei was similar in plantaris and soleus muscles of OZR and LZR animals (Figure 2A). However, there were fewer total myonuclei in muscles of OZR animals compared to LZR animals. There was a significant, $\sim 30 \%$ and $20 \%$ decrease, in the number of myonuclei per muscle fiber cross section in plantaris and soleus muscles respectively, of OZR compared to the LZR (Figure 2B). Together these data signify that although the percentage of satellite cells (as indicated by Pax7) to total myonuclei is not reduced, there are less total myonuclei in the OZR. This suggests that there was not a preferential loss of satellite cells in the muscles of the OZR, but rather, there was a proportional decrease in the number of satellite cells and myonuclei in muscles of OZR compared to LZR. 
Apoptotic signaling proteins. We examined if increased nuclear apoptosis may account for the fewer nuclei found in muscles fibers of the OZR compared with the LZR. Surprisingly, immunoblot analysis showed similar levels of AIF, ARC, APAF-1, and Bad protein content in control muscles of OZR and LZR (Figure 3). Similarly, apoptotic nuclei as reflected by the frequency of TUNEL positive nuclei were less than $1 \%$ of the total myonuclei and there was no difference in the number of apoptotic nuclei in the muscle cross-sections from LZR and OZR animals. These data suggest that apoptosis is not increased and therefore cannot account for the fewer number of myonuclei and satellite cells in muscles of the OZR compared with the LZR.

Satellite cell proliferation. One possible explanation for the lower number of myonuclei is that satellite cell proliferation and replacement of nuclei could be impaired in control muscles. To test this possibility, we examined satellite cell proliferation in the muscles of the OZR compared to the LZR, in control muscles. To determine if satellite cell proliferation could be rescued to contribute to muscle hypertrophy, we examined loaded plantaris muscles. BrdU time release pellets were implanted in all animals to label proliferated satellite cells. In the contralateral control limb there was a significant absence of BrdU positive nuclei in the OZR compared to the LZR in both the plantaris (Figure 4D) and soleus muscles (Figure 4E). In this study, only one BrdU positive myonuclei was observed in all the control plantaris muscle cross sections that were examined from OZR, and only two BrdU positive myonuclei were observed in all of the control OZR soleus muscles. In contrast, every cross section that was examined in the LZR had a minimum of one BrdU positive nuclei. These data support the hypothesis that there is a decrease in satellite cell proliferation in the control muscles of the OZR compared to the LZR. On the other hand, loading of the plantaris muscle induced a significant increase in the number 
of BrdU positive muscle nuclei in both the OZR and LZR (Figure 4D). The number of BrdU positive nuclei was similar in loaded muscles from OZR animals.

Myogenic regulatory factors and Akt protein expression. As expected, immunoblot analysis demonstrated that there was a significant decrease in both MyoD and myogenin protein levels in the control plantaris muscles of the OZR compared to the LZR (Figure 5). After 7-days of loading there was a similar $\sim 2$ and $\sim 3$-fold increase in the relative protein level of myogenin and MyoD, respectively, in both the LZR and OZR. After 21-days of loading, there was no longer a difference in the protein expression of MyoD and myogenin in the loaded plantaris muscles of LZR compared to the control limbs. However, MyoD and myogenin protein levels remained elevated in the plantaris muscles from OZR after 21-days of loading compared to the contralateral control (Figure 5).

There was a decrease in total Akt protein expression as well as the relative Akt2 isoform content, with no changes in Akt1 content in the control muscles of the OZR compare to the LZR. Compensatory loading increased the protein expression of both Akt1 and Akt2 protein content in plantaris muscles of the LZR and the OZR (Figure 6). After 21-days of loading, there was no difference in total Akt, Akt1, or Akt2 protein expression in the loaded plantaris muscle of the OZR compared to the LZR. These data indicated that although the protein expression levels of myogenic regulatory factors and Akt are reduced in control muscles in the OZR model of metabolic syndrome, they can be restored with a sufficient stimulus such that induced during compensatory loading. 


\section{DISCUSSION}

This study demonstrated a number of novel findings regarding satellite cell proliferation in the skeletal muscles of the OZR model of metabolic syndrome. First, there was a decrease in the number of myonuclei in muscle fiber cross-sections of the OZR compared with the LZR. Second, this study is the first to show that hypertrophy is not impaired in muscles of the OZR model of metabolic syndrome, if the stimulus is adequate. In addition, to the best of our knowledge, this is the first study to observe any form of loading-induced hypertrophy in any rodent model of metabolic syndrome. The third novel finding is that although there is no change in the proportion of quiescent satellite cells in control muscles, there was a significant attenuation of satellite cell proliferation of adult muscle under normal control loading conditions in the OZR compared with the LZR. The attenuation of satellite cell proliferation in control soleus and plantaris muscles that we observed in this study, may result in a decreased replacement of myonuclei during normal nuclear turnover. This could account for the decreased nucleic acid content in the skeletal muscles of the OZR compared to LZR observed by Durschlag and colleagues (16), as well as the decreased number of myonuclei in muscle fiber cross-sections in the OZR compared to the LZR. It has been previously shown that both Akt protein expression and activity levels are decreased in control muscles of the OZR when compared with the LZR (24). Because Akt signaling is a major component contributing to skeletal muscle hypertrophy $(7,11)$, it was anticipated that the lower Akt protein levels in plantaris muscles of the OZR would result in attenuated hypertrophy in response to compensatory loading compared to the LZR. However, no attenuation of satellite cell proliferation or muscle hypertrophy was found in the OZR after compensatory loading of the plantaris muscle. 
Muscle hypertrophy in response to normal growth or muscle loading in adults is critically dependent on the proliferation and differentiation of satellite cells (30). Reduction in muscle DNA content (10) as a result of reduced muscle nuclei content (35) is one mechanism contributing to lower muscle transcriptional activity and muscle mass with aging, and potentially leading to sarcopenia in aging. Thus, it is possible that in a similar fashion, reduced proliferation of satellite cells will contribute to lower nuclear content in skeletal muscle of OZR, which may have contributed to reduced muscle mass in control muscles compared with LZR. In this study, satellite cell proliferation was determined by identifying nuclei inside the basal lamina that had incorporated BrdU during compensatory hypertrophy of the plantaris muscle of OZR and LZR. We would not expect to see a high number of satellite cells being activated in adult skeletal muscle in humans under normal basal conditions. However, unlike humans, rodents, continue to grow throughout their life cycle so one would expect to see a small amount of satellite cell proliferation even in adult rodent muscles. This expectation was confirmed in our finding of BrdU positive myonuclei in the LZR control soleus and plantaris muscles. The initial hypothesis proposed for this study was that satellite cell proliferation would be inhibited in the OZR model of metabolic syndrome, regardless of loading. This hypothesis was partial confirmed by the almost complete absence of BrdU positive myonuclei in the control plantaris and soleus muscles of the OZR. On the other hand, after loading, the number of BrdU positive myonuclei was elevated in the LZR, but surprisingly there was an almost equal amount of BrdU positive nuclei in the loaded plantaris muscle of the OZR and the LZR. We did anticipate that if satellite cell proliferation was restored it would coincide with a restoration of Akt and myogenic regulatory factor protein expression as we observed in this study. Previous studies from our lab and others have shown that loading-induced hypertrophy is accompanied by increases in MyoD and 
myogenin $(2,10)$, whereas, muscle wasting and aging are usually accompanied by decreases or attenuated increases in protein levels of myogenic transcription factors $(2,15,26)$. In old birds, the lower levels of myogenic regulatory factors appear to result from reduced contributions from satellite cells (25); however, restoration of myogenic regulatory factor levels from muscle loading could reflect changes in both myonuclei and satellite cells (25). In the present study, it is likely that the increased load on the plantaris muscle was sufficient to increase the activation of Akt in a contraction dependent manner (32) and that the increase in Akt induced increased expression of myogenic regulatory factors (23).

Traditional treatments for metabolic syndrome, as recommended by the American Diabetes Association, include weight loss and aerobic exercise. Aerobic exercise increases whole-body glucose disposal and improves insulin sensitivity, mainly through increased expression of GLUT-4 protein (17). However, aerobic exercise is not considered an effective means to induce skeletal muscle hypertrophy. On the other hand, resistance exercise has also been shown to increase glucose transport into the muscle (38) and is widely accepted as a means to induce muscle hypertrophy.

To the best of our knowledge, this is the first study to demonstrate hypertrophy in an animal model of metabolic syndrome. It is important to note that metabolic syndrome did not limit muscle hypertrophic adaptations to increased loading. Another important finding of this study is that there was a restoration of Akt2 protein expression in hypertrophied muscles of OZR after overload. Akt2 specifically has been linked to disruptions in GLUT4 regulation, glucose uptake, as well as skeletal muscle hypertrophy $(8,11,31)$. Skeletal muscle, by virtue of its mass, is the primary site for glucose and fatty acid oxidation, both of which are important complications with metabolic syndrome $(6,27)$. These findings suggest that resistance training, 
or some other form of loading, may be a viable addition to the treatment and/or prevention of metabolic syndrome in humans.

To our knowledge, this is the first study in which satellite cell quantification and proliferation with metabolic syndrome has been investigated. We do not think that increased apoptotic signaling could account for the lower number of myonuclei and satellite cells in crosssections of control muscles of the OZR, because we have failed to observe any increases in markers of apoptosis (TUNEL positive nuclei; protein levels of AIF, Apaf-1, ARC or BAD) in control muscles of the OZR compared with the LZR. Furthermore, it is unlikely that metabolic syndrome attenuates the sustained increases in ribosomes, thereby limiting translational capacity, as is the case in some chronic diseases (1), because in the present study, the plantaris muscles had similar hypertrophic adaptations to compensatory loading in OZR and LZR. We speculate that lower Akt and MyoD levels in control muscles of OZR might in turn result in decreased satellite cell proliferation. This hypothesis is supported by recent data that show that leptin promotes proliferation and inhibits myogenin expression and myoblast differentiation in vitro (39), and therefore the lack of leptin might result in an inhibition of satellite cell proliferation. In the current study, there was a significant decrease in the protein expression of myogenic regulatory factors, myogenin and $\mathrm{MyoD}$, as well as Akt, which could account for the decreased satellite cell proliferation in the control muscles of the OZR. It is not clear if the lower levels of MyoD and Akt are leptin dependent or independent, or simply a response to or a consequence of metabolic syndrome. Thus, it is possible that deficient leptin signaling or some other aspect of metabolic syndrome attenuates the expression of these proteins. To test this further, other models of obesity and metabolic syndrome would need to be investigated in which leptin levels were manipulated. Nevertheless, in the current study, MyoD, myogenin, and Akt protein expression 
were restored with loading, indicating that a significant stimulus, such as compensatory loading, is capable of overriding the attenuation of these proteins. Our results show that overloadinduced muscle hypertrophy and satellite cell proliferation occurs at similar levels in skeletal muscles of OZR and LZR, suggesting that satellite cell function per se is not limited in metabolic syndrome.

In conclusion, our data suggest that satellite cell proliferation is suppressed in control muscles of OZR with metabolic syndrome. This may lead to an impaired replacement of nuclei during normal turnover, and in turn, may contribute to the reduced number of myonuclei per muscle and the lower muscle mass in animals with metabolic syndrome. These findings underscore the need for further research to more fully understand the mechanisms responsible for attenuated satellite cell proliferation in control muscles in the OZR and to determine if satellite cell activity or proliferation is reduced in other models of the metabolic syndrome. 


\section{Acknowledgements.}

The antibodies D18, was developed by Dr. Joshua Sanes, PAX7 was developed by Dr. Atsushi Kawakami, and 2E8 was developed by Dr. Eva Engvall. These antibodies were obtained from the Developmental Studies Hybridoma Bank developed under the auspices of the NICHD and maintained by The University of Iowa, Department of Biological Sciences, Iowa City, IA 52242. This study was supported in part by support from the National Institutes of Health, National Institute on Aging Grant R01AG021530. 


\section{References}

1. Adams GR. Satellite cell proliferation and skeletal muscle hypertrophy. Appl Physiol Nutr Metab 31: 782-790, 2006.

2. Alway SE, Degens H, Krishnamurthy G and Smith CA. Potential role for Id myogenic repressors in apoptosis and attenuation of hypertrophy in muscles of aged rats. Am J Physiol Cell Physiol 283: C66-C76, 2002.

3. Aragno M, Mastrocola R, Catalano MG, Brignardello E, Danni O and Boccuzzi G. Oxidative stress impairs skeletal muscle repair in diabetic rats. Diabetes 53: 1082-1088, 2004.

4. Argiles JM, Busquets S, Alvarez B and Lopez-Soriano FJ. Mechanism for the increased skeletal muscle protein degradation in the obese Zucker rat. J Nutr Biochem 10: 244-248, 1999.

5. Barbato JE, Zuckerbraun BS, Overhaus M, Raman KG and Tzeng E. Nitric oxide modulates vascular inflammation and intimal hyperplasia in insulin resistance and the metabolic syndrome. Am J Physiol Heart Circ Physiol 289: H228-H236, 2005.

6. Bjornholm $\mathbf{M}$ and Zierath JR. Insulin signal transduction in human skeletal muscle: identifying the defects in Type II diabetes. Biochem Soc Trans 33: 354-357, 2005.

7. Bodine SC, Stitt TN, Gonzalez M, Kline WO, Stover GL, Bauerlein R, Zlotchenko E, Scrimgeour A, Lawrence JC, Glass DJ and Yancopoulos GD. Akt/mTOR pathway is a crucial 
regulator of skeletal muscle hypertrophy and can prevent muscle atrophy in vivo. Nat Cell Biol 3: 1014-1019, 2001.

8. Bouzakri K, Zachrisson A, Al Khalili L, Zhang BB, Koistinen HA, Krook A and Zierath JR. siRNA-based gene silencing reveals specialized roles of IRS-1/Akt2 and IRS-2/Akt1 in glucose and lipid metabolism in human skeletal muscle. Cell Metab 4: 89-96, 2006.

9. Bray GA. The Zucker-fatty rat: a review. Fed Proc 36: 148-153, 1977.

10. Carson JA and Booth FW. Myogenin mRNA is elevated during rapid, slow, and maintenance phases of stretch-induced hypertrophy in chicken slow-tonic muscle. Pflugers Arch 435: 850-858, 1998.

11. Cho H, Mu J, Kim JK, Thorvaldsen JL, Chu Q, Crenshaw EB, III, Kaestner KH, Bartolomei MS, Shulman GI and Birnbaum MJ. Insulin resistance and a diabetes mellitus-like syndrome in mice lacking the protein kinase Akt2 (PKB beta). Science 292: 1728-1731, 2001.

12. Cornelison DD, Olwin BB, Rudnicki MA and Wold BJ. MyoD(-/-) satellite cells in single-fiber culture are differentiation defective and MRF4 deficient. Dev Biol 224: 122-137, 2000.

13. Dasarathy S, Dodig M, Muc SM, Kalhan SC and McCullough AJ. Skeletal muscle atrophy is associated with an increased expression of myostatin and impaired satellite cell function in the portacaval anastamosis rat. Am J Physiol Gastrointest Liver Physiol 287: G1124-G1130, 2004. 
14. Degens H and Alway SE. Skeletal muscle function and hypertrophy are diminished in old age. Muscle Nerve 27: 339-347, 2003.

15. Degens H, Swisher AK, Heijdra YF, Siu PM, Dekhuijzen PN and Alway SE. Apoptosis and Id2 expression in diaphragm and soleus muscle from the emphysematous hamster. Am J Physiol Regul Integr Comp Physiol 293: R135-R144, 2007.

16. Durschlag RP and Layman DK. Skeletal muscle growth in lean and obese Zucker rats. Growth 47: 282-291, 1983.

17. Friedman JE, Sherman WM, Reed MJ, Elton CW and Dohm GL. Exercise training increases glucose transporter protein GLUT-4 in skeletal muscle of obese Zucker (fa/fa) rats. FEBS Lett 268: $13-16,1990$.

18. Frisbee JC, Samora JB, Peterson $\mathbf{J}$ and Bryner $\mathbf{R}$. Exercise training blunts microvascular rarefaction in the metabolic syndrome. Am J Physiol Heart Circ Physiol 291: H2483-H2492, 2006.

19. Frost RA and Lang CH. Protein kinase B/Akt: a nexus of growth factor and cytokine signaling in determining muscle mass. J Appl Physiol 103: 378-387, 2007.

20. Galinier A, Carriere A, Fernandez Y, Carpene C, Andre M, Caspar-Bauguil S, Thouvenot JP, Periquet B, Penicaud L and Casteilla L. Adipose tissue proadipogenic redox changes in obesity. J Biol Chem 281: 12682-12687, 2006. 
21. Guerre-Millo M. Regulation of ob gene and overexpression in obesity. Biomed Pharmacother 51: 318-323, 1997.

22. Herbert JM, Bernat A and Chatenet-Duchene L. Effect of ciprofibrate on fibrinogen synthesis in vitro on hepatoma cells and in vivo in genetically obese Zucker rats. Blood Coagul Fibrinolysis 10: 239-244, 1999.

23. Kaneko S, Feldman RI, Yu L, Wu Z, Gritsko T, Shelley SA, Nicosia SV, Nobori T and Cheng JQ. Positive feedback regulation between Akt2 and MyoD during muscle differentiation. Cloning of Akt2 promoter. J Biol Chem 277: 23230-23235, 2002.

24. Kim YB, Peroni OD, Franke TF and Kahn BB. Divergent regulation of Akt1 and Akt2 isoforms in insulin target tissues of obese Zucker rats. Diabetes 49: 847-856, 2000.

25. Lowe DA and Alway SE. Stretch-induced myogenin, MyoD, and MRF4 expression and acute hypertrophy in quail slow-tonic muscle are not dependent upon satellite cell proliferation. Cell Tissue Res 296: 531-539, 1999.

26. Lowe DA, Lund T and Alway SE. Hypertrophy-stimulated myogenic regulatory factor mRNA increases are attenuated in fast muscle of aged quails. Am J Physiol 275: C155-C162, 1998.

27. Olsen DB, Sacchetti M, Dela F, Ploug T and Saltin B. Glucose clearance is higher in arm than leg muscle in type 2 diabetes. $J$ Physiol 565: 555-562, 2005. 
28. Pei H, Gu J, Thimmalapura PR, Mison A and Nadler JL. Activation of the 12-lipoxygenase and signal transducer and activator of transcription pathway during neointima formation in a model of the metabolic syndrome. Am J Physiol Endocrinol Metab 290: E92-E102, 2006.

29. Phillips MS, Liu Q, Hammond HA, Dugan V, Hey PJ, Caskey CJ and Hess JF. Leptin receptor missense mutation in the fatty Zucker rat. Nat Genet 13: 18-19, 1996.

30. Rosenblatt JD, Yong D and Parry DJ. Satellite cell activity is required for hypertrophy of overloaded adult rat muscle. Muscle Nerve 17: 608-613, 1994.

31. Sakamoto K, Arnolds DE, Fujii N, Kramer HF, Hirshman MF and Goodyear LJ. Role of Akt2 in contraction-stimulated cell signaling and glucose uptake in skeletal muscle. Am J Physiol Endocrinol Metab 291: E1031-E1037, 2006.

32. Sakamoto K, Hirshman MF, Aschenbach WG and Goodyear LJ. Contraction regulation of Akt in rat skeletal muscle. J Biol Chem 277: 11910-11917, 2002.

33. Siu PM and Alway SE. Mitochondria-associated apoptotic signalling in denervated rat skeletal muscle. J Physiol 565: 309-323, 2005.

34. Siu PM, Pistilli EE, Butler DC and Alway SE. Aging influences cellular and molecular responses of apoptosis to skeletal muscle unloading. Am J Physiol Cell Physiol 288: C338-C349, 2005. 
35. Thompson RW, McClung JM, Baltgalvis KA, Davis JM and Carson JA. Modulation of overload-induced inflammation by aging and anabolic steroid administration. Exp Gerontol 41: 1136-1148, 2006.

36. Vaziri ND, Xu ZG, Shahkarami A, Huang KT, Rodriguez-Iturbe B and Natarajan R. Role of AT-1 receptor in regulation of vascular MCP-1, IL-6, PAI-1, MAP kinase, and matrix expressions in obesity. Kidney Int 68: 2787-2793, 2005.

37. Xu Q and Wu Z. The insulin-like growth factor-phosphatidylinositol 3-kinase-Akt signaling pathway regulates myogenin expression in normal myogenic cells but not in rhabdomyosarcomaderived RD cells. J Biol Chem 275: 36750-36757, 2000.

38. Yaspelkis BB, III. Resistance training improves insulin signaling and action in skeletal muscle. Exerc Sport Sci Rev 34: 42-46, 2006.

39. Yu T, Luo G, Zhang L, Wu J, Zhang H and Yang G. Leptin promotes proliferation and inhibits differentiation in porcine skeletal myoblasts. Biosci Biotechnol Biochem 72: 13-21, 2008.

40. Zammit PS, Relaix F, Nagata Y, Ruiz AP, Collins CA, Partridge TA and Beauchamp JR. Pax7 and myogenic progression in skeletal muscle satellite cells. J Cell Sci 119: 1824-1832, 2006. 
Table 1 Animal characteristics.

\begin{tabular}{lll}
\hline & LZR & OZR \\
\hline Body weight (g) & $296 \pm 17$ & $497 \pm 78^{*}$ \\
Plantaris control (mg) & $272 \pm 14$ & $220 \pm 18^{*}$ \\
Soleus control (mg) & $167 \pm 20$ & $144 \pm 9^{*}$ \\
Glucose (mg/dl) & $100.7 \pm 49$ & $193.2 \pm 44$ \\
\hline
\end{tabular}

LZR, lean Zucker rats; OZR, obese Zucker rats. ${ }^{*}=$ significant vs. LZR Data reported as mean \pm SE. 


\section{FIGURE LEGENDS}

Figure 1. A compensatory load was placed on the plantaris muscle by denervating the soleus and gastrocnemius muscles. The contra-lateral control muscle received a sham surgery. The data shown are the percent change in the muscle wet-weight in the loaded plantaris, with 7- or 21days of loading, compared to the contralateral control. The effect of loading on muscle wetweight was determined by comparing muscle wet-weights from control and loaded limbs. The percent change in muscle wet weight was calculated for each individual animal and the means from these data are presented for each animal group ( $n=6 /$ group). After 7-days of loading the percent change in muscle weight was not significant in either the LZR or OZR, however at 21days of loading the percent change in both phenotypes was significant. Data presented as mean + SE. *, $\mathrm{p}<0.05$ vs. contralateral control. Abbreviations: LZR, Lean Zucker rat; OZR, Obese Zucker rat; -7, 7 days of loading; -21, 21 days of loading.

Figure 2. Quiescent satellite cells were labeled with a Pax7 antibody and reported as a percent of the total myonuclei in the control plantaris and soleus muscles. Myonuclei were identified with DAPI and quantified if they were located within the basal lamina. Representative images of muscle cross-sections are shown with antibody labeling to Pax7 only (A); Pax7 plus the DAPI nuclear stain (B); and Pax7, DAPI, and Laminin antibody labeling (C). Each Pax7 positive nuclei was counted in 6 non-over-lapping microscopic fields. The data were normalized to the total number of nuclei in the same number of fields to obtain the percent of Pax7 nuclei as a percentage of total myonuclei. There was no difference in the proportion of Pax7 positive nuclei to total myonuclei between the LZR and OZR in either the plantaris or soleus muscles (D). In addition, the numbers of myonuclei for each muscle-fiber cross section were also examined. 
There were a significantly lower amount of nuclei in cross-sections of muscle fibers in the OZR compared to the LZR in both soleus and plantaris muscles (E). Data presented as means $\pm \mathrm{SE}$. *, $\mathrm{p}<0.05$ OZR ( $\mathrm{n}=12)$ vs. LZR ( $\mathrm{n}=12)$. Abbreviations: LZR, Lean Zucker rat; OZR, obese Zucker rat.

Figure 3. Representative immunoblots of apoptotic signaling proteins in control plantaris muscles from the lean Zucker rat (LZR) and the obese Zucker rat (OZR). There were no differences between the content of these proteins in muscles of OZR and LZR (quantification of blot data are not shown) .

Figure 4. A representative immunofluorescent image (green) of BrdU stained with Alexa-488 (A), BrdU labeling as in A coupled with and a DAPI (blue) nuclear stain (B), and incubated with a (red) rhodamine conjugated anti-Laminin IgG2a antibody (C). Labeling of BrdU (green), Laminin (red), and DAPI (blue) was used to identify the BrdU-positive nuclei within the muscle fibers to estimate the proliferation of muscle satellite cells in 6 non-overlapping fields. The number BrdU positive nuclei are shown as a percentage of all muscle nuclei in the plantaris (D) and soleus muscles (E). Only the BrdU positive nuclei within the basal lamina were quantified. The BrdU labeling index was calculated as the number of BrdU labeled nuclei total nuclei $^{-1}$. 100. This provided an index of satellite cell proliferation. The data for the soleus muscles are control values only, loading experiments were performed only on plantaris muscles ( $\mathrm{n}=6$ for all groups). Data presented as means $\pm \mathrm{SE} .{ }^{*}, \mathrm{p}<0.05$ OZR-7 vs. LZR-7, or OZR-21 vs. LZR-21 (comparison between control values at same days post surgery). ${ }^{* *}, \mathrm{p}<0.05$ Loaded vs. 
contralateral control. Abbreviations: LZR, Lean Zucker rat; OZR, Obese Zucker rat; -7, 7 days of loading; -21, 21 days of loading; control, contralateral control.

Figure 5. Immunoblot analysis of the protein expression levels of the myogenic regulatory factors MyoD (A) and myogenin (B) in control and loaded plantaris muscles. Data are expressed as optical density $\mathrm{x}$ band area normalized to GapDH. The inset displays representative images for control and experimental muscles. Data presented as means \pm SE. ${ }^{*}, \mathrm{p}<0.05$ OZR-7 vs. LZR-7, or OZR-21 vs. LZR-21 (comparison between control values at same days post surgery). **, $\mathrm{p}<0.05$ loaded vs. contralateral control. Abbreviations: LZR, Lean Zucker rat; OZR, Obese Zucker rat; -7, 7 days of loading; -21, 21 days of loading; control, contralateral control. ( $\mathrm{n}=6$ for all groups).

Figure 6. Immunoblot analysis of the protein expression levels of total Akt (A), Akt1 (B), and Akt2 (C) isoforms in control and loaded plantaris muscles. Data are expressed optical density $\mathrm{x}$ band area normalized to GapDH. Inset displays representative images for control and experimental muscles (D). Data presented as means \pm SE. $*=p<0.05$ OZR-7 vs. LZR-7, or OZR-21 vs. LZR-21 (comparison between control values at same days post surgery). **, p < 0.05 Loaded vs. contralateral control. Abbreviations: LZR, Lean Zucker rat; OZR, Obese Zucker rat; -7, 7 days of loading; -21, 21 days of loading; control, contralateral control; OD, optical density, a.u., arbitrary units. ( $\mathrm{n}=6$ for all groups). 
Figure 1

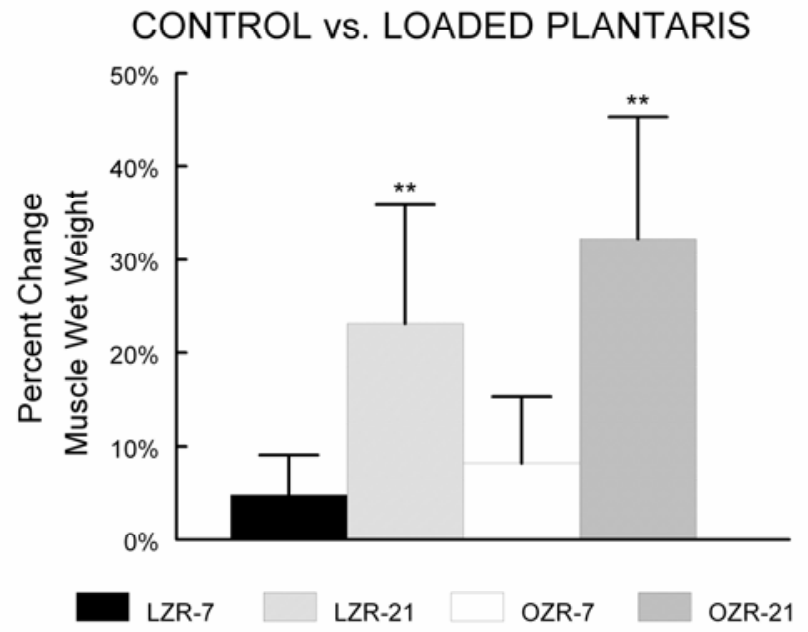


Figure 2

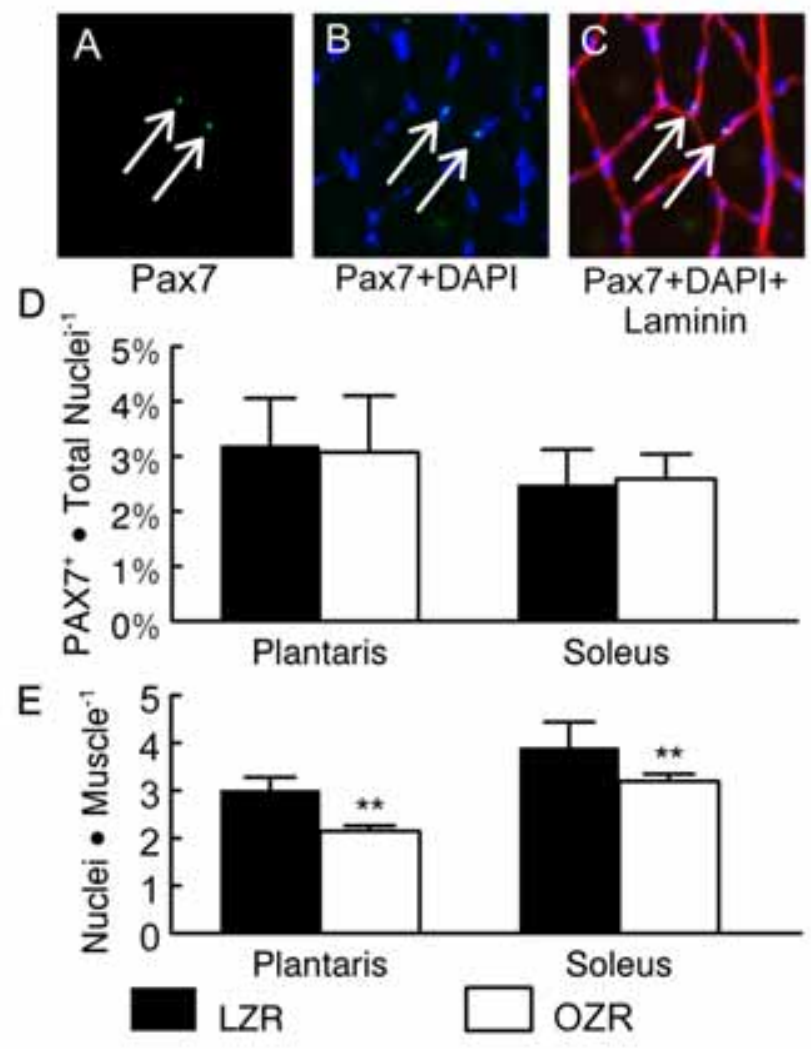


Figure 3
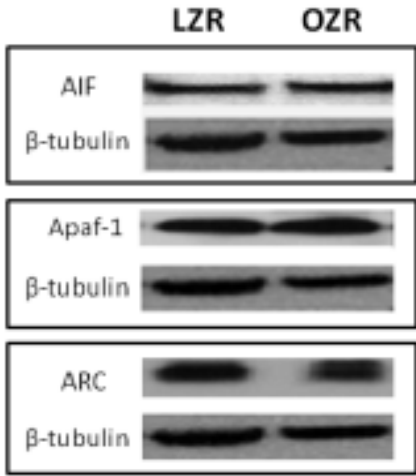

BAD

-

$\beta$-tubulin

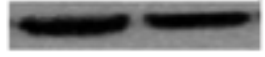


Figure 4

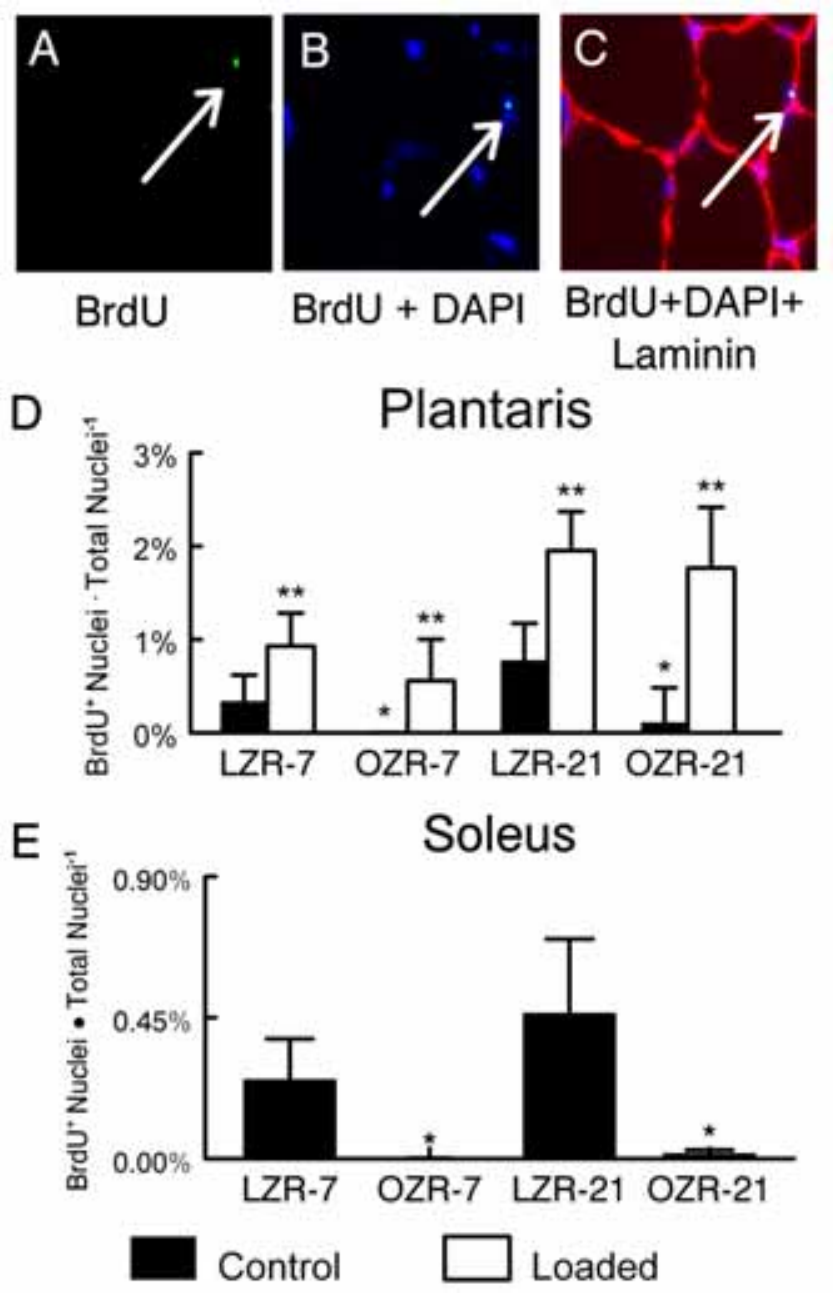


Figure 5

A)

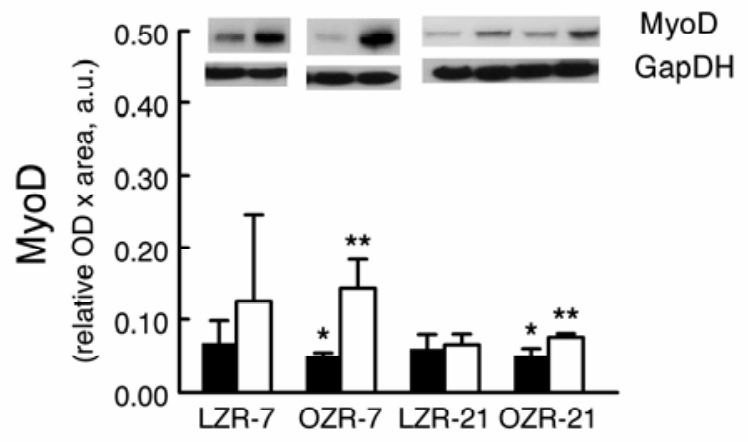

B)

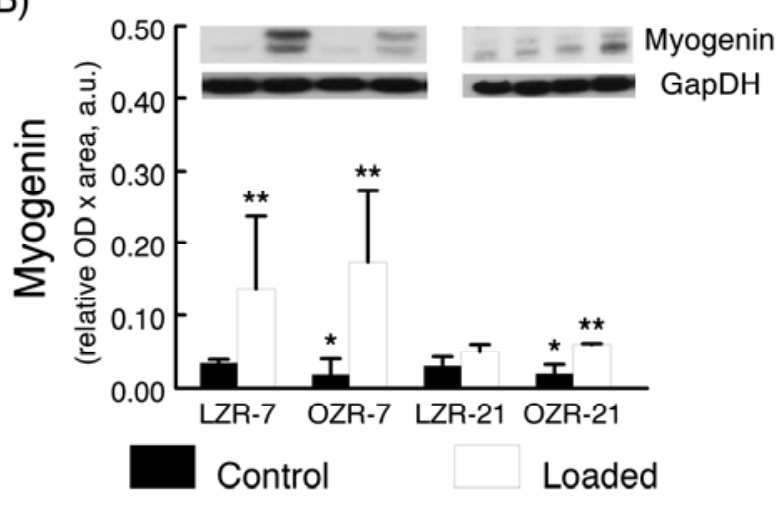


Figure 6

A)

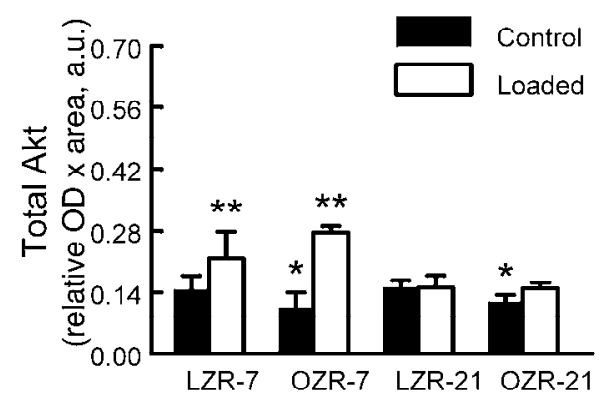

C)

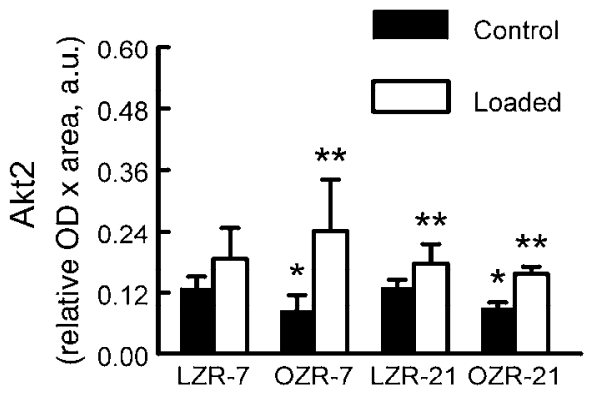

B)

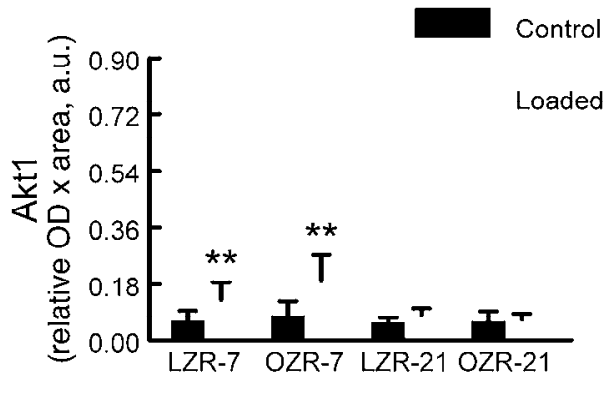

D)

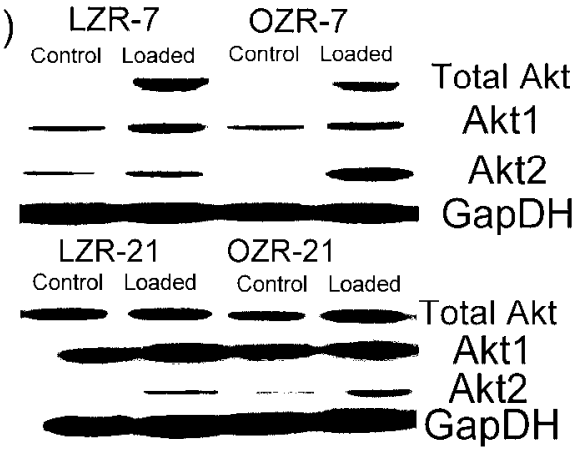




\section{Palmitate increases Bax mediated apoptotic signaling C2C12 myotubes \\ Jonathan M. Peterson, Yan Wang, Randall W. Bryner, David L. Williamson, and Stephen E.}

Alway

\section{Abstract}

Mitochondria induced apoptotic signaling in differentiated skeletal muscle in response to palmitate treatment has been recently reported in L6 myotubes, but it is unknown if Bax signaling contributes to this phenomenon. Additionally, since palmitate treatment decreases growth factor mediated Akt activation, the association of Akt activity and Bax-Bcl-2 binding was also examined. Akt content and phospho-Akt ${ }^{\text {ser473 }}$ were reduced in $\mathrm{C} 2 \mathrm{C} 12$ myotubes after treatment with palmitate. This reduction in phospho-Akt ${ }^{\mathrm{ser} 43}$ activity coincided with increased apoptosis in $\mathrm{C} 2 \mathrm{C} 12$ myotubes as shown by a 2-fold increase in DNA fragmentation, a $\sim 5$-fold increase in caspase-3 activity, a 2.5-fold increase in caspase 9 activity, and a 2-fold increase in cytochrome c release from the mitochondria. Furthermore, there was a small but significant increase in the amount of the pro-apoptotic protein Bax with palmitate treatment. To determine if palmitate treatment decreased the ability for Bcl-2 to bind and inhibit Bax, an immunoprecipitation (IP) assay to $\mathrm{Bcl}-2$ was performed. IP analysis demonstrated that palmitate treatment significantly lowered the binding of Bax to Bcl-2, which in turn allows the pro-apoptotic effects of Bax to proceed. Furthermore, treatment of the $\mathrm{C} 2 \mathrm{C} 12$ myotubes with Bax siRNA was able to attenuate the apoptotic effects of palmitate treatment. Together, these data show that similar to the L6 cell line, palmitate induces mitochondrial-associated apoptosis in $\mathrm{C} 2 \mathrm{C} 12$ myotubes. Our novel finding is that, palmitate treatment corresponded to reductions in Akt signaling and induces apoptosis through attenuated Bax-Bcl-2 binding. 


\section{Introduction}

Obesity increases the risk for heart disease, hypertension and type 2 diabetes mellitus. Increased accumulation of intramuscular lipids without corresponding increases in $\beta$-oxidation can lead to insulin resistance dyslipidemia and lipotoxicity Excess lipid accumulation is thought to lead to increased oxidative stress and dysfunction in cardiac muscle $(15,17)$ although the role in skeletal muscle has not been well studied.

Palmitate is the most abundant systemic saturated fatty acid in the circulation, and therefore it has been used frequently, to examine the effects of saturated fatty acids in dyslipidemia on various tissues $(7,10,22,30,32)$. Treatment of different cell types with palmitate in vitro has resulted in apoptosis $(9,22,25,31)$, and has been found to inhibit Akt/Protein kinase B (Akt) activity in response to insulin $(6,7,27)$. However, shorter carbon chained saturated fatty acids, i.e. laurate, have been demonstrated not to interfere with Akt signaling $(6,7)$, but their impact on apoptosis has not been examined.

Although not previously examined in conjunction with palmitate treatment, one of the primary ways in which Akt inhibits apoptosis is through control of the B-cell leukemia/lymphoma-2 (Bcl-2) family. Akt signaling acts directly and indirectly to promote the binding of the anti-apoptotic protein $\mathrm{Bcl}-2$ to the pro-apoptotic protein $\mathrm{Bcl}-2$ associated $\mathrm{X}$ protein $(\mathrm{Bax})(14,16,33)$. Once Bax is released from Bcl-2, there is a Bax-Bax-oligomerization, that inserts into the mitochondrial membrane, and causes mitochondrial permeabilization (33). Once the mitochondrial membrane is permeablized, there is a release of proapoptotic factors, including apoptosis inducing factor (AIF), Smac/Diablo, and cytochrome $c(5,18)$. When free of the mitochondria AIF translocate to the nucleus and cause DNA fragmentation independently of 
caspases. Similarly, cytochrome $c$ is released from the mitochondria and results in the activation of caspase-9 and subsequently caspase- 3 which leads to DNA fragmentation and cell death (5, 19). Lastly, when released from the mitochondria Smac/Diablo attenuates the apoptotic inhibitory proteins, such as XIAP (13). Once released from the mitochondria, these proteins function to induce DNA fragmentation and apoptosis.

Palmitate treatment has been shown to induce apoptosis in L6 myotubes (25), and Bcl-2 overexpression has been demonstrated to inhibit palmitate induced apoptosis in a non-muscle cell lines (9). However, whether palmitate treatment can attenuate the ability of Bcl-2 to bind Bax has not been examined. Therefore, the purposes of this study were to determine if palmitate treatment, but not the shorter chain fatty acid laurate: (i) induces apoptotic signaling in mouse C2C12 myotubes; (ii) results in the release of mitochondrial apoptotic factors cytochrome c, AIF, and smac/Diablo; (iii) attenuates Bax-Bcl-2 binding; (iv) induces apoptosis that is dependent on Bax signaling.

\section{Materials and Methods}

Cell culture. C2C12 myoblasts were purchased from American Type Culture Collection (ATCC, Manassas, VA). The cells were cultured in $100 \mathrm{~mm}$ polystyrene culture dishes in Dulbecco Modified Eagle's Medium (Invitrogen, USA) supplemented with 10\% FBS and 1\% antibiotic antimycotic mixture and passaged in $0.25 \%$ trypsin. The cells were maintained in a humidified incubator under an atmosphere of $5 \% \mathrm{CO} 2$ at $37^{\circ} \mathrm{C}$. For differentiation into myotubes, the myoblasts were grown to confluency and transferred to DMEM containing ITS 
liquid media (Sigma-Aldrich, St. Louis, MO). Myotubes were used for experiments following 4 days of differentiation. All experiments were performed in triplicate.

Palmitate (Sigma Chemicals; St. Louis, MO) was administered to cells as described by Chavez and Summers $(6,7)$ with dodecanoic acid (laurate) used as a short chain free fatty acid (FFA) to differentiate the effects of FFAs alone and FFAs which interfere with Akt signaling. . An additional control group received only the media. Briefly, palmitate was dissolved in ethanol and diluted in DMEM containing 2\% BSA. C2C12 myotubes were incubated with the FFAs ( $0.75 \mathrm{mM}$ final concentration) in $1 \%$ FBS-DMEM for $16 \mathrm{~h}$, washed with DHANKS, and then incubated with the FFA in serum free DMEM for 2 hours. 1\% FBS was reintroduced to the media 10 minutes prior to collection, except where indicated.

siRNA transfection. The myotubes were transfected with scrambled, nonspecific siRNA without mammalian homology, or Bax siRNA (Santa Cruz Biotechnology, Santa Cruz, CA) using Lipofectamine 2000 (Invitrogen Carlsbad, CA). Individual siRNAs (80 pmols/transfection) were transfected using Lipofectamine in serum-free DMEM for 6 hours. A $2 \mathrm{x}$ concentration $(2 \% \mathrm{FBS}, 4 \% \mathrm{BSA}$, and $1.25 \mathrm{mM}$ of palmitate) of media was then added to each well and the samples were incubated for an additional 12 hours.

Cytochrome c Assay. The extent of cytochrome $\mathrm{c}$ that was released from the mitochondria was determined in a mitochondrial-free cytoplasmic protein fraction as previously described (28). C2C12 myotubes were collected after treatment in ice-cold extraction buffer in the presence of a protease inhibitor cocktail (PIC; Sigma-Aldrich). Briefly, cells were lysed in icecold Mito-buffer (20 mM HEPES pH 7.5, $10 \mathrm{mM} \mathrm{KCl,} 1.5 \mathrm{mM} \mathrm{MgCl} 2,1 \mathrm{mM}$ EGTA, $1 \mathrm{mM}$ EDTA, $1 \mathrm{mM}$ dithiothreitol, $250 \mathrm{mM}$ sucrose, and $0.1 \mathrm{mM}$ phenylmethylsulfonyl fluoride) by homogenization in a small glass homogenizer with Teflon pestle. The homogenates were 
centrifuged at $800 \mathrm{~g}$ to remove nuclei and cell debris and then centrifuged at 16,000 $\mathrm{g}$ for $20 \mathrm{~min}$ at $4^{\circ} \mathrm{C}$ to pellet the mitochondria. The supernate contained the mitochondrial-free cytosolic protein fraction and this used for determining the release of cytochrome $\mathrm{c}$ and Smac/Diablo from the mitochondria. Purity of the fractions were determine through immunoblot analysis of antiMnSOD (a mitochondrial isoform of superoxide dismutase)and anti-CuZnSOD (a cytosolic isoform of superoxide dismutase) as previously performed in our laboratory (28), data not shown.

A cytochrome $c$ ELISA kit (\#5265, Medical and Biological Laboratories; Japan) was used to assess the protein content of cytochrome $c$ in the mitochondria-free cytosol fraction to evaluate the release of the mitochondrial cytochrome $c$ into the cytosol. The change in color was monitored at a wavelength of $450 \mathrm{~nm}$ using a Dynex MRX plate reader. Measurements were performed in duplicate with all comparisons performed with the same assay. The cytochrome $c$ content was analyzed as $\mathrm{OD}_{450}$ per milligram of protein, and then normalized to protein concentration.

Akt/PKB Activity Assay. Akt/PKB activity was determined by an Akt/PKB Kinase Activity Kit (EKS-400A; Stressgen, Victoria BC). Because the basal level of Akt/PKB activity was below the sensitivity of the assay, myotubes were first treated with $100 \mathrm{nM}$ of insulin for 10 minutes before harvesting the cells. The change in color optical density (OD) was measured at a wavelength of $405 \mathrm{~nm}$ by using a Dynex MRX plate reader controlled through PC software (Revelation; Dynatech Laboratories, CA, USA). Measurements were performed in duplicate. The $\mathrm{OD}_{405}$ reading was then normalized to the milligrams of protein used in the assay.

Nuclear and cytoplasmic protein extracts. The nuclear and cytoplasmic protein extracts were obtained using the method described by Rothermel et al. (26) and performed routinely in our lab 
(28). Briefly, the cells were washed 3 times in ice-cold phosphate buffered saline (PBS) then incubated in lysis buffer (10 mM NaCl, $1.5 \mathrm{mM} \mathrm{MgCl} 2,20 \mathrm{mM}$ HEPES, pH 7.4, 20\% glycerol, $0.1 \%$ Triton $\mathrm{X}-100$, and $1 \mathrm{mM}$ dithiothreitol) for 5 minutes at $4^{\circ} \mathrm{C}$. The cells were gently homogenized in a small glass homogenizer with Teflon pestle. The homogenates were centrifuged at $1,000 \mathrm{rpm}$ for $1 \mathrm{~min}$ at $4^{\circ} \mathrm{C}$. The supernatants contained the cytoplasmic protein fraction and were collected. The remaining nuclear pellet was washed twice in lysis buffer and then resuspended in lysis buffer containing $0.6 \mathrm{M} \mathrm{NaCl}$. The mixture was incubated for $1 \mathrm{~h}$ at $4^{\circ} \mathrm{C}$ and centrifuged at $14,000 \mathrm{rpm}$ for $15 \mathrm{~min}$ at $4^{\circ} \mathrm{C}$. The supernatants contained the nuclear protein fraction. The total protein contents of the cytoplasmic extracts were quantified in duplicate by using bicinchoninic acid reagents (Pierce, Rockford, IL) and bovine serum albumin (BSA) standards.

A portion of the cytosolic extract (without addition of protease inhibitors) was stored and used for fluorometric caspase activity assays, while protease inhibitor cocktail (PIC, SigmaAldrich, St Louis, MO) was added to the nuclear and remaining cytosolic portion for further analysis.

Signaling protein levels were determined by immunoblotting. Myotubes were washed 3 times in ice-cold PBS then 1x SDS sample buffer (50 mM Tris-HCl, pH 6.8, 2\% SDS, 6\% glycerol, $1 \% \beta$-mercaptolethanol, $0.02 \%$ bromophenol blue) was added directly to the myotubes. 2x SDS lysis buffer was added to an equal volume of mitochondrial free cytosolic protein extract or nuclear protein extract, respectively. Samples were lysed with a 25 gauge needle and boiled for $5 \mathrm{~min}$ at $100^{\circ} \mathrm{C}$. Samples were separated on a $4-12 \%$ gradient polyacrylamide gel (Invitrogen, USA). Gels were blotted to nitrocellulose membranes (Bio-Rad, Hercules, CA) and stained with Ponceau red (Sigma Chemical Co, St Louis, MO, USA) to confirm equal loading. 
Membranes were blocked in 5\% non-fat milk in Tris buffered saline with $0.05 \%$ Tween 20 (TBS-T) and then probed with primary antibodies, against Akt, and Akt Ser ${ }^{473}$ phosphorylation (Cell Signaling Tech.), Bad, Bax, or Bcl-2 (Santa Cruz Biotechnology, Santa Cruz, CA), Smac/Diablo, AIF (BD biosciences) and $\beta$-tubulin (Abcam, Cambridge, MA) was also used a loading control. Secondary antibodies were conjugated to horseradish peroxidase (Chemicon, CA, USA) and signals were developed by chemiluminescence (ECL advance, Amersham Biosciences) and visualized by exposing the membranes to X-ray films (BioMax MS1, Eastman Kodak, Rochester, NY, USA). Digital records of the films were captured with a Kodak 290 camera. The resulting bands were quantified as optical density (OD) x band area by a one-dimensional (1-D) image analysis system (Eastman Kodak, Rochester, NY, USA) and expressed normalized to $ß$-Tubulin. The sizes of the proteins were verified by using standard molecular-weight markers (Bio-Rad, Hercules, CA, USA).

Fluorometric caspase activity assay. Activity of the caspase-9, 3, and 8 were analyzed by a commercial caspase assay kit (APO-54A-019-KI01, Apotech, Switzerland) according to the manufacturer's procedure and as previously performed in our laboratory (28). Caspase-3 and caspase- 9 were measured as indices of mitochondrial induced apoptosis, whereas caspase 8 is a non-mitochondrial dependent caspase.

Briefly, the cytosolic extract without protease inhibitor was incubated in an equal volume of assay buffer (50 mM PIPES, $0.1 \mathrm{mM}$ EDTA, 10\% glycerol, $10 \mathrm{mM}$ DTT, pH 7.2) with $100 \mu \mathrm{M}$ of the fluorogenic 7-amino-4-trifluoromethyl coumarin (AFC)-conjugated substrate (Ac-DEVDAFC, Alexis Corp., San Diego, CA, USA) at $37^{\circ} \mathrm{C}$ for $2 \mathrm{~h}$. The change in fluorescence was measured on a spectrofluorometer with an excitation wavelength of $390 / 20 \mathrm{~nm}$, and an emission wavelength of 530/25 nm (CytoFluor; Applied Biosystems, Foster City, CA, USA) before and 
after the $2 \mathrm{~h}$ incubation. Caspase activity was estimated as the change in mean fluorescence intensity (MFI) expressed as arbitrary units normalized to protein concentration. Measurements were performed in triplicate.

DNA fragmentation. A cell death detection ELISA kit (Roche Applied Science, Indianapolis, IN, USA) was used to quantitatively determine the apoptotic DNA fragmentation by measuring the cytosolic histone-associated mono- and oligonucleosomes. The change in optical density (OD) was measured at a wavelength of $450 \mathrm{~nm}$ by using a Dynex MRX plate reader controlled through PC software (Revelation; Dynatech Laboratories, CA, USA). Measurements were performed in duplicate, with samples from OZR and LZR analyzed at the same time. The $\mathrm{OD}_{450}$ reading was then normalized control samples. Measurements were performed in triplicate.

Bax and Bcl-2 binding. To determine if Bax to Bcl-2 binding corresponded to Akt $\mathrm{Ser}^{473}$ phosphorylation, myotubes were serum starved for two hours with or without the addition of a commercially available Akt inhibitor (124005, Calbiochem, Germany). 1\% FBS was reintroduced to the media 10 minutes before collection of the myotubes. Similarly, to determine if the binding of $\mathrm{Bax}$ to $\mathrm{Bcl}-2$ was altered with palmitate treatment, $\mathrm{Bcl}-2$ was immunoprecipitated and the binding of Bax was determined through immunoblot analysis.

After treatment, myotubes were harvested in CHAPS buffer (40 mM HEPES, pH 7.5, 120 $\mathrm{mM} \mathrm{NaCl}, 1 \mathrm{mM}$ EDTA, $10 \mathrm{mM}$ pyrophosphate, $10 \mathrm{mM}$-glycerolphosphate, $40 \mathrm{mM} \mathrm{NaF}, 1.5$ $\mathrm{mM}$ sodium vanadate, $0.3 \%$ CHAPS, $0.1 \mathrm{mM}$ PMSF, $1 \mathrm{mM}$ benzamidine, and $1 \mathrm{mM} \mathrm{DTT}$ ), rocked for $20 \mathrm{~min}$ at $4^{\circ} \mathrm{C}$ and then centrifuged at $1,000 \mathrm{~g}$ for $10 \mathrm{~min}$ at $4^{\circ} \mathrm{C}$. An aliquot from the resulting supernatant was preserved as total protein. The remaining supernatant was incubated with anti-Bcl-2 $\left(0.2 \mu \mathrm{g} / 100 \mu \mathrm{l}\right.$; Santa Cruz), and incubated overnight at $4^{\circ} \mathrm{C}$. Prior to analysis, the immune complexes were collected for $1 \mathrm{~h}$ at $4^{\circ} \mathrm{C}$ with a goat anti-mouse BioMag IgG (Quigen, 
310004) beads, blocked with $0.1 \%$ nonfat dry milk in CHAPS buffer. The beads were collected using a magnetic stand and washed with $200 \mathrm{mM}$ CHAPS and $60 \mathrm{mM}$ HEPES. The precipitates were eluted in 5x SDS sample buffer (250 mM Tris-HCl pH 6.8, 10\% SDS, 30\% Glycerol, 5\% $\beta$-mercaptoethanol and $0.02 \%$ bromophenol blue) and then boiled for $5 \mathrm{~min}$. The beads were collected with a magnetic stand, and the supernatant was collected and subjected to SDS-PAGE. Statistical analyses. Statistical analyses were performed using the SPSS 10.0 software package. A one way Analysis of variance (ANOVA) was performed on the difference in all measured variables. Statistical significance was accepted at $P<0.05$. All data are given as means $\pm \mathrm{SE}$.

\section{Results}

Palmitate attenuated Akt signaling. To determine the ability of palmitate pre-treatment to inhibit Akt phosphorylation, serum was removed from the media for 2 hours, and then FBS was reintroduced into the media (final concentration was 1\% FBS) for 10 minutes. Representative blots for total Akt, Akt1, Akt2, and Akt $\mathrm{Ser}^{473}$ phosphorylation protein expression levels are shown in Figure 1A with control, laurate, or palmitate treatment. Total Akt was reduced by $30 \pm$ $3 \%$ in palmitate treated myotubes compared to control or laurate treated myotubes. There was also a $41 \pm 7 \%$ decrease in Akt Ser $^{473}$ phosphorylation in palmitate treated myotubes. In a separate experiment, palmitate treatment resulted in a $33 \pm 3 \%$ decrease in overall Akt activity in response to $100 \mathrm{nM}$ insulin (Figure 1B).

Palmitate increased Bax protein concentration. To determine if palmitate treatment affected the Bcl-2 family protein expression levels, these proteins were examined through immunoblot analysis. There was no change in content of the pro-apoptotic protein Bad, nor was there any change in the concentration in the content of the anti-apoptotic protein Bcl-2. However, there 
was a small increase, $\sim 20 \%$, in the protein content of the pro-apoptotic protein Bax (Figure 2). These data may indicate that the actions of palmitate treatment may be dependent on the increase of the Bax protein.

Palmitate induced release of mitochondrial apoptotic proteins. The proteins cytochrome c, AIF, and Smac/Diablo all contribute to apoptotic signaling when they are released from the mitochondria into the cytoplasm. The addition of palmitate to the myotubes increased the cytoplasmic content of cytochrome c 2-fold compared to control treatments (Figure 3A). In addition, palmitate treatment also increased the release of Smac/Diablo and AIF from the mitochondria (Figure 3B).

Palmitate increased Caspase Activity. Palmitate treatment also resulted in a 5-fold increase in caspase-3 activity, a 2.5 fold increase in caspase- 9 activity, with no change in caspase 8 activity (Figure 4). These data indicate palmitate induced mitochondria-dependent caspase signaling because caspase- 9 activation is dependent on release of cytochrome c from the mitochondria, whereas caspase 8 is activated independently of mitochondria outer membrane permeabilization.

Palmitate induced DNA fragmentation. Because caspase-3 is the effector caspase which, when activated cleave DNA, we measured DNA fragmentation in $\mathrm{C} 2 \mathrm{C} 12$ myotubes. Palmitate and laurate treatment induced a 7-fold and 3-fold increase in DNA fragmentation, respectively, compared to control treatment (Figure 5). Palmitate treatment generated a 2.5 -fold increase in DNA fragmentation compared to the shorter chained saturated FFA laurate (Figure 5).

Palmitate induced Bax signaling. Since Akt signaling is significantly reduced with palmitate treatment, but not laurate, and Akt signaling can contribute to the control of Bax to Bcl-2 binding, an immunoprecipitation to Bcl-2 was performed in the presence or absence of $1 \%$ FBS 
and the binding of Bax to Bcl-2 was determined. In control samples, the addition of FBS increased the amount of Akt $\operatorname{Ser}^{473}$ phosphorylation $~ 50$ fold and corresponded to an increase binding of Bax to Bcl-2 of 10-fold compared to serum starved samples (Figure 6A). However, treatment of samples with palmitate, but not laurate, greatly attenuated the Bax to Bcl-2 binding in response to FBS (Figure 6B).

Bax siRNA attenuated palmitate mediated apoptosis. As expected, treatment with Bax siRNA reduced Bax protein content in both control and palmitate treated myotubes (Figure 7A). The reduction in Bax protein expression with siRNA attenuated the increase in DNA fragmentation and caspase activity that otherwise occurred after palmitate treatment (Figure 7B-D). In addition, we noted that the siRNA transfection protocol induced a 2-fold increase in DNA fragmentation compared to untreated controls (data not shown).

\section{Discussion}

The novel findings of this study are: (i) both palmitate and laurate treatment increased DNA fragmentation indicating that saturated FFA can induce apoptosis (ii) palmitate, but not laurate, treatment increased mitochondria mediated apoptosis in $\mathrm{C} 2 \mathrm{C} 12$ myotubes as indicated by increased the release of cytochrome $c$, Smac/Diablo, and AIF from the mitochondria indicating both caspase dependent and caspase independent apoptotic mechanisms with palmitate treatment; (iii) palmitate, but not laurate, treatment inhibited Akt activity and attenuated the ability of FBS to increase Bax-Bcl-2 binding in $\mathrm{C} 2 \mathrm{C} 12$ myotubes; and (iv) knock down of Bax

protein significantly attenuated the ability of palmitate treatment to induced apoptosis in $\mathrm{C} 2 \mathrm{C} 12$ myotubes. Pre-treatment of $\mathrm{C} 2 \mathrm{C} 12$ myotubes with palmitate has been used to mimic aberrant 
lipid signaling. which is one particular aspect common with metabolic syndrome and type 2 diabetes $(6,7,9,25,27)$. Palmitate, and other long chain saturated FFAs, result in increased formation of ceramide, which inhibits Akt activity, whereas laurate and other saturated short chain FFAs do not result in ceramide accumulation or Akt inhibition $(6,7,21)$. This is noteworthy because ceramide levels are elevated in insulin-resistant humans subjects (1). Because Akt signaling is both disrupted with metabolic syndrome $(6,7)$ and has a major role in inhibiting apoptosis $(11,12,16)$, we hypothesized that palmitate would decrease Akt phosphorylation and activate mitochondrial-associated apoptotic signaling in mouse $\mathrm{C} 2 \mathrm{C} 12$ myotubes. Specifically, we hypothesized that palmitate would increase mitochondrial-associated apoptosis through attenuation of $\mathrm{Bax}$ to $\mathrm{Bcl}-2$ binding.

It has been well documented that skeletal muscle apoptosis is an integral part of skeletal muscle loss with aging $(2,29)$; the role of skeletal muscle apoptosis in metabolic syndrome has not been examined. Palmitate treatment has recently been shown to induce mitochondrial DNA damage and apoptosis in L6 myotubes (25), however this study did not determine whether a shorter carbon chain FFA, such as laurate, would also induced DNA damage or apoptosis. In our hands, both laurate and palmitate resulted in increased DNA damage. Nevertheless, palmitate resulted in augmented apoptotic signaling compared to laurate treatment, signifying that palmitate treatment induces additional apoptotic signaling compared to shorter FFAs. It is likely that the decrease in Akt signaling after palmitate treatment contributes to the increase in apoptosis when compared to laurate treatment. However, it is also possible that palmitate, or its metabolites, allosterically interfere with Bax and Bcl-2 binding. These possibilities are both supported by our data, but either situation supports our hypotheses that palmitate induces mitochondrial apoptosis and that it is dependent on Bax signaling. 
Mitochondrial associated apoptosis in C2C12 cells. When the mitochondrial outer membrane is permeabilized, it releases proapoptotic factors, such as AIF, Smac/Diablo, and cytochrome $c$, each of which can independently increase apoptosis $(5,18)$. When released from the mitochondria, AIF translocates to the nucleus where it can cleave the DNA directly. Smac/Diablo, binds and prevents the actions of a number of apoptosis inhibitory proteins. In contrast, cytochrome c forms a complex with Apaf-1 and pro-caspase-9 to form the apoptosome. The apoptosome cleaves pro-caspase-9 into its active form. Caspase- 9 then activates caspase-3, an apoptotic effector that leads to DNA fragmentation and cell death $(5,19)$. The results of the present study confirm that palmitate treatment increased nuclear apoptosis in $\mathrm{C} 2 \mathrm{C} 12$ cells. This was confirmed through increases in nuclear levels of AIF, increased cytoplasmic levels of cytochrome $c$ and Smac/Diablo, and elevated caspase-9 and -3 activity levels, and lastly, increased DNA fragmentation (Figures 3-5). The reason for increased DNA fragmentation with laurate treatment compared to controls is unknown, but may be due to increased lipid oxidation $(20,31)$. Nevertheless, the increase in DNA fragmentation with laurate treatment is independent from any apoptotic signaling mechanisms examined in this study.

Bax: Bcl interactions in palmitate treatment. The primary novel finding of this study was that palmitate treatment, attenuated the ability of growth-factor-rich serum (FBS) to increase BaxBcl-2 binding (Figure 6B). When growth factors were removed from the culture medium, Bax was dissociated from Bcl-2 but this was quickly reversed ( $\sim 10$ min post treatment) when growthfactor-rich serum was reintroduced to the culture medium (Figure 6A). The pattern of Bax and Bcl-2 during palmitate treatment coincides with the amount of Akt phosphorylation. In addition the Bax-Bcl-2 binding was prevented when an Akt inhibitor was added to the media. This supports the hypothesis that Akt directly acts on Bax to increase its binding to Bcl-2 (8). Once 
Bax is released from Bcl-2 there is a Bax-Bax-oligomerization. This Bax-Bax protein complex then inserts into the outer mitochondrial membrane, causing mitochondrial permeabilization and release of proapoptotic factors: AIF, Smac/Diablo, and cytochrome $c$ (33). The release of these proteins from the mitochondria results in DNA fragmentation and loss of the nucleus $(5,19)$. Although the loss of only a few nuclei will not result in elimination of the entire myotube, the loss of sufficient numbers of nuclei in a single myotube would result in cell death.

Metabolic syndrome is the most prevalent metabolic health risk in the world, affecting more than 47 million Americans (23). Skeletal muscle is an important target tissue in the study of metabolic syndrome as it accounts for more than half of total body insulin resistance, and is also a key tissue for lipids uptake and oxidation $(3,4,24)$. Therefore, the loss of skeletal muscle can further exacerbate the risks associated with metabolic syndrome. In this study $\mathrm{C} 2 \mathrm{C} 12$ myotubes were used as an in vitro model of skeletal muscle and palmitate was used to mimic one aspect common in metabolic syndrome, dyslipidemia. This study demonstrated that long chain saturated fatty acids, i.e. palmitate, can reduce Akt signaling and increase Bax-mediated mitochondrial induced apoptosis. These findings indicate that people with metabolic syndrome may have increase apoptotic signaling and underscores the need for in vivo studies examining the effects of Akt signaling, skeletal muscle apoptosis, and metabolic syndrome. 


\section{Acknowledgements.}

This study supported by NIH: National Institute on Aging Grant R01 AG021530. 
Reference List

1. Adams JM, Pratipanawatr T, Berria R, Wang E, DeFronzo RA, Sullards MC and Mandarino LJ. Ceramide content is increased in skeletal muscle from obese insulinresistant humans. Diabetes 53: 25-31, 2004.

2. Alway SE, Degens H, Krishnamurthy G and Smith CA. Potential role for Id myogenic repressors in apoptosis and attenuation of hypertrophy in muscles of aged rats. Am J Physiol Cell Physiol 283: C66-C76, 2002.

3. Basu A, Basu R, Shah P, Vella A, Johnson CM, Nair KS, Jensen MD, Schwenk WF and Rizza RA. Effects of type 2 diabetes on the ability of insulin and glucose to regulate splanchnic and muscle glucose metabolism: evidence for a defect in hepatic glucokinase activity. Diabetes 49: 272-283, 2000.

4. Bjornholm M and Zierath JR. Insulin signal transduction in human skeletal muscle: identifying the defects in Type II diabetes. Biochem Soc Trans 33: 354-357, 2005.

5. Cai L, Li W, Wang G, Guo L, Jiang Y and Kang YJ. Hyperglycemia-induced apoptosis in mouse myocardium: mitochondrial cytochrome C-mediated caspase-3 activation pathway. Diabetes 51: 1938-1948, 2002.

6. Chavez JA, Knotts TA, Wang LP, Li G, Dobrowsky RT, Florant GL and Summers SA. A role for ceramide, but not diacylglycerol, in the antagonism of insulin signal transduction by saturated fatty acids. J Biol Chem 278: 10297-10303, 2003.

7. Chavez JA and Summers SA. Characterizing the effects of saturated fatty acids on insulin signaling and ceramide and diacylglycerol accumulation in 3T3-L1 adipocytes and C2C12 myotubes. Arch Biochem Biophys 419: 101-109, 2003.

8. Datta SR, Dudek H, Tao X, Masters S, Fu H, Gotoh Y and Greenberg ME. Akt phosphorylation of BAD couples survival signals to the cell-intrinsic death machinery. Cell 91: 231-241, 1997.

9. de Pablo MA, Susin SA, Jacotot E, Larochette N, Costantini P, Ravagnan L, Zamzami $\mathbf{N}$ and Kroemer $\mathbf{G}$. Palmitate induces apoptosis via a direct effect on mitochondria. Apoptosis 4: 81-87, 1999.

10. de Vries JE, Vork MM, Roemen TH, de Jong YF, Cleutjens JP, van der Vusse GJ and van Bilsen $\mathbf{M}$. Saturated but not mono-unsaturated fatty acids induce apoptotic cell death in neonatal rat ventricular myocytes. J Lipid Res 38: 1384-1394, 1997.

11. del Peso L, Gonzalez-Garcia M, Page C, Herrera R and Nunez G. Interleukin-3induced phosphorylation of BAD through the protein kinase Akt. Science 278: 687-689, 1997. 
12. Downward J. PI 3-kinase, Akt and cell survival. Semin Cell Dev Biol 15: 177-182, 2004.

13. Du C, Fang M, Li Y, Li L and Wang X. Smac, a mitochondrial protein that promotes cytochrome c-dependent caspase activation by eliminating IAP inhibition. Cell 102: 3342, 2000.

14. Er E, Oliver L, Cartron PF, Juin P, Manon S and Vallette FM. Mitochondria as the target of the pro-apoptotic protein Bax. Biochim Biophys Acta 1757: 1301-1311, 2006.

15. Gambert S, Vergely C, Filomenko R, Moreau D, Bettaieb A, Opie LH and Rochette L. Adverse effects of free fatty acid associated with increased oxidative stress in postischemic isolated rat hearts. Mol Cell Biochem 283: 147-152, 2006.

16. Gardai SJ, Hildeman DA, Frankel SK, Whitlock BB, Frasch SC, Borregaard N, Marrack P, Bratton DL and Henson PM. Phosphorylation of Bax Ser184 by Akt regulates its activity and apoptosis in neutrophils. J Biol Chem 279: 21085-21095, 2004.

17. Ghosh S and Rodrigues B. Cardiac cell death in early diabetes and its modulation by dietary fatty acids. Biochim Biophys Acta 1761: 1148-1162, 2006.

18. Kim R, Emi M and Tanabe K. Role of mitochondria as the gardens of cell death. Cancer Chemother Pharmacol 1-9, 2005.

19. Li P, Nijhawan D, Budihardjo I, Srinivasula SM, Ahmad M, Alnemri ES and Wang X. Cytochrome c and dATP-dependent formation of Apaf-1/caspase-9 complex initiates an apoptotic protease cascade. Cell 91: 479-489, 1997.

20. Listenberger LL, Ory DS and Schaffer JE. Palmitate-induced apoptosis can occur through a ceramide-independent pathway. J Biol Chem 276: 14890-14895, 2001.

21. Merrill AH, Jr. and Jones DD. An update of the enzymology and regulation of sphingomyelin metabolism. Biochim Biophys Acta 1044: 1-12, 1990.

22. Mishra R and Simonson MS. Saturated free fatty acids and apoptosis in microvascular mesangial cells: palmitate activates pro-apoptotic signaling involving caspase 9 and mitochondrial release of endonuclease G. Cardiovasc Diabetol 4: 2, 2005.

23. National Institute of Diabetes and Digestive and Kidney Diseases. National Diabetes Statistics fact sheet: general information and national estimates on diabetes in the United States, 2005. National Institute of Health, 20052005.

24. Olsen DB, Sacchetti M, Dela F, Ploug T and Saltin B. Glucose clearance is higher in arm than leg muscle in type 2 diabetes. J Physiol 565: 555-562, 2005.

25. Rachek LI, Musiyenko SI, LeDoux SP and Wilson GL. Palmitate induced mitochondrial deoxyribonucleic acid damage and apoptosis in 16 rat skeletal muscle cells. Endocrinology 148: 293-299, 2007. 
26. Rothermel B, Vega RB, Yang J, Wu H, Bassel-Duby $\mathbf{R}$ and Williams RS. A protein encoded within the Down syndrome critical region is enriched in striated muscles and inhibits calcineurin signaling. J Biol Chem 275: 8719-8725, 2000.

27. Schmitz-Peiffer C, Craig DL and Biden TJ. Ceramide generation is sufficient to account for the inhibition of the insulin-stimulated PKB pathway in C2C12 skeletal muscle cells pretreated with palmitate. J Biol Chem 274: 24202-24210, 1999.

28. Siu PM and Alway SE. Mitochondria-associated apoptotic signalling in denervated rat skeletal muscle. J Physiol 565: 309-323, 2005.

29. Siu PM, Pistilli EE, Butler DC and Alway SE. Aging influences cellular and molecular responses of apoptosis to skeletal muscle unloading. Am J Physiol Cell Physiol 288: C338-C349, 2005.

30. Staiger K, Staiger H, Weigert C, Haas C, Haring HU and Kellerer M. Saturated, but not unsaturated, fatty acids induce apoptosis of human coronary artery endothelial cells via nuclear factor-kappaB activation. Diabetes 55: 3121-3126, 2006.

31. Turpin SM, Lancaster GI, Darby I, Febbraio MA and Watt MJ. Apoptosis in skeletal muscle myotubes is induced by ceramides and is positively related to insulin resistance. Am J Physiol Endocrinol Metab 291: E1341-E1350, 2006.

32. Welters HJ, Tadayyon M, Scarpello JH, Smith SA and Morgan NG. Monounsaturated fatty acids protect against beta-cell apoptosis induced by saturated fatty acids, serum withdrawal or cytokine exposure. FEBS Lett 560: 103-108, 2004.

33. Zha H, Aime-Sempe C, Sato T and Reed JC. Proapoptotic protein Bax heterodimerizes with Bcl-2 and homodimerizes with Bax via a novel domain (BH3) distinct from BH1 and BH2. J Biol Chem 271: 7440-7444, 1996. 


\section{Figures Legends}

Figure 1: A) Akt protein and Akt $\mathrm{Ser}^{473}$ phosphorylation expression in $\mathrm{C} 2 \mathrm{C} 12$ myotubes. Palmitate treatment significantly reduced the protein expression of Akt as well as Akt Ser ${ }^{473}$ phosphorylation. Graph shows mean \pm SE presented as optical density (OD) $\mathrm{x}$ area expressed in arbitrary units. B) Akt activity in $\mathrm{C} 2 \mathrm{C} 12$ myotubes. Samples were treated overnight in $1 \%$ FBS, then incubated for 2 hours in serum free media. 10 minutes before collection $100 \mathrm{nM}$ of insulin was added to the media. Palmitate treatment significantly reduced the activity level of Akt. Data was normalized to total protein content $* \mathrm{p}<0.05$ verse control samples.

Figure 2: Bcl-2, Bax, and Bad protein expression in $\mathrm{C} 2 \mathrm{C} 12$ myotubes. Palmitate had no effect on either Bcl-2 or Bad protein expression. However, palmitate treatment significantly increased the amount of Bax protein expression in $\mathrm{C} 2 \mathrm{C} 12$ myotubes. The data are expressed as optical density (OD) $x$ area (in arbitrary units) and they are displayed as mean \pm SE. $* p<0.05$ vs. control samples.

Figure 3: Apoptotic signaling proteins released from the mitochondria. Palmitate treatment significantly increased the release of Cytochrome c (A), Smac/Diablo, and apoptosis inducing factor (B) from the mitochondria. The data are are displayed as mean $\pm \mathrm{SE}$. ${ }^{*} \mathrm{p}<0.05$, vs. control samples.

Figure 4: Caspase Activity Assay Figure in C2C12 myotubes. Palmitate treatment significantly increased caspase- 3 and 9 activity. The data are expressed as fluorescent intensity (MFI) per $\mu \mathrm{g}$ protein and they are displayed as mean $\pm \mathrm{SE} .{ }^{*} \mathrm{p}<0.05$ vs. control samples.

Figure 5: DNA fragmentation in $\mathrm{C} 2 \mathrm{C} 12$ myotubes. Palmitate treatment significantly increased the content of fragmented DNA as determined by a cell death ELISA assay. The data are expressed as optical density (OD) $\mathrm{x}$ area (in arbitrary units) and they are displayed as mean $\pm \mathrm{SE}$. $*_{p}<0.05$ vs. control samples.

Figure 6: Bcl-2 immunoprecipitation assay of control samples or with the addition of the Akt inhibitor (A) with and without 1\% FBS added following 2 hours of serum starvation. B) After treatment with palmitate for 20 hours there was a significant decrease in the amount of Bax protein that was bound to Bcl-2 with the re-introduction of serum to the media. The data are expressed as optical density (OD) $\mathrm{x}$ area (in arbitrary units) and they are displayed as mean $\pm \mathrm{SE}$. $*_{p}<0.05$ vs. control samples.

Figure 7: Bax protein expression with Bax or scrambled siRNA and control or palmitate treatments (A). Bax siRNA attenuated palmitate induced apoptotic signaling as shown by decreased DNA fragmentation (B), decreased caspase 3 activity (C), and decreased caspase 9 activity (D). The data are expressed as optical density (OD) $\mathrm{x}$ area (in arbitrary units) and they are displayed as mean \pm SE. ${ }^{*} p<0.05$ vs. Scramble siRNA treated control sample. ${ }^{* *} \mathrm{p}<0.05$ vs. scrambled siRNA-palmitate treated sample. 
Figure 1

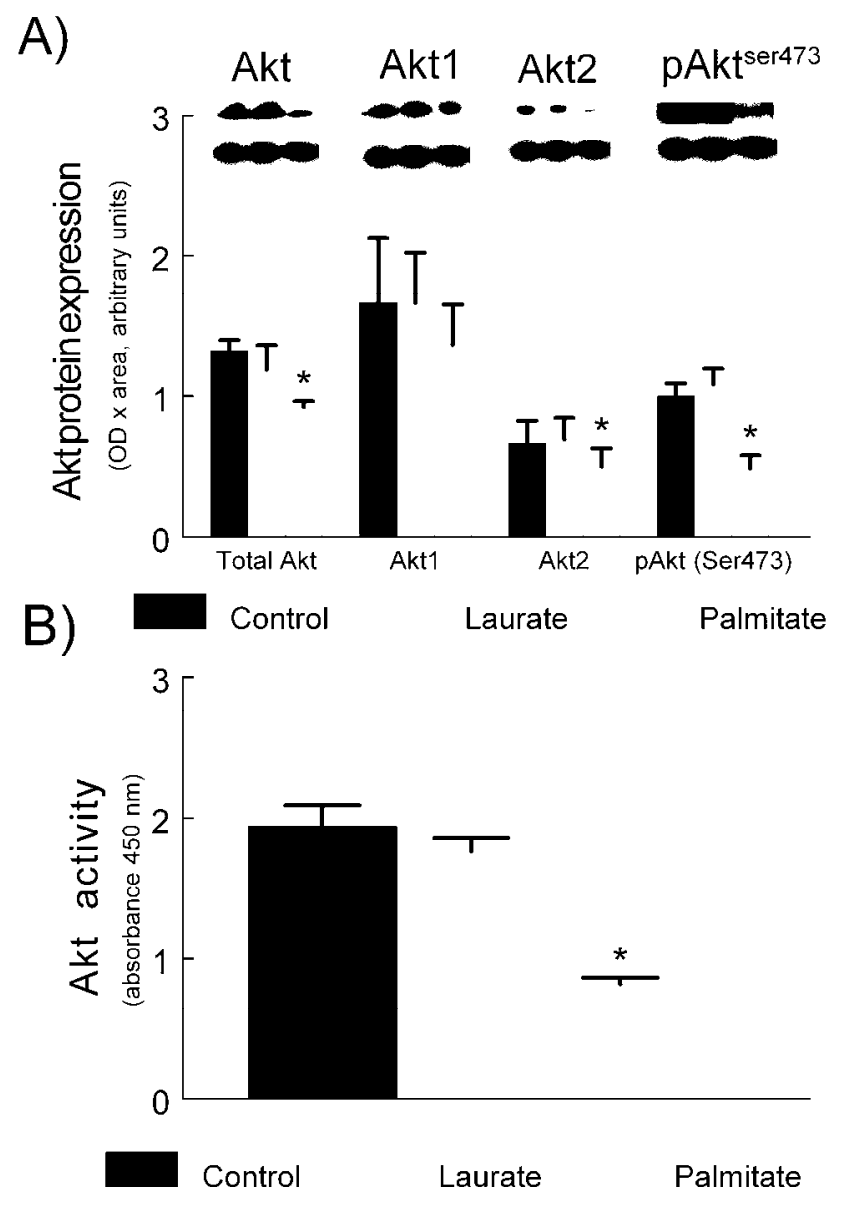


Figure 2

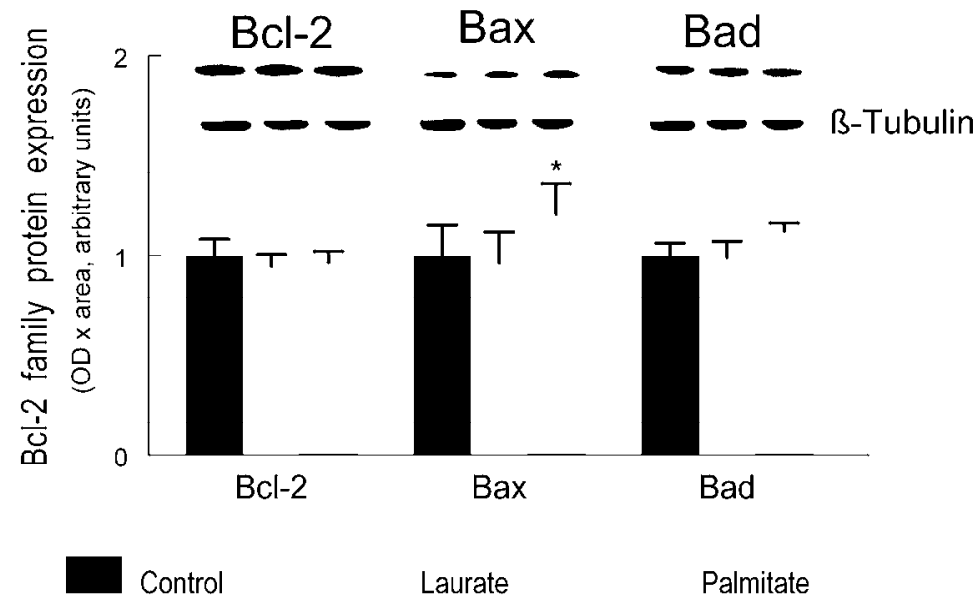


Figure 3

A)

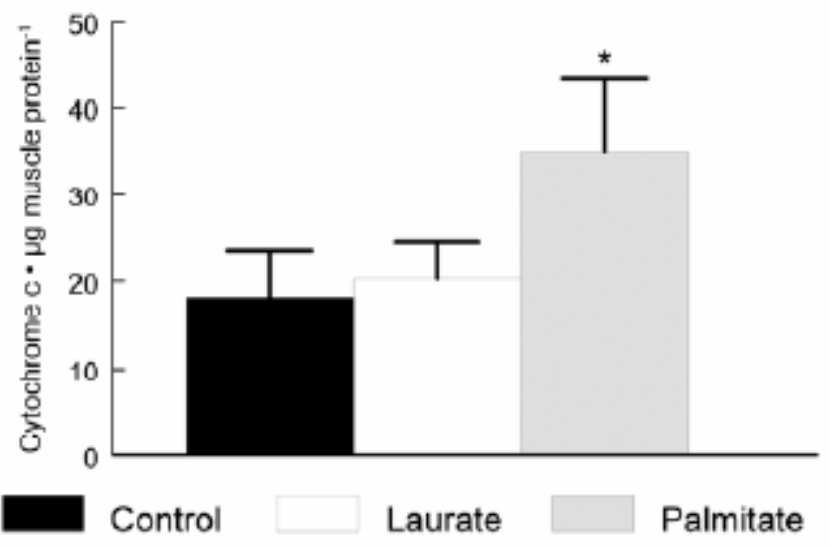

B)

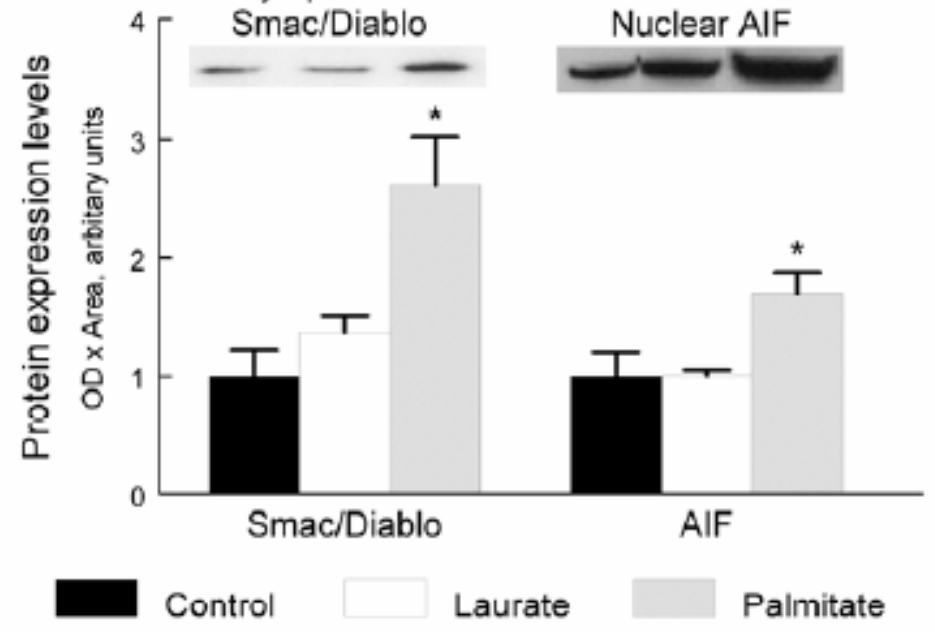


Figure 4

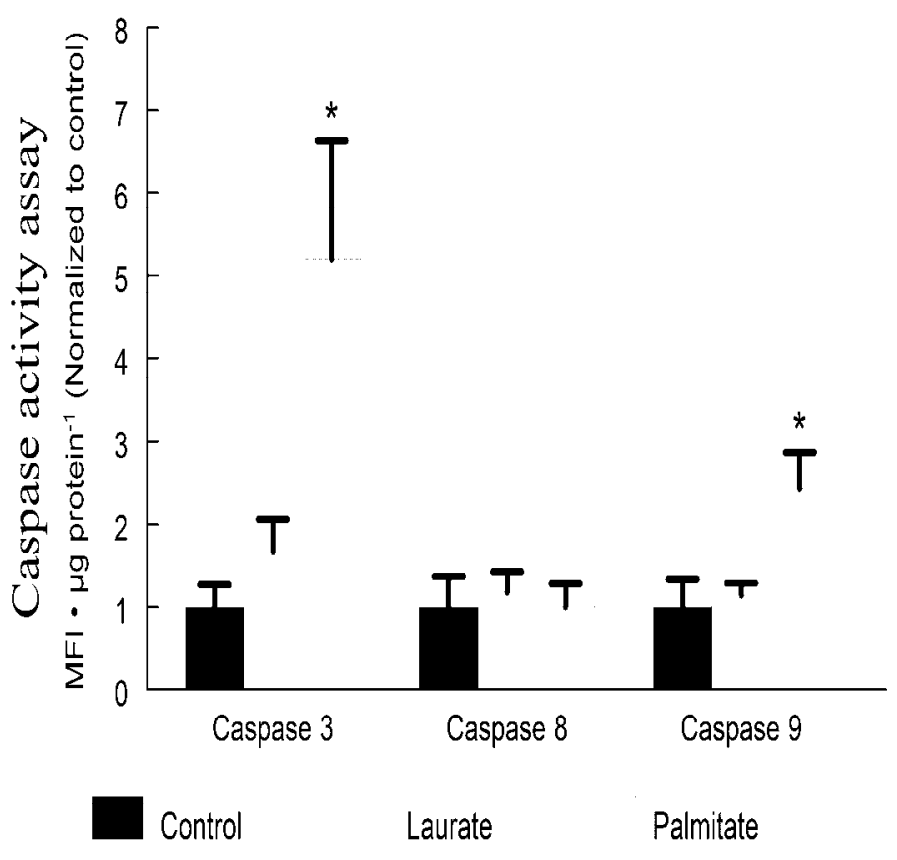


Figure 5

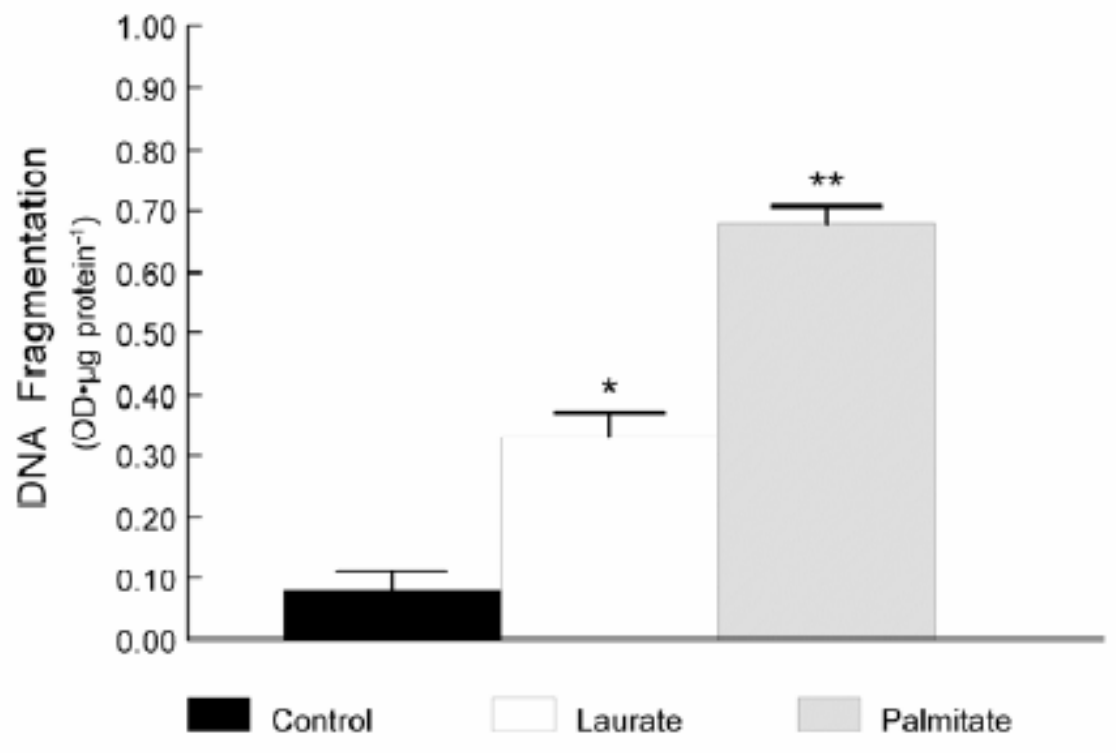


Figure 6

A)

Whole Cell Lysate

Total Akt

pAkt ${ }^{\text {ser473 }}$

$\mathrm{Bcl}-2$

Bax

B-Tubulin

Bcl-2 IP:Bound protein fraction

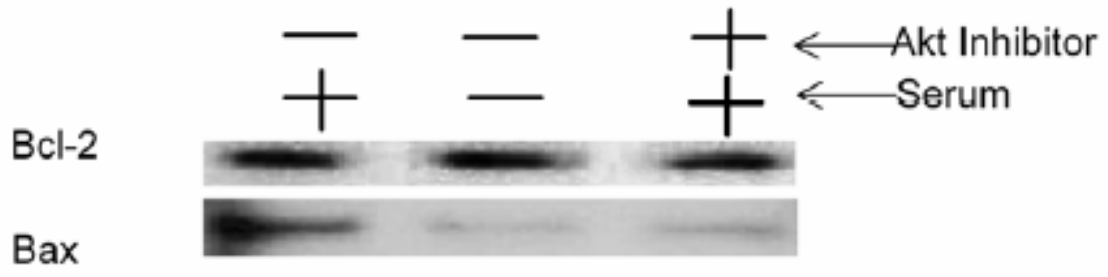

B) $\quad$ Bcl-2 IP: After palmitate treatment

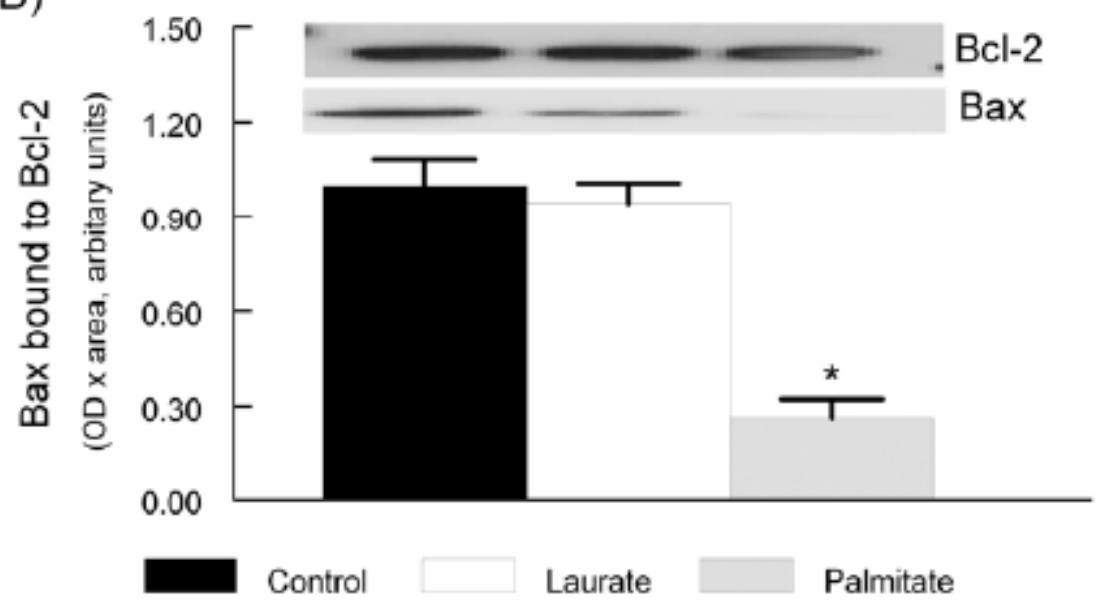


Figure 7

A)

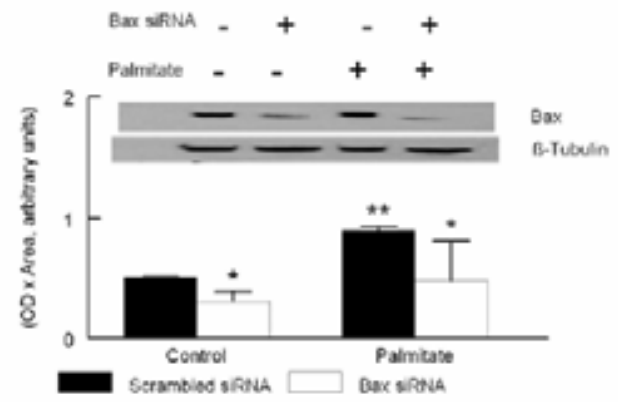

B)
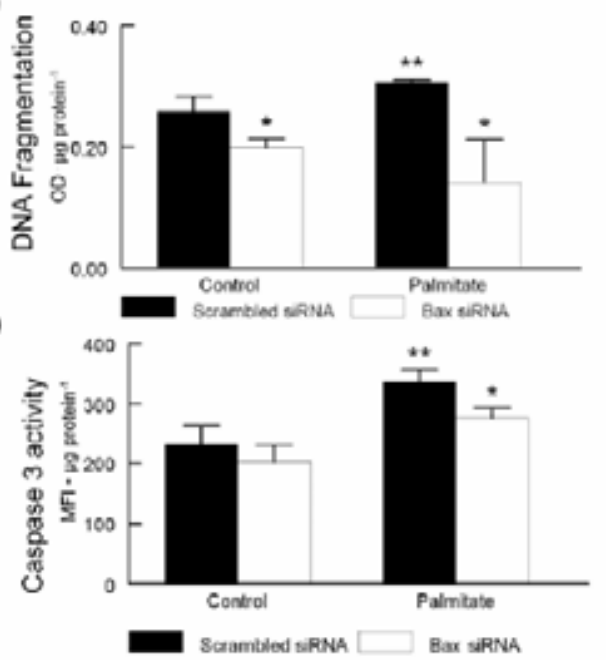

D)

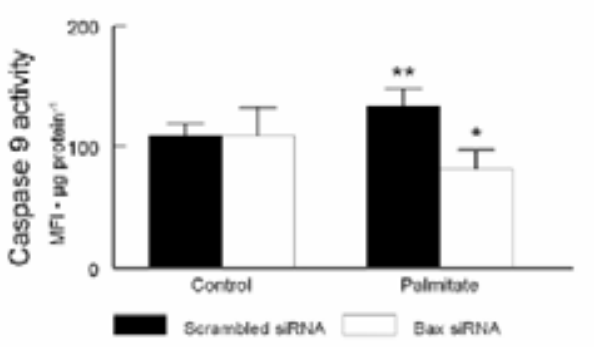




\title{
MITOCHONDRIAL APOPTOTIC SIGNALING IS ELEVATED IN CARDIAC BUT NOT SKELETAL MUSCLE IN THE OBESE ZUCKER RAT AND IS REDUCED WITH AEROBIC EXERCISE
}

Jonathan M. Peterson, Randall W. Bryner, Amy Sindler, Jefferson C. Frisbee and Stephen E.

\author{
Alway
}

\section{Abstract}

Cardiac and skeletal muscles are both negatively affected by factors linked to metabolic syndrome including insulin resistance and obesity. Metabolic syndrome has been associated with increased mitochondrial apoptosis in cardiac tissue; however, the incidence of mitochondrial apoptosis in skeletal muscle with metabolic syndrome has not been examined. In this study we examined the effect of obesity and insulin resistance on key proteins regulating mitochondrial apoptosis in the cardiac and skeletal muscles and their response to aerobic training. For this study the left ventricle, the soleus, and gastrocnemius muscles were examined from 16 obese Zucker rats (OZR) and aged matched lean Zucker rats (LZR). Eight animals of each phenotype were aerobically trained on a treadmill for 9 weeks; the remaining animals were untrained controls. Cardiac Bcl-2 protein expression level was $~ 50 \%$ lower in the OZR compared with the LZR, with no difference in either of the skeletal muscles. Bax protein expression levels were similar in the cardiac and skeletal muscles of the OZR compared to the LZR. However, there was a $\sim 7$-fold increase in the Bax protein accumulation in the myocardial mitochondrial protein fraction of the OZR compared to the LZR. Furthermore, there was an increase in cytochrome $c$ released from the mitochondria, and a corresponding increase in caspase- 9 and caspase- 3 activity in the cardiac muscles of the OZR compared to the LZR. Moreover, DNA fragmentation was elevated $\sim 2$-fold in the cardiac muscles of the OZR, indicating increased apoptosis. There was no change in cytosolic cytochrome $c$, caspase activity, or DNA fragmentation in the skeletal muscles of 
the OZR compared to the LZR. Aerobic exercise training reduced Bax protein expression levels in both LZR and OZR animals and increased Bcl-2 protein expression levels in the OZR in the cardiac muscles. Furthermore, cytosolic cytochrome $c$, caspase activity, and DNA fragmentation were all reduced in the cardiac muscle of the OZR after exercise, with no change in the skeletal muscles. Combined these data show that mitochondrial apoptosis is elevated in the cardiac but not skeletal muscles of the OZR, but aerobic exercise training was effective in reducing cardiac mitochondrial apoptotic signaling.

KEY WORDS: Insulin resistance, Bax, Bcl-2, mitochondrial signaling, muscle wasting 


\section{Introduction}

Apoptosis is a highly organized and tightly coordinated biological process, which plays a vital role in monitoring a variety of non-pathological cellular events (e.g., tissue turnover). Aberrant regulation of apoptosis has been implicated in the pathogenesis of certain severe muscle-related diseases including Duchenne and facioscapulo human muscular dystrophy (21). The molecular events resulting in the activation and subsequent execution of the apoptotic program is principally controlled under the simultaneous influence of both proand anti-apoptotic signaling which are primarily regulated by specific apoptotic regulatory proteins.

The B-cell leukemia/lymphoma-2 (Bcl-2) family of upstream regulators of apoptosis are crucial intracellular checkpoint proteins in the apoptotic signaling pathway $(9,10,18)$. BCL-2 family members, Bcl-2 associated X (Bax) protein and Bcl-2 have been identified as the main proteins involved in the regulation of mitochondrial-associated apoptotic signaling particularly as they relate mitochondrial ion channel forming activities. Bax has been demonstrated to translocate to the mitochondria and expose its N-terminus via a conformational change upon induction of apoptosis $(2,4,8,14,18,29)$. This conformational change permits the Bax-Bax-oligomerization and insertion of Bax into the outer mitochondrial membrane (31), which is followed rapidly by the release of the apoptogenic factors (e.g., cytochrome $c$ ) from the mitochondrial intermembrane space $(6,7,16)$. Collectively, Bax oligomerization is thought to be critical for mitochondrial membrane permeabilization whereas Bcl-2 opposes the pro-apoptotic activity of Bax by preventing BaxBax-oligomerization $(2,18,31)$. Although the precise mechanism of Bax-mediated apoptogenic factor release from the mitochondrial intermembrane space is still under active 
investigation, it is indisputable that Bax plays an important role in promoting the activation of apoptotic signaling cascades.

Mitochondrial-associated apoptotic signaling including an elevation in the Bax/Bcl-2 ratio has been implicated in muscle wasting and aging-associated losses of skeletal muscle $(1,23)$. The obese Zucker $(f a / f a)$ rat $(\mathrm{OZR})$ is used as an animal model for metabolic syndrome because it exhibits severe skeletal muscle insulin resistance, hyperglycemia, and hyperlipidemia $(12,32)$. Recently, myocardial mitochondrial apoptosis has been demonstrated to be elevated in this model of metabolic syndrome $(15,17)$. However, although the skeletal muscles of the OZR are smaller than the lean zucker rats (LZR), mitochondrial apoptotic signaling has not been examined in this model Although, metabolic syndrome has not been linked to skeletal muscle apoptosis it has been linked to skeletal muscle atrophy (3), additionally, metabolic syndrome has been associated with increased apoptosis in cardiac tissue $(5,15,17)$. It is possible that increased $\mathrm{Bax} / \mathrm{Bcl}-2$ ratio, with metabolic syndrome, contributes to increase susceptibility to apoptosis in cardiac as well as atrophy in skeletal muscles.

The first purpose of this study was to confirm an increase in mitochondrial apoptotic signaling in the cardiac muscles of the OZR compared to the LZR and to determine if mitochondrial apoptotic signaling is elevated in the skeletal muscles of the OZR compared to the lean phenotype. Furthermore, our lab has previously demonstrated that aerobic exercise training can reduce apoptotic signaling in both skeletal and cardiac muscles (24). However the effects of exercise on mitochondrial apoptotic signaling, in a model of metabolic syndrome, have not been examined in either cardiac or skeletal muscles. Therefore, the second purpose of this study was to determine if aerobic exercise training would reduce 
mitochondrial apoptotic signaling in the cardiac and/or skeletal muscles of the OZR model of metabolic syndrome.

\section{Materials and Methods}

\section{Animals}

OZR ( $\mathrm{n}=16)$ and LZR ( $\mathrm{n}=16)$ (Harlan, Indianapolis, IN) were housed in pathogen-free conditions, at $20-22^{\circ} \mathrm{C}$ with a reversed $12: 12$-h light-dark cycle, and fed rat chow and water ad libitum throughout the study period. The institutional animal use and care committee from West Virginia University School of Medicine approved all experiments. The animal care standards were followed by adhering to the recommendations for the care of laboratory animals as advocated by the American Association for Accreditation of Laboratory Animal Care and fully conformed to the Animal Welfare Act of the U.S. Department of Health and Human Services.

\section{Treadmill exercise}

Both the OZR and LZR were randomly assigned into equal groups of sedentary (OZR, $\mathrm{n}=8$; LZR, $\mathrm{n}=8$ ) or exercise-trained (OZR-ET, $\mathrm{n}=8$; LZR-ET, $\mathrm{n}=8$ ). The exercise-trained animals were trained by running on a motorized rodent treadmill (Columbus Instruments, Columbus, OH) 5 days weekly for 9 wk at $0 \%$ grade. During the first 3 wk of training, the animals began 15 minutes at a speed of $10 \mathrm{~m} / \mathrm{min}$, which was gradually increased to $55 \mathrm{~min} /$ day at 20 $\mathrm{m} / \mathrm{min}$ for the OZR-ET and $24 \mathrm{~m} / \mathrm{min}$ for the LZR-ET. This pace was maintained for the remainder of the study. Because the OZR animals are heavier, the same running pace would result in more total work than the lighter LZR. The higher training intensity for the LZR was 
to attempt to match the training intensity of the LZR-ET to the much heavier OZR-ET ( $\sim 40 \%$ increase in body weight). We have previously shown that this training protocol stimulates a moderate endurance training effect with a similar $\sim 25 \%$ increase in citrate synthase activity in both the OZR-ET and LZR-ET (12).

\section{Muscles examined}

Muscles from control and exercise-trained animals were harvested after anesthetizing the animals with $2 \%$ isoflurane. The gastrocnemius and soleus muscles from each limb were dissected from the surrounding connective tissues, and 4-5 $\mathrm{mm}$ of the left ventricle were quickly removed and frozen immediately in liquid nitrogen and stored at $-80^{\circ} \mathrm{C}$ until further analysis.

\section{Western Blots}

Total Protein homogenates were prepared in lysis buffer $(20 \mathrm{mM}$ Tris $\mathrm{pH} 7.5,150 \mathrm{mM} \mathrm{NaCl}$, 1\% Nonidet P-40, 0.5\% Sodium Deoxycholate, $1 \mathrm{mM}$ EDTA, 0.1\% SDS) with the addition of Protease inhibitor cocktail (PIC; Sigma). Separate mitochondrial and mitochondria free protein fractions were also prepared according to methods as previously performed in our lab (25). Briefly, samples were homogenized in mitochondrial isolation buffer (20 mM HEPES pH 7.5, $10 \mathrm{mM} \mathrm{KCl,} 1.5 \mathrm{mM} \mathrm{MgCl2,} 1$ mM EGTA, 1 mM EDTA, $1 \mathrm{mM}$ dithiothreitol, 250 $\mathrm{mM}$ sucrose) with protease inhibitor cocktail (Sigma-Aldrich, St Louis, MO, USA). The homogenates were centrifuged at $800 \mathrm{x}$ g to remove nuclei and cell debris followed by centrifugation at $16,000 \times \mathrm{g}$ for $20 \mathrm{~min}$ at $4^{\circ} \mathrm{C}$ to pellet the mitochondria. The supernatants were used as mitochondria-free cytosol. The mitochondrial pellet was washed twice then 
resuspended in total protein lysis buffer for analysis of Bax associated with the mitochondrial membrane.

Protein contents were quantified in duplicate by using bicinchoninic acid reagents (Pierce, Rockford, IL, USA) and bovine serum albumin (BSA) standards. $50 \mu \mathrm{g}$ of soluble protein was boiled for $4 \mathrm{~min}$ at $100^{\circ} \mathrm{C}$ in Laemmli buffer and separated on a 4-12\% gradient polyacrylamide gel (Invitrogen, USA). The gels were blotted to nitrocellulose membranes (Bio-Rad, Hercules, CA, USA) and stained with Ponceau red (Sigma Chemical Co, St Louis, MO, USA) to confirm equal loading and transferring of proteins to the membrane in each lane.

The membranes were then blocked in 5\% non-fat milk in Tris buffered saline with $0.05 \%$ Tween 20 (TBS-T) and probed with anti-Bcl-2 or Bax antibodies (Santa Cruz, CA, USA). Additionally, as a second means of confirming equal loading, the membranes were also probed for B-Tubulin (Abcam, MA, USA). Secondary antibodies were conjugated to horseradish peroxidase (Chemicon, CA, USA) and the signals were developed by chemiluminescence (ECL advance, Amersham Biosciences). The signals were visualized by exposing the membranes to X-ray films (BioMax MS-1, Eastman Kodak, Rochester, NY, USA), and digital records of the films were captured with a Kodak 290 camera. The resulting bands were quantified as optical density (OD) $\mathrm{x}$ band area by a one-dimensional (1D) image analysis system (Eastman Kodak, Rochester, NY, USA) and expressed in arbitrary units normalized to ß-Tublin.

\section{Cytochrome $c$ Assay}

The concentration of cytochrome $c$ in the mitochondrial-free cytosol was measured with an ELISA kit (Medical and Biological Laboratories; Japan). The change in color was 
monitored at a wavelength of $450 \mathrm{~nm}$ using a Dynex MRX plate reader. Measurements were performed in duplicate with all comparisons performed with the same assay. The cytochrome $c$ content was expressed as $\mathrm{OD}_{450}$ per milligram of protein and reported as relative to LZR control values.

\section{Fluorometric caspase activity assay}

To determine whether changes in Bax or Bcl-2 resulted in any downstream apoptotic events the activity of caspase- 3 and caspase- 9 were analyzed by a commercial caspase assay kit (APO-54A-019-KI01, Apotech, Switzerland) according to the manufacturer's procedure and as previously performed in our laboratory (24). Briefly, $50 \mathrm{mg}$ of muscle samples were gently homogenized with a Teflon pestle on ice in $1 \mathrm{ml}$ of nuclear isolation lysis buffer (10 $\mathrm{mM} \mathrm{NaCl}, 1.5 \mathrm{mM} \mathrm{MgCl}_{2}, 20 \mathrm{mM}$ HEPES, $\mathrm{pH}$ 7.4, 20\% glycerol, 0.1\% Triton X-100, and 1 $\mathrm{mM}$ dithiothreitol). The homogenates were centrifuged at $1,000 \mathrm{rpm}$ for $1 \mathrm{~min}$ at $4^{\circ} \mathrm{C}$. The supernatants contained the cytoplasmic protein fraction and were collected. The cytoplasmic protein fraction was then used for the caspase activity assays and also for the cell death ELISA.

Samples were mixed in equal parts assay buffer (50 mM PIPES, $0.1 \mathrm{mM}$ EDTA, 10\% glycerol, $10 \mathrm{mM}$ DTT, $\mathrm{pH}$ 7.2) and then $100 \mu \mathrm{M}$ of the fluorogenic 7-amino-4trifluoromethyl coumarin (AFC)-conjugated substrate (Ac-DEVD-AFC, Alexis Corp., San

Diego, CA, USA) was added at $37^{\circ} \mathrm{C}$ for $2 \mathrm{~h}$. The change in fluorescence was measured on a spectrofluorometer with an excitation wavelength of $390 / 20 \mathrm{~nm}$, and an emission wavelength of 530/25 nm (CytoFluor; Applied Biosystems, Foster City, CA, USA) before and after the 2 $\mathrm{h}$ incubation. Caspase activity was estimated as the change in arbitrary fluorescence units 
normalized to milligrams of protein used in the assay and data was reported relative to LZR. All measurements were performed in triplicate.

\section{Cell Death ELISA}

A cell death detection ELISA kit (Roche Applied Science, Indianapolis, IN, USA) was used to quantitatively determine the apoptotic DNA fragmentation by measuring the cytosolic histone-associated mono- and oligonucleosomes. The change in color was measured at a wavelength of $450 \mathrm{~nm}$ by using a Dynex MRX plate reader controlled through PC software (Revelation; Dynatech Laboratories, CA, USA). Measurements were performed in duplicate, with samples from OZR and LZR analyzed at the same time. The $\mathrm{OD}_{450}$ reading was then normalized to the milligrams of protein used in the assay.

\section{Statistical analyses}

Statistical analyses were performed using the SYSTAT 11.0 software package. A one way Analysis of variance (ANOVA) was performed on the difference in all measured variables. Statistical significance was accepted at $P<0.05$. All data are given as means \pm standard error.

\section{RESULTS}

\section{Animal Characteristics}

Fasting blood glucose, insulin, body weight, citrate synthase activity, and mean arterial blood pressure have been reported previously (12). These data show that the OZR used in our study were obese, hyperinsulinemic, hyperglycemic, and hyperlipidemic. This is consistent with previous studies which observed similar traits in these animals $(3,32)$. 
Briefly, Nine weeks of treadmill exercise reduced body mass by $\sim 23 \%$, reduced fasting insulin by $\sim 38 \%$, and reduced plasma triglycerides by $\sim 34 \%$ in EX-OZR vs. sedentary (SED) OZR (12). Additionally, the nine weeks of treadmill exercise use in this study increased citrate synthase activity $\sim 40 \%$ in both phenotypes (12). The mass of the heart, gastrocnemius, and soleus muscles are reported in Table 1.

\section{Bax protein contents}

Bax levels were comparable in cardiac and skeletal muscles of OZR and LZR animals. However, aerobic exercise reduced Bax levels in the cardiac muscles of the OZR by $35 \%$ (Figure 1A). On the other hand, no differences were observed in Bax protein content of the skeletal muscles either between animal phenotype or between exercise training in either the gastrocnemius or soleus muscles.

\section{Bcl-2 protein contents}

Representative western blots and the quantified optical density and areas of the protein bands of the anti-apoptotic protein Bcl-2 are shown in Figure 1B. In the heart, Bcl-2 protein expression in the OZR was about half of the Bcl-2 found in the LZR. Additionally, exercise training increased $\mathrm{Bcl}-2$ protein expression in the OZR hearts by approximately $25 \%$. On the other hand, no differences were observed in Bcl-2 content of the skeletal muscles between LZR and OZR in either the gastrocnemius or soleus muscles. Moreover, exercise training had no effect on Bcl-2 protein content in either the gastrocnemius or soleus muscles.

\section{Bax/Bcl-2 ratio}


The ability for Bcl-2 to inhibit the activity of Bax is dependent on the ratio of these two proteins. When Bax is in excess, Bcl-2 cannot bind and sequester all the Bax, thus allowing more Bax to act on the mitochondrial membrane. In the heart there was a 2-fold increase in the ratio of Bax to Bcl-2 in the OZR compared to LZR (Figure 1C). Aerobic exercise had a trend towards a decrease in this ratio in the heart of the trained OZR vs. control OZR ( $\mathrm{p}=0.072)$. No differences were observed in the Bax to Bcl-2 ratio in either the soleus or the gastrocnemius muscles among the groups.

\section{Mitochondrial Bax accumulation}

To determine if changes in $\mathrm{Bax} / \mathrm{Bcl}-2$ ratios resulted in an increase accumulation of Bax to the mitochondrial membrane of the heart, the mitochondrial protein was isolated in samples taken from the myocardium. There was a large accumulation of Bax in the myocardial mitochondrial protein fraction (Figure 3A) of OZR compared to LZR. The amount of Bax associated with the mitochondrial protein fraction was reduced in the exercise trained OZR, although there was still a significant accumulation when compared to the LZR. On the other hand there was no observable accumulation of Bax in the isolated mitochondrial protein fraction from either the soleus or gastrocnemius muscles regardless of phenotype (data not shown).

\section{Cytochrome $c$ ELISA}

Increased permeability of mitochondrial membranes and opening of the mitochondrial permeability pore results in cytochrome $c$ release from the mitochondria to the cystosol. Increased cytosolic cytochrome $c$ has been attributed to caspase-dependent apoptosis (7). The non-mitochondrial cytosolic protein fractions of cardiac muscles from the 
OZR had a small but significant, $\sim 30 \%$, increase in cytochrome $c$ compared to the LZR

(Figure 5). Aerobic training abolished this increase in cytochrome $c$ accumulation in the cystosol in cardiac muscles samples of the OZR when compared to the LZR. No differences were noted in the amount of cytochrome $c$ in the mitochondria-free cytosolic protein fraction between the OZR and LZR in the gastrocnemius muscles or soleus muscles.

\section{Caspase activity}

Caspase 3 and caspase 9 activities were examined to confirm the significance of increases in the Bax to Bcl-2 ratio in downstream mitochondrial apoptotic signaling in the cardiac muscle samples. When the mitochondrial membrane is permeablized and cytochrome $c$ is released, cytochrome $c$ in turn activates caspase 9. When activated, caspase 9 in turn activates caspase 3 an effector caspase which causes DNA fragmentation and apoptosis. In this study, both caspase 3 and caspase 9 were elevated by more than $30 \%$ in the cardiac muscle samples of the OZR compared to LZR. Exercise training in the OZR returned the activity level of both caspases to levels found in the LZR.

There was a significant elevation of both caspase 3 and caspase 9 activities in the denervated gastrocnemius muscles compared to the intra-animal control muscle. Similar to the Bax and Bcl-2 protein data, there was no difference in the extent of these changes between the LZR and OZR.

\section{Cell Death ELISA}

To determine whether the observed changes in apoptotic signaling resulted in cell death, DNA fragmentation was quantified in the cardiac and denervated gastrocnemius muscles. In the cardiac muscle there was a $\sim 40 \%$ increase in DNA fragmentation in the OZR 
compared to the LZR. Exercise training reduced DNA fragmentation in cardiac muscle samples from the OZR to levels similar to the LZR (Figure 8A). Exercise training had no effect on the DNA fragmentation in the myocardium of LZR animals.

\section{Discussion}

The important finding of this study is that Bax-mediated mitochondrial apoptotic signaling is elevated in the cardiac but not skeletal muscles of the OZR. This finding was supported by both an increased Bax to Bcl-2 ratio and an increased Bax protein in the mitochondrial protein fraction of the cardiac but not skeletal muscles of the OZR. Furthermore, apoptotic signaling downstream of the mitochondria including cytoplasmic cytochrome $c$ and caspase 3 and 9 activities were also all elevated in cardiac muscle samples, as was the level of DNA fragmentation. Furthermore, 9 weeks of treadmill training reduced apoptotic signaling in the cardiac muscle but had no effect in the skeletal muscles of the OZR.

It is estimated that the prevalence of metabolic syndrome is greater than 20 percent of the population in the Unites States (11). Similar to subjects with metabolic syndrome, the OZR suffers from hyperglycemia, dyslipidemia, and hyperinsulinemia $(12,32)$. Diabetic conditions, including hyperglycemia, dyslipidemia, and hyperinsulinemia, have been demonstrated to cause mitochondrial membrane hyper-polarization and the formation of reactive oxygen species and apoptosis in cardiac $(5,7,13,30)$ and smooth muscles $(27,28)$. Although apoptosis has not been previously examined in diabetic skeletal muscle, we hypothesized that apoptotic signaling would be similar in skeletal muscle and cardiac muscle. Since apoptosis is elevated in response to various diabetic conditions, we expected to see 
increased presence of the mitochondrial apoptotic markers Bax, Bcl-2, and cytosolic cytochrome $\mathrm{c}$ in cardiac and skeletal muscles of the OZR as compared to LZR. Furthermore, because endurance exercise has been shown to attenuate apoptotic signaling (24) we anticipated a reduction in apoptotic signaling in cardiac and skeletal muscles of OZR with 9weeks of treadmill training.

\section{Bax, Bcl-2 and Bax/Bcl2 ratios in cardiac and skeletal muscles of lean and obese rats.}

The ratio of Bcl-2 to Bax is indicative of mitochondrial induced apoptotic potential as Bcl-2 binds and opposes the pro-apoptotic activity of Bax by preventing Bax conformational change or translocation to the mitochondria $(8,18,31)$. Once incorporated into the mitochondria $\mathrm{Bax}$ is believed to form a pore in the mitochondria membrane that releases proteins (e.g. Cytochrome c) which results in a continuation of the apoptotic signaling cascade (e.g. Caspase 9 and caspase 3) $(2,26,29)$. In this study we observed an increase in the Bax to Bcl-2 ratio and an increased Bax protein in the mitochondrial protein fraction of the cardiac but not skeletal muscles of the OZR. Furthermore, there was an increase in cytochrome $c$ accumulation in the cytosol from cardiac muscles but not skeletal muscles in the OZR compared to the LZR. Additionally, apoptotic signaling downstream of the mitochondria including caspase 3 and 9 activities were also elevated in cardiac muscle samples of the OZR compared to the LZR. This shows that mitochondrial permeability was increased in the cardiac cells of OZR, and that apoptotic signaling was elevated in the cardiac muscles samples as well. Together, these data may partially explain the increase susceptibility to ischemia-reperfusion injury as the cardiac muscle is more prone to apoptosis with metabolic syndrome $(5,13)$. 


\section{Exercise improves apoptotic signaling in the myocardium of lean and obese rats.}

The second part of this study was to determine the impact that 9-weeks of treadmill exercise would have on the Bax to Bcl-2 ratio and associated apoptotic signaling. The influence of exercise training on apoptosis has not been fully examined, and only a few studies have attempted to define the relationship of acute strenuous exercise with apoptosis in skeletal muscle $(19,20)$. Siu and colleagues (24) found reduced DNA fragmentation in ventricle and soleus samples of trained animals when compared to control animals. Furthermore, both mRNA and protein contents of Bcl-2 increased in both soleus and ventricle muscles of endurance trained animals when compared with control animals. However, Bax mRNA levels decreased in the soleus of exercise trained animals when compared with control animals. In the present study we observed a tread towards a decreased Bax to Bcl-2 ratio $(p=0.072)$ with 9-weeks of treadmill exercise in the cardiac muscle samples of the OZR. In addition we observed a significant decrease in the amount of Bax in the mitochondrial protein fraction $(\sim 50 \%$ reduction) of the cardiac muscle samples of the OZR after exercise training. Furthermore, we observed a reduction in both caspase 9 and 3 activities in the myocardium of the OZR with 9-weeks of treadmill exercise. Together, these data indicate that aerobic exercise prevents mitochondrial apoptotic signaling in cardiac muscles of OZR.

Additionally, we have found that the Bax/Bcl-2 ratio was similar in LZR and OZR skeletal muscle samples and exercise did not improve this ratio. These data suggest that metabolic syndrome may have a different effect in skeletal verses cardiac muscles. Furthermore, these data suggest that skeletal muscle is more resistance to exercise-induced improvements in apoptotic signaling than cardiac muscle. We cannot rule out the possibility 
that more intense or longer exercise training parameters may have improved apoptotic signaling in skeletal muscles of the LZR or the OZR animals. Previous training studies in our lab were performed with a treadmill speed of $28 \mathrm{~m} /$ minute, compared to 24 for the LZR and 20 for the OZR (the OZR would not comply with faster pace). Nevertheless, the exercise parameters in this study were sufficient to induce improvements in citrate synthase activity (12), and mitochondrial protein (Cytochrome $c$ Oxidase, unpublished).

Sandri and colleagues investigated the influence of acute intense exercise on apoptosis in skeletal muscles of both young normal and dystrophin-deficient $(m d x)$ mice (20). They found that the DNA double strand breaks (as an indicator of DNA fragmentation) measured by in situ terminal deoxynucleotidyl transferase-mediated nick end labeling (TUNEL) increased by $\sim 20 \%, 48 \mathrm{~h}$ after a night of spontaneous wheel running in both normal and $m d x$ mice skeletal muscles. Using DNA gel electrophoresis, they reported that the amount of fragmented chromosomal DNA was greater in the skeletal muscles from $m d x$ mice after the $16 \mathrm{~h}$ spontaneous wheel running when compared with their non-exercise partners. The same laboratory reported that TUNEL-positive myonuclei existed after $16 \mathrm{~h}$ of spontaneous running in skeletal muscles of both C57B and $m d x$ mice (22). Furthermore, they found that Bcl-2 protein levels decreased after spontaneous exercise in muscle of $m d x$ mice. Similar results of increased apoptotic nuclei and a decreased ratio of Bcl-2/Bax have also been documented in skeletal muscles after a $16 \mathrm{~h}$ spontaneous wheel running in normal healthy animals (19). Activation of apoptosis in muscle tissue following acute bouts of exercise is not fully understood; however, these studies suggest that strenuous exercise may induce apoptosis in skeletal locomotion muscles. In our study the animals were trained gradually and for 9-weeks. We did not observe any increased apoptotic signaling with exercise in skeletal or cardiac muscles of OZR based on Bax, Bcl-2 or DNA fragmentation 
data. It is possible that an acute bout of exercise may have altered apoptotic signaling proteins in either cardiac or skeletal muscles; however that was beyond the scope of this paper.

\section{Acknowledgement.}

This study supported by NIH: National Institute on Aging Grant R01 AG021530 to SEA. 
Reference List

1. Alway SE, Degens H, Krishnamurthy G and Chaudhrai A. Denervation stimulates apoptosis but not Id2 expression in hindlimb muscles of aged rats. $J$ Gerontol A Biol Sci Med Sci 58: 687-697, 2003.

2. Antonsson B, Montessuit S, Lauper S, Eskes R and Martinou JC. Bax oligomerization is required for channel-forming activity in liposomes and to trigger cytochrome c release from mitochondria. Biochem J 345 Pt 2: 271-278, 2000.

3. Argiles JM, Busquets S, Alvarez B and Lopez-Soriano FJ. Mechanism for the increased skeletal muscle protein degradation in the obese Zucker rat. J Nutr Biochem 10: 244-248, 1999.

4. Basanez G, Nechushtan A, Drozhinin O, Chanturiya A, Choe E, Tutt S, Wood KA, Hsu Y, Zimmerberg $\mathbf{J}$ and Youle RJ. Bax, but not Bcl-xL, decreases the lifetime of planar phospholipid bilayer membranes at subnanomolar concentrations. Proc Natl Acad Sci U S A 96: 5492-5497, 1999.

5. Bojunga J, Nowak D, Mitrou PS, Hoelzer D, Zeuzem S and Chow KU. Antioxidative treatment prevents activation of death-receptor- and mitochondriondependent apoptosis in the hearts of diabetic rats. Diabetologia 47: 2072-2080, 2004.

6. Cai L and Kang YJ. Cell death and diabetic cardiomyopathy. Cardiovasc Toxicol 3: 219-228, 2003.

7. Cai L, Li W, Wang G, Guo L, Jiang Y and Kang YJ. Hyperglycemia-induced apoptosis in mouse myocardium: mitochondrial cytochrome C-mediated caspase-3 activation pathway. Diabetes 51: 1938-1948, 2002.

8. Cartron PF, Moreau C, Oliver L, Mayat E, Meflah K and Vallette FM. Involvement of the $\mathrm{N}$-terminus of Bax in its intracellular localization and function. FEBS Lett 512: 95-100, 2002.

9. Chao DT and Korsmeyer SJ. BCL-2 family: regulators of cell death. Annu Rev Immunol 16: 395-419, 1998.

10. Chao DT, Linette GP, Boise LH, White LS, Thompson CB and Korsmeyer SJ. Bcl-XL and Bcl-2 repress a common pathway of cell death. J Exp Med 182: 821-828, 1995.

11. Ford ES, Giles WH and Dietz WH. Prevalence of the metabolic syndrome among US adults: findings from the third National Health and Nutrition Examination Survey. JAMA 287: 356-359, 2002.

12. Frisbee JC, Samora JB, Peterson $\mathbf{J}$ and Bryner $\mathbf{R}$. Exercise training blunts microvascular rarefaction in the metabolic syndrome. Am J Physiol Heart Circ Physiol 291: H2483-H2492, 2006. 
13. Frustaci A, Kajstura J, Chimenti C, Jakoniuk I, Leri A, Maseri A, Nadal-Ginard B and Anversa P. Myocardial cell death in human diabetes. Circ Res 87: 1123-1132, 2000 .

14. Hsu YT, Wolter KG and Youle RJ. Cytosol-to-membrane redistribution of Bax and Bcl-X(L) during apoptosis. Proc Natl Acad Sci U S A 94: 3668-3672, 1997.

15. Katakam PV, Jordan JE, Snipes JA, Tulbert CD, Miller AW and Busija DW. Myocardial preconditioning against ischemia-reperfusion injury is abolished in Zucker obese rats with insulin resistance. Am J Physiol Regul Integr Comp Physiol 292: R920-R926, 2007.

16. Kim R, Emi M and Tanabe K. Role of mitochondria as the gardens of cell death. Cancer Chemother Pharmacol 1-9, 2005.

17. Lu MC, Tzang BS, Kuo WW, Wu FL, Chen YS, Tsai CH, Huang CY and Lee SD. More Activated Cardiac Mitochondrial-dependent Apoptotic Pathway in Obese Zucker Rats. Obesity (Silver Spring) 15: 2634-2642, 2007.

18. Mikhailov V, Mikhailova M, Pulkrabek DJ, Dong Z, Venkatachalam MA and Saikumar P. Bcl-2 prevents Bax oligomerization in the mitochondrial outer membrane. J Biol Chem 276: 18361-18374, 2001.

19. Podhorska-Okolow M, Sandri M, Zampieri S, Brun B, Rossini K and Carraro U. Apoptosis of myofibres and satellite cells: exercise-induced damage in skeletal muscle of the mouse. Neuropathol Appl Neurobiol 24: 518-531, 1998.

20. Sandri M, Carraro U, Podhorska-Okolov M, Rizzi C, Arslan P, Monti D and Franceschi C. Apoptosis, DNA damage and ubiquitin expression in normal and $\mathrm{mdx}$ muscle fibers after exercise. FEBS Lett 373: 291-295, 1995.

21. Sandri M, El Meslemani AH, Sandri C, Schjerling P, Vissing K, Andersen JL, Rossini K, Carraro U and Angelini C. Caspase 3 expression correlates with skeletal muscle apoptosis in Duchenne and facioscapulo human muscular dystrophy. A potential target for pharmacological treatment? J Neuropathol Exp Neurol 60: 302$312,2001$.

22. Sandri M, Podhorska-Okolow M, Geromel V, Rizzi C, Arslan P, Franceschi C and Carraro U. Exercise induces myonuclear ubiquitination and apoptosis in dystrophin-deficient muscle of mice. J Neuropathol Exp Neurol 56: 45-57, 1997.

23. Siu PM and Alway SE. Mitochondria-associated apoptotic signalling in denervated rat skeletal muscle. J Physiol 565: 309-323, 2005.

24. Siu PM, Bryner RW, Martyn JK and Alway SE. Apoptotic adaptations from exercise training in skeletal and cardiac muscles. FASEB J 18: 1150-1152, 2004.

25. Siu PM, Pistilli EE and Alway SE. Apoptotic responses to hindlimb suspension in gastrocnemius muscles from young adult and aged rats. Am J Physiol Regul Integr Comp Physiol 2005. 
26. Susin SA, Daugas E, Ravagnan L, Samejima K, Zamzami N, Loeffler M, Costantini P, Ferri KF, Irinopoulou T, Prevost MC, Brothers G, Mak TW, Penninger J, Earnshaw WC and Kroemer G. Two distinct pathways leading to nuclear apoptosis. J Exp Med 192: 571-580, 2000.

27. Taniyama Y and Griendling KK. Reactive oxygen species in the vasculature: molecular and cellular mechanisms. Hypertension 42: 1075-1081, 2003.

28. Touyz RM. Reactive oxygen species and angiotensin II signaling in vascular cells -implications in cardiovascular disease. Braz J Med Biol Res 37: 1263-1273, 2004.

29. Wolter KG, Hsu YT, Smith CL, Nechushtan A, Xi XG and Youle RJ. Movement of Bax from the cytosol to mitochondria during apoptosis. J Cell Biol 139: 12811292, 1997.

30. Yue TL, Bao W, Gu JL, Cui J, Tao L, Ma XL, Ohlstein EH and Jucker BM. Rosiglitazone treatment in Zucker diabetic Fatty rats is associated with ameliorated cardiac insulin resistance and protection from ischemia/reperfusion-induced myocardial injury. Diabetes 54: 554-562, 2005.

31. Zha H, Aime-Sempe C, Sato T and Reed JC. Proapoptotic protein Bax heterodimerizes with Bcl-2 and homodimerizes with Bax via a novel domain (BH3) distinct from BH1 and BH2. J Biol Chem 271: 7440-7444, 1996.

32. Zucker LM. Fat mobilization in vitro and in vivo in the genetically obese Zucker rat "fatty". J Lipid Res 13: 234-243, 1972. 


\begin{tabular}{lcccc}
\hline & LZR $(n=8)$ & LZR-ET $(n=8)$ & OZR $(n=8)$ & OZR-ET $(n=8)$ \\
\hline Heart, mg & $945 \pm 82$ & $923 \pm 83$ & $1052 \pm 98^{*}$ & $1143 \pm 71^{*}$ \\
Soleus, mg & $174 \pm 12$ & $168 \pm 10$ & $149 \pm 11^{*}$ & $140 \pm 14^{*}$ \\
Gastrocnemius, mg & $1698 \pm 104$ & $1645 \pm 124$ & $1298 \pm 140^{*}$ & $1229 \pm 153^{*}$ \\
& & & & \\
\hline
\end{tabular}

Table 1: Values are means $\pm \mathrm{SE} ; n$, no. of animals. LZR, lean Zucker rat; EX, exercise; OZR, obese Zucker rat. * $\mathrm{p}<0.05$ vs. LZR. 


\section{Figure Legends}

Figure 1. Average Bax and Bcl-2 protein expression are shown in the heart, soleus, and gastrocnemius muscles of lean (LZR) and obese (OZR) animals. The inserts show representative western blots for $\operatorname{Bax}(\mathrm{A})$ and $\mathrm{Bcl}-2$ (B) from LZR and OZR rats with or without 9 weeks of endurance exercise. Equal protein loading was confirmed for all samples by normalizing optical density to $\beta$-tubulin for the each protein sample. The gels were scanned densitometrically and the area and optical density of each band was determined. Data for each protein band were calculated as optical density $\mathrm{x}$ band area, normalized to the $\beta$-tubulin band. (C) The Bax/Bcl-2 ratio is shown for heart, soleus and gastrocnemius muscle samples from LZR and OZR rats after 9 weeks of endurance exercise. All data are reported as means \pm SE. $*$ p $<0.05$ OZR vs. LZR; $* * p<0.05$ OZR exercise vs. OZR control.

Figure 2. To verify that the increase in Bax-to-Bcl-2 ratio resulted in an increase translocation of Bax to the mitochondrial membrane, mitochondria protein was isolated from the heart tissue. The data are expressed relative to LZR data for each muscle. The data show that cardiac mitochondrial Bax was greater in the OZR than the LZR but mitochondrial Bax was lower in cardiac muscle samples taken from exercise trained (ET) OZR compared to sedentary animals. All data are reported as means \pm SE. ${ }^{*} \mathrm{p}<0.05$ OZR vs. LZR; ** $\mathrm{p}<0.05$ OZR exercise vs. OZR control; ** $\mathrm{p}<0.05$ OZR exercise vs. obese and lean control.

Figure 3. A cytochrome $c$ ELISA was conducted on cardiac muscle samples from control and exercise trained (ET) LZR and OZR rats. Protein concentration of the sample was determined by the BCA assay. The cytochrome $c$ data are expressed as ng $\bullet \mu l$ muscle protein ${ }^{-}$ 
1. All data are reported as means \pm SE. $* p<0.05$ OZR vs. LZR; ${ }^{* *} \mathrm{p}<0.05$ OZR exercise vs. OZR control; ** $p<0.05$ OZR exercise vs. obese and lean control.

Figure 4. Caspase 3 and 9 activities were determined on cardiac muscle samples from control and exercise trained (ET) LZR and OZR rats. Activities are expressed relative to protein concentration. All data are reported as mean \pm SE. * $p<0.05$ vs. LZR control; ** $\mathrm{p}<0.05$ vs. OZR control.

Figure 5. DNA fragmentation was determined on cardiac muscle samples from control and exercise trained (ET) LZR and OZR rats. Optical density of the assay was recorded and reported relative to protein concentration. All data are reported as means \pm SE. $* \mathrm{p}<0.05$ vs. LZR control; ** $\mathrm{p}<0.05$ vs. OZR control. 
Figure 1: Bax and BCL-2

A)

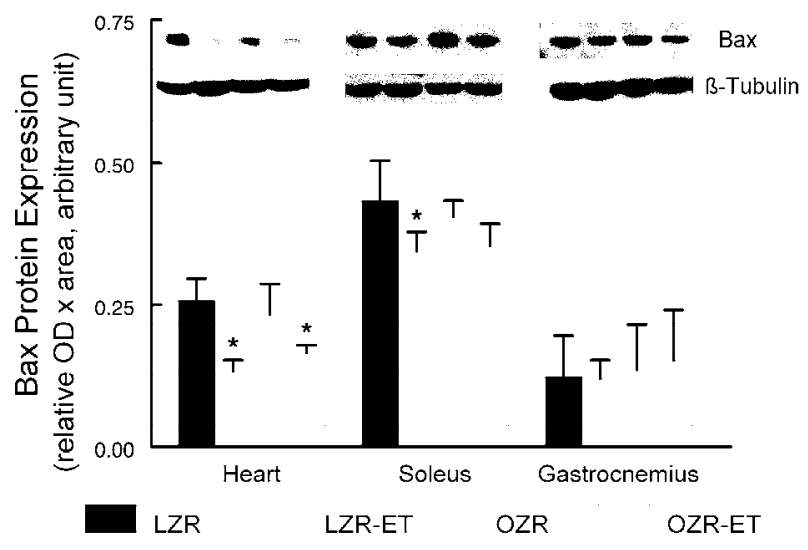

B)

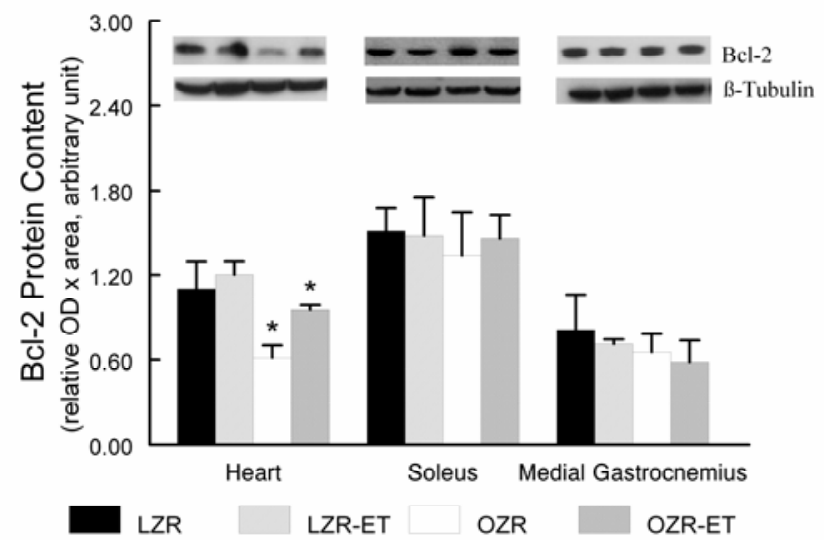

C) 


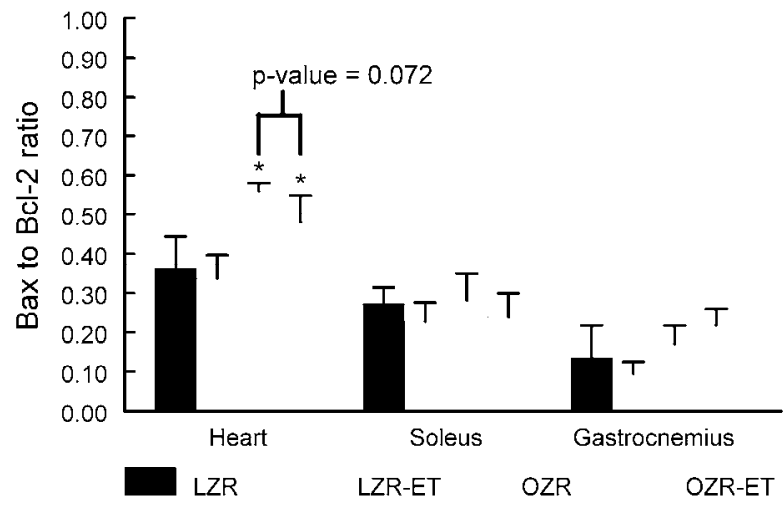


Figure 2: Cardiac Mitochondrial Bax

A)

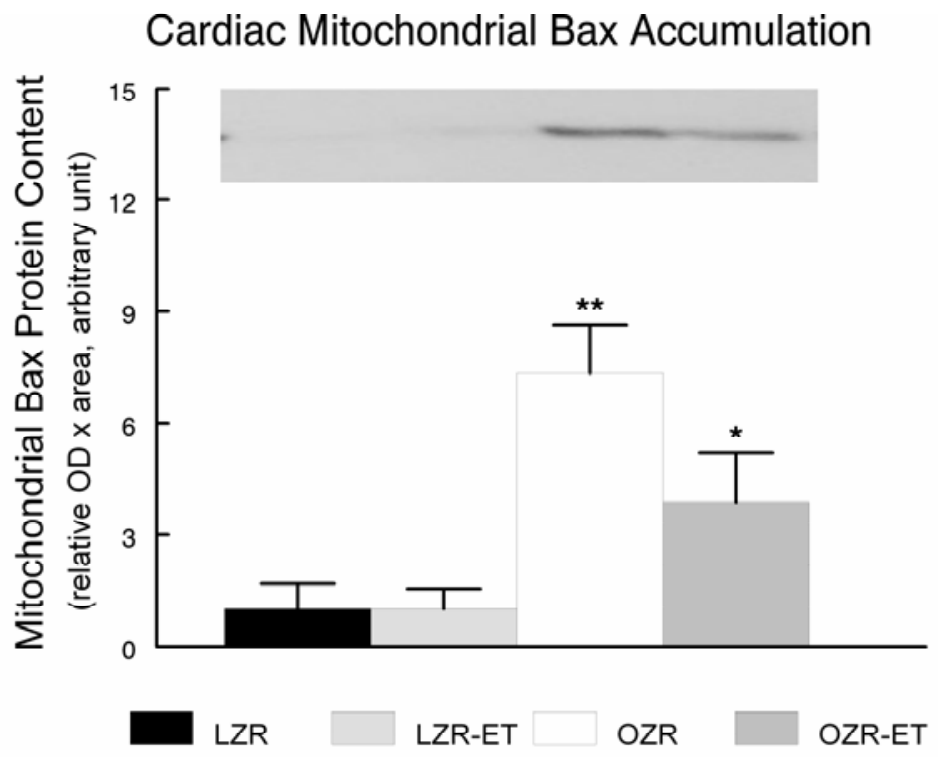

B)

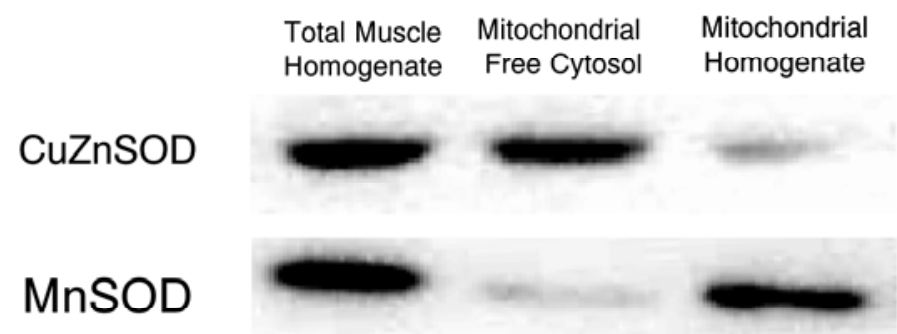


Figure 3: Cytochrome $c$

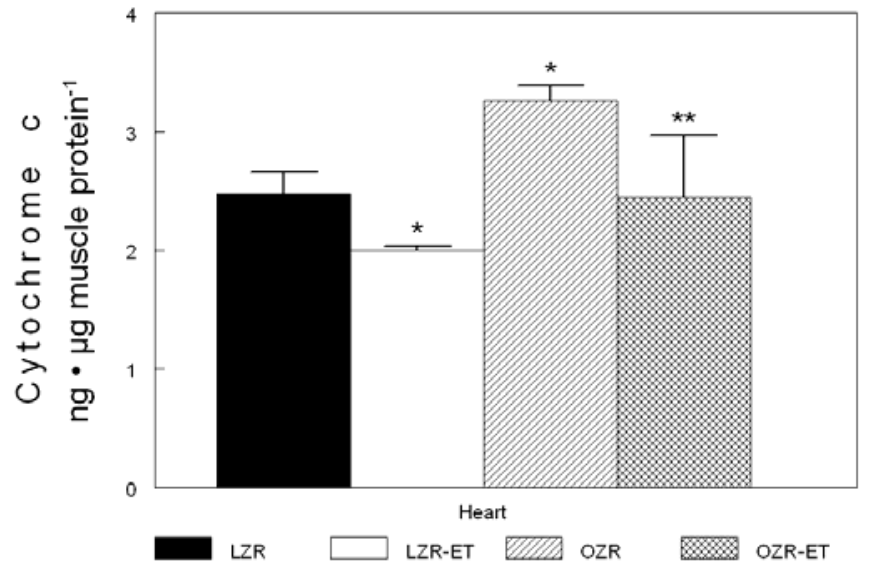


Figure 4: Caspase Activity

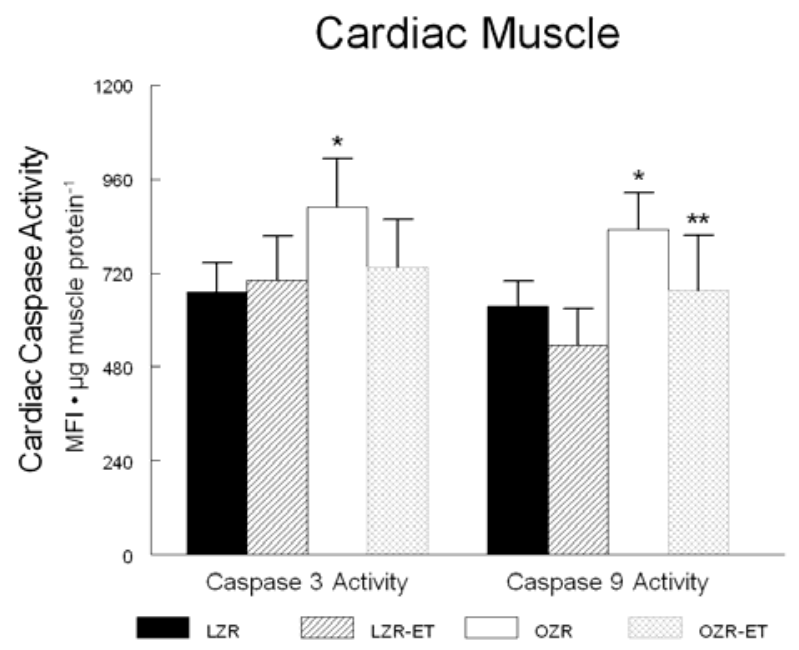


Figure 5: DNA Fragmentation

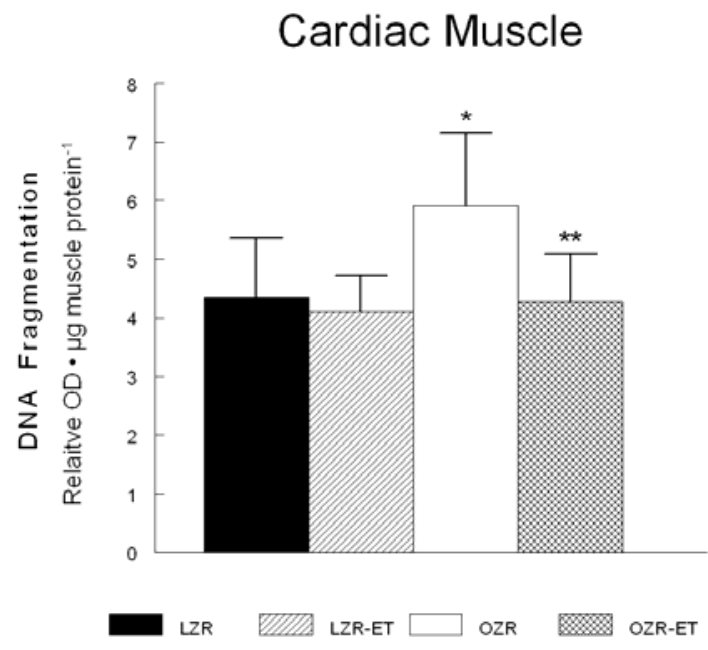




\section{Additional DATA for specific aim 4, not yet published}

\section{METHODS}

\section{Denervation procedure}

Hindlimb denervation was performed on a separate cohort of animals as routinely performed in our lab $(1,23)$. Briefly, the animals were placed under a general anesthesia using $2 \%$ isoflourene, and after cessation of reflex activity, the tibial nerve was dissected proximal to the cranial border of the gastrocnemius muscle. Care was taken to avoid any damage to the nerves, blood vessels and connective tissues. The medial and lateral branches of the tibial nerve that innervate the plantar flexor muscles (i.e. gastrocnemius and soleus) were cut, and the cut nerve ends were sutured into the biceps femoris muscle to ensure that the nerve stumps did not reinnervate the gastrocnemius muscle. Innervation to the plantaris and the deep toe flexor muscles were left intact so that the animals ambulated normally around the cage after the surgical denervation. Following the surgery, the hamstring muscle layers were closed with reabsorbable suture, and the skin incisions were closed with wound clips. The incision sites were covered with an antibacterial cream to prevent infection. The contralateral limb served as the intra-animal control. We have observed that the animals recovered quickly and were able to walk around within $\sim 45$ min post surgery (1). Withdrawal of innervation to the medial gastrocnemius results in an highly-favorable apoptotic environment for this muscle (23).

\section{Muscles examined.}

Muscles from Control and exercise-trained animals were harvested after anesthetizing the animals with $2 \%$ isoflourene and then euthanized by decapitation. The medial gastrocnemius and soleus muscles from each limb were dissected from the surrounding connective tissues, 
and $4-5 \mathrm{~mm}$ of the apex cordis from the heart was quickly removed and frozen immediately in liquid nitrogen and stored at $-80^{\circ} \mathrm{C}$ until further analysis.

In the second cohort of animals the gastrocnemius muscles was collect seven days after the surgical denervation, animals were anaesthetized using $2 \%$ isoflourene and the animals were then euthanized by decapitation. The gastrocnemius muscles from each limb were dissected from the surrounding connective tissues, removed, and stored at $-80^{\circ} \mathrm{C}$. Animals were subsequently euthanized via cardiac puncture.

\section{RESULTS}

Denervated Gastrocnemius Muscle. As neither obesity nor exercise training altered the Bax or Bcl-2 content in the skeletal muscle an additional cohort of animals was added in which the gastrocnemius muscle was denervated to induce an apoptotic response (1). Seven days of denervation resulted in a $\sim 30 \%$ increase in the Bax protein content in the gastrocnemius muscle of both the LZR and OZR. There was also a non-significant increase the Bcl-2 content in both phenotypes which resulted in denervation demonstrating no increase in the Bax to Bcl-2 ratio (figure S1).

Caspase activity. To confirm the significance of increase Bax to Bcl-2 ratio in downstream mitochondrial apoptotic signaling caspase 3 and caspase 9 activities were examined. In the denervated gastrocnemius muscles there was a significant elevation of both caspase 3 and caspase 9 activities compared to the intra-animal control. Similar to the Bax and Bcl-2 protein data there was no difference in the extent of these changes between the LZR and OZR. 
Cell Death ELISA. To determine whether the observed changes in apoptotic signaling resulted in cell death, DNA fragmentation was quantified in the cardiac and denervated gastrocnemius muscles. With denervation there was a significant increase $(\sim 1.5$ fold $)$ in DNA fragmentation for both the LZR and OZR compared to the intra-animal control limb. However, in agreement with the Bax and Bcl-2 data, there was no difference in the magnitude of these changes between the LZR and OZR.

\section{DISCUSSION}

It was rationalized that in young adult OZR the effects of obesity may not sufficient to reveal differences in apoptotic signaling between the LZR and OZR. However, if apoptosis was induced in skeletal muscle we expected that the OZR would have a magnified apoptotic signaling response compared to LZR. To induce skeletal muscle apoptosis we denervated the rat gastrocnemius because we have previously shown that this approach induces apoptosis (1). However, although denervation resulted in nuclear apoptosis in this experiment, there was no difference in the magnitude of change between the intra-animal controls of the LZR verses the OZR. Contrary to our hypotheses, these data suggest that obesity and metabolic syndrome does not exacerbate apoptotic signaling in skeletal muscle. 


\section{FIGURE LEGENDS}

Figure S-1. Representative western blots for Bax and Bcl-2 (A) in denervated and control gastrocnemius muscles from LZR and OZR are shown in the figure insert. Equal loading was confirmed for all samples by normalizing optical density to $\beta$-tublin for the each protein sample. The gels were scanned denistometrically and the area and optical density of each band was determined. Data for each protein band were calculated as optical density $\mathrm{x}$ band area, normalized to the $\beta$-tubulin band. The $\mathrm{Bax} / \mathrm{Bcl}-2$ ratio denervated and control gastrocnemius muscles from LZR and OZR (B). All data are reported as means \pm SE. * $\mathrm{p}<0.05$ OZR vs. LZR.

Figure S-2. Caspase 3 and 9 activities were determined in control and denervated gastrocnemius muscles of LZR and OZR. Activities are expressed relative to protein concentration. All data are reported as means \pm SE. ${ }^{*} \mathrm{p}<0.05$ vs. LZR control, ${ }^{* *} \mathrm{p}<0.05$ vs. OZR control.

Figure S-3. DNA fragmentation was determined in control and denervated gastrocnemius muscles of a second cohort of LZR and OZR. Optical density of the assay was recorded and reported relative to protein concentration. All data are reported as means \pm SE. * $p<0.05$ vs LZR control, ** $\mathrm{p}<0.05$ vs. OZR control. 
Figure S-1:

A)

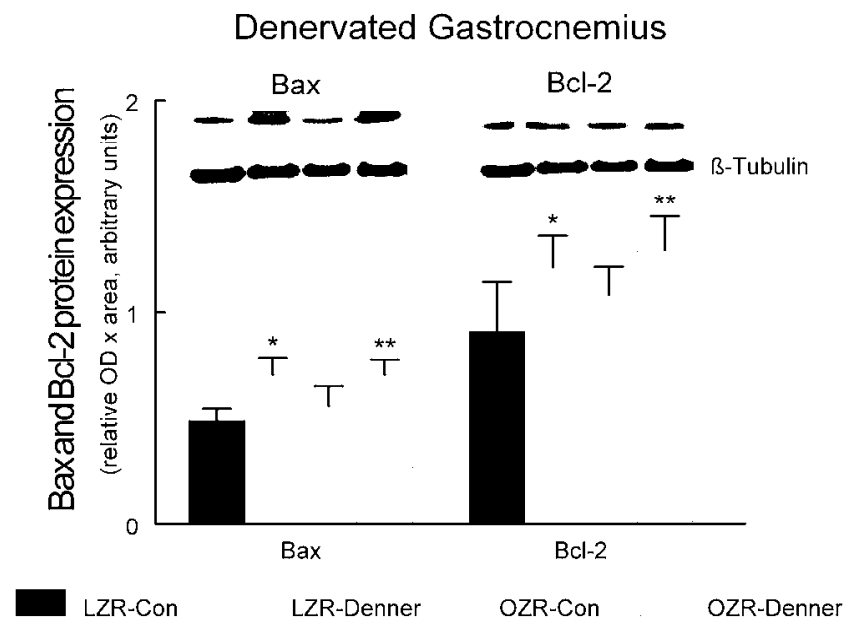

B)

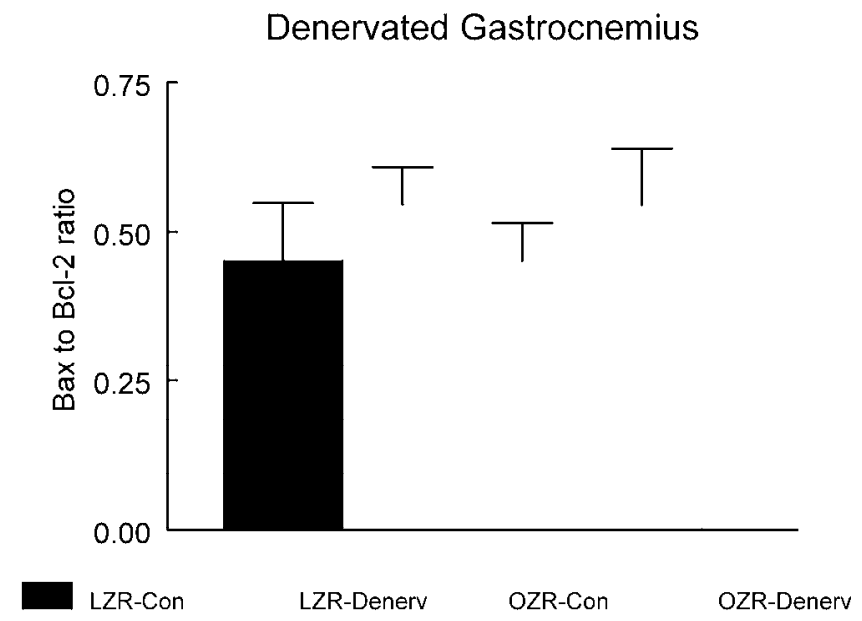


Figure S-2

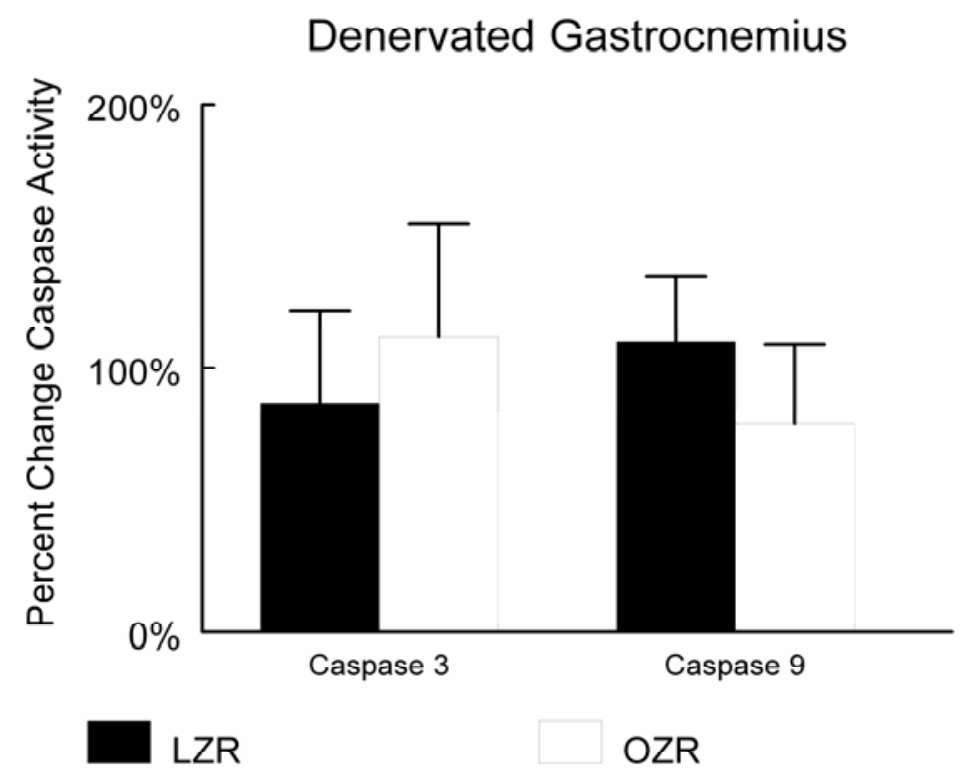


Figure S-3

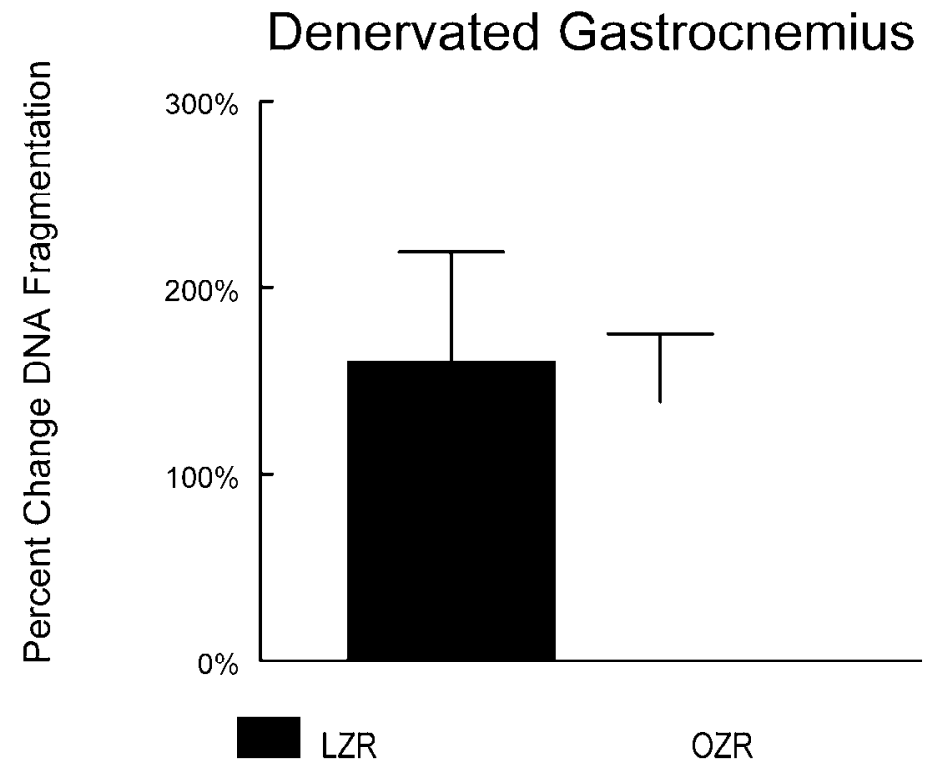




\section{DISCUSSION}

\section{Findings and Conclusions from this project}

The studies in this dissertation examine the contribution of satellite cell activation, differentiation, and myonuclear apoptosis for maintenance of the myonuclear domain and skeletal muscle hypertrophy in models of metabolic syndrome and obesity. The primary finding was that there was a significant decrease in proliferation and differentiation of C2C12 myoblasts, an in vitro model of satellite cells, when the cells were incubated with palmitate, a primary lipid that is upregulated in obesity and the metabolic syndrome. Furthermore, there was also a significant decrease in satellite cell activation in control muscles of the OZR compared with the LZR. The decreased proliferation and differentiation, in vitro, and the decreased satellite cell activation, in vivo, corresponded to attenuated Akt signaling in both models of obesity and the metabolic syndrome. It is possible that the decreased Akt protein expression in these models accounts for the attenuation of myoblast/satellite cell activation and differentiation. In support of this hypothesis, Akt protein expression increased in response to compensatory loading, and there was no difference in the amount of satellite cell activation in loaded muscles of the OZR compared with the LZR. It is likely that the increased load placed on the plantaris muscle by denervation of its synergists was sufficient to induce an increase in Akt protein expression in the OZR $(17,18)$, and the enhanced Akt protein expression was sufficient for the increase in satellite cell activation in the OZR.

\section{Role of palmitate in regulation of myoblasts and myonuclei}


The data presented in this dissertation clearly show that palmitate treatment has the capability to induce apoptosis in C2C12 myotubes. Furthermore, Akt activity is inhibited by palmitate in C2C12 cells and this is consistent with observations in other studies (3, 4). However, an apoptotic stimulatory role for palmitate in muscles of animals with metabolic syndrome does not appear to be important in vivo. Although Akt activity was reduced in the skeletal muscles of the OZR compared to the LZR, there was no increased incidence of apoptosis or apoptotic signaling. The absence of apoptotic signaling in the skeletal muscles of the OZR was surprising. However, in addition to increased circulating levels of fatty acids, the OZR have a variety of other factors that may have acted to protect the skeletal muscle from the negative effects of palmitate. One example of this is the elevated UCP3 protein expression observed in the OZR compared to the LZR (see supplemental data). UCP3 is believed to protect the mitochondria from free fatty acid-induced damage (12, 20). Comparatively, in our hands palmitate-treated myotubes showed no increase in UCP3 protein expression. Another explanation for the possible lack of apoptosis in the skeletal muscles of the OZR could be the fact that although the OZR have elevated palmitate levels, there is also an increase in the amount of unsaturated free fatty acids as well. It has been proposed that unsaturated free fatty acids may have a protective role and help stabilize and/or slow down the metabolism of saturated free fatty acids (22). 


\section{Limitation and Future Directions}

The rationale for this project was that reduced skeletal muscle mass with metabolic syndrome would be detrimental, because skeletal muscles are the primary tissue in regards to glucose and fatty acid oxidation (1, 2, 16). Disruptions of either glucose or fatty acid oxidation are major contributors to complications associated with obesity and the metabolic syndrome. Understanding the mechanism in which obesity and the metabolic syndrome may inhibit skeletal muscle growth may lead to treatment options aimed at improving skeletal muscle growth and hypertrophy.

The design of this study specifically focused on examining the mechanism to explain the smaller skeletal muscles in the OZR compared to the LZR. This study design also examined the effects of the saturated free fatty acid palmitate on myoblasts (an in vitro model of satellite cells) and myotubes (an in vitro model of mature skeletal muscle). Palmitate was selected because the OZR have a significantly higher plasma and intramuscular concentration of palmitate compared to the $\operatorname{LZR}(13,21)$. Furthermore, palmitate has been previously shown to be sufficient to inhibit Akt activity due to it's metabolite ceramide $(3,4)$.

Although the selection of palmitate in vitro was appropriate for this study, it also accounts for one limitation of this study design. High palmitate levels are not the only difference between the OZR and LZR. Future in vitro studies should focus on other aspects of metabolic syndrome besides higher palmitate levels. For example, non-saturated free fatty acids, which are also elevated in the OZR, have different metabolites and have been demonstrated to stabilize the saturated fatty acids and may protect the cells from apoptosis $(4,10,11,19)$. To test this hypothesis the monounsaturated fatty acid oleate would be added to the media to determine whether it protects the myotubes from apoptotic signaling induced by palmitate. The co- 
incubation of oleate with palmitate has been previously demonstrated to reverse palmitateinduced insulin resistance and inflammation in skeletal muscle cells (7). The research design for testing the effects that oleate would have on reversing palmitate mediated apoptotic signaling in C2C12 myotubes would be performed in five groups as follows: (i) Palmitate only $(0.075 \mathrm{mM})$, (ii) Palmitate and Oelate ( $0.75 \mathrm{mM}$ of each), (iii) Palmitate and Oelate (0.375 $\mathrm{mM}$ of each), (iv) Oleate only (0.75 mM), and (v) Laurate (0.75 mM).

The findings of this study demonstrated that elevated palmitate was sufficient to inhibit skeletal muscle proliferation and differentiation, at least in vitro. However, besides increased palmitate levels, the OZR also has increased levels of adipokines, particularly leptin. To determine whether these additional adipokines, (i.e. Leptin) also interfere with myoblast proliferation and differentiation this study design will be repeated with the addition of adipokines to the cells and their influence on proliferation and differentiation would be determined. Together, understanding the affects of these adipokines may be beneficial for understanding additional mechanism in which obesity and the metabolic syndrome may interfere with skeletal muscle growth and hypterophy.

Although the OZR is a well established genetic model of obesity and metabolic syndrome, follow-up studies using diet induced obesity could be performed. Briefly, animals would be divided into a normal chow diet (10\% calories from fat) compared to high-fat diet (60\% calories from fat and fed ad libitum for 9 weeks, as performed by others previously (5, 8, 23). After nine-weeks of feeding, the BrdU implantation procedure preformed in this study would be repeated in these animals.

Although satellite cell activation was reduced in the unloaded skeletal muscles of the OZR compared to the LZR, we were able to induce significant satellite cell activation with 
compensatory loading. This highlights another limitation of the present study as compensatory loading is a physiological, but severe, loading model that would be unrepeatable in translationa research. This was the first study to demonstrate hypertrophy in a rat model of obesity and the metabolic syndrome, and demonstrates that hypertrophy and satellite cell activation is possible. However, future work needs to be done to determine if less severe models of loading could also restore satellite cell activation. For example, Cutlip et al. have develop a chronic exposure to stretch-shortening contractions model in rats using a dynamometer for testing mal-adaptation in young verse old rats (9). This model could be used in OZR, or in high-fat fed rats, to test for maladaptation or satellite cell activation (through BrdU incorporation).

It would be important to discover if there is a decrease in the satellite cell activation in young developing adolescents. The results of the National Health and Nutrition Examination Survey 2003-2004 indicate that the prevalence of obesity is increasing, especially in young people, effecting approximately $17 \%$ of Americans 2-19 years of age $(6,14,15)$. With increased obesity there is an elevation of lipids in the circulation, similar to that observed in the OZR. It would be important to discover if there is a decrease in the satellite cell activation in young developing adolescents and to discover if this could be restored with loading (resistance training). These data may provide important information in developing treatment strategies for obese adolescents and alter the way in which obesity and the metabolic syndrome is managed. 
Reference List

1. Basu A, Basu R, Shah P, Vella A, Johnson CM, Nair KS, Jensen MD, Schwenk WF and Rizza RA. Effects of type 2 diabetes on the ability of insulin and glucose to regulate splanchnic and muscle glucose metabolism: evidence for a defect in hepatic glucokinase activity. Diabetes 49: 272-283, 2000.

2. Bjornholm $\mathbf{M}$ and Zierath JR. Insulin signal transduction in human skeletal muscle: identifying the defects in Type II diabetes. Biochem Soc Trans 33: 354-357, 2005.

3. Chavez JA, Knotts TA, Wang LP, Li G, Dobrowsky RT, Florant GL and Summers SA. A role for ceramide, but not diacylglycerol, in the antagonism of insulin signal transduction by saturated fatty acids. J Biol Chem 278: 10297-10303, 2003.

4. Chavez JA and Summers SA. Characterizing the effects of saturated fatty acids on insulin signaling and ceramide and diacylglycerol accumulation in 3T3-L1 adipocytes and C2C12 myotubes. Arch Biochem Biophys 419: 101-109, 2003.

5. Chou CJ, Cha MC, Jung DW, Boozer CN, Hashim SA and Pi-Sunyer FX. High-fat diet feeding elevates skeletal muscle uncoupling protein 3 levels but not its activity in rats. Obes Res 9: 313-319, 2001.

6. Cole TJ, Flegal KM, Nicholls D and Jackson AA. Body mass index cut offs to define thinness in children and adolescents: international survey. BMJ 335: 194, 2007.

7. Coll T, Eyre E, Rodriguez-Calvo R, Palomer X, Sanchez RM, Merlos M, Laguna JC and Vazquez-Carrera $\mathbf{M}$. Oleate reverses palmitate-induced insulin resistance and inflammation in skeletal muscle cells. J Biol Chem 2008.

8. Corbalan MS, Margareto J, Martinez JA and Marti A. High-fat feeding reduced muscle uncoupling protein 3 expression in rats. J Physiol Biochem 55: 67-72, 1999.

9. Cutlip RG, Baker BA, Geronilla KB, Mercer RR, Kashon ML, Miller GR, Murlasits $\mathbf{Z}$ and Alway SE. Chronic exposure to stretch-shortening contractions results in skeletal muscle adaptation in young rats and maladaptation in old rats. Appl Physiol Nutr Metab 31: 573-587, 2006.

10. de Vries JE, Vork MM, Roemen TH, de Jong YF, Cleutjens JP, van der Vusse GJ and Van Bilsen M. Saturated but not mono-unsaturated fatty acids induce apoptotic cell death in neonatal rat ventricular myocytes. J Lipid Res 38: 1384-1394, 1997. 
11. Hardy S, El Assaad W, Przybytkowski E, Joly E, Prentki M and Langelier Y. Saturated fatty acid-induced apoptosis in MDA-MB-231 breast cancer cells. A role for cardiolipin. J Biol Chem 278: 31861-31870, 2003.

12. Himms-Hagen $\mathbf{J}$ and Harper ME. Physiological role of UCP3 may be export of fatty acids from mitochondria when fatty acid oxidation predominates: an hypothesis. Exp Biol Med (Maywood ) 226: 78-84, 2001.

13. Kasser TR and Martin RJ. Palmitate metabolism and norepinephrine sensitivity in brown adipose, liver, and white adipose tissues of Zucker rats. Proc Soc Exp Biol Med 169: 320325, 1982.

14. Ogden CL, Carroll MD, Curtin LR, McDowell MA, Tabak CJ and Flegal KM. Prevalence of overweight and obesity in the United States, 1999-2004. JAMA 295: 15491555, 2006.

15. Ogden CL, Yanovski SZ, Carroll MD and Flegal KM. The epidemiology of obesity. Gastroenterology 132: 2087-2102, 2007.

16. Olsen DB, Sacchetti M, Dela F, Ploug $\mathbf{T}$ and Saltin B. Glucose clearance is higher in arm than leg muscle in type 2 diabetes. J Physiol 565: 555-562, 2005.

17. Sakamoto K, Arnolds DE, Fujii N, Kramer HF, Hirshman MF and Goodyear LJ. Role of Akt2 in contraction-stimulated cell signaling and glucose uptake in skeletal muscle. Am J Physiol Endocrinol Metab 291: E1031-E1037, 2006.

18. Sakamoto K, Hirshman MF, Aschenbach WG and Goodyear LJ. Contraction regulation of Akt in rat skeletal muscle. J Biol Chem 277: 11910-11917, 2002.

19. Staiger K, Staiger H, Weigert C, Haas C, Haring HU and Kellerer M. Saturated, but not unsaturated, fatty acids induce apoptosis of human coronary artery endothelial cells via nuclear factor-kappaB activation. Diabetes 55: 3121-3126, 2006.

20. Tsuboyama-Kasaoka $\mathbf{N}$ and Ezaki O. Mitochondrial uncoupling protein 3 (UCP3) in skeletal muscle. Front Biosci 6: D570-D574, 2001.

21. Turcotte LP, Swenberger JR, Zavitz TM and Yee AJ. Increased fatty acid uptake and altered fatty acid metabolism in insulin-resistant muscle of obese Zucker rats. Diabetes 50: 1389-1396, 2001.

22. Unger RH and Orci L. Lipoapoptosis: its mechanism and its diseases. Biochim Biophys Acta 1585: 202-212, 2002.

23. Yaspelkis BB, III, Lessard SJ, Reeder DW, Limon JJ, Saito M, Rivas DA, Kvasha I and Hawley JA. Exercise reverses high-fat diet-induced impairments on compartmentalization and activation of components of the insulin-signaling cascade in skeletal muscle. Am J Physiol Endocrinol Metab 293: E941-E949, 2007. 


\title{
EFFECTS OF EXERCISE AND OBESITY ON UCP3 CONTENT IN RAT HINDLIMB MUSCLES
}

\author{
JM Peterson, RW Bryner, JC Frisbee and SE Alway
}

Laboratory of Muscle Biology and Sarcopenia

Division of Exercise Physiology, West Virginia University School of Medicine, Robert C. Byrd Health Science Center, Morgantown, WV 26506

Send correspondence and reprint requests to:

Dr. Randall W. Bryner, Division of Exercise Physiology, School of Medicine,

Robert C. Byrd Health Science Center, West Virginia University, Morgantown WV 26506-9227, USA

Phone: 304-293-0441

Fax: 304-293-7105

Email: rbryner@hsc.wvu.edu

Running title: Obese Zucker rats and UCP3 


\section{ABSTRACT}

Uncoupling protein 3 (UCP3) is a mitochondrial inner membrane protein which is thought to shuttle nonmetabolize fatty acids, particularly when there are excessive fatty acids present. PURPOSE: Obese zucker rats (OZR) have systematically elevated levels of fatty acids, with decrease fatty acid metabolism. We hypothesized that basal UCP3 protein expression levels would be elevated in the skeletal muscles of the OZR compared to the lean zucker rats (LZR). In addition, because aerobic exercise training has been shown to elevate the ability of skeletal muscle to metabolize lipids, we also hypothesized that aerobic exercise training would decreased UCP3 protein expression in the skeletal muscles, and that this decrease would be more pronounced in the skeletal muscles of the OZR. METHODS: OZR and LZR animals were aerobically trained on a motorized treadmill for 55 minutes a day 5 days per week for 9 weeks. UCP3 and oxidative enzymes were measured in the plantaris, gastrocnemius, and soleus muscles of the animals. RESULTS: Basal UCP3 protein expression was found to be elevated 8-fold in the plantaris muscles and 3-fold in the gastrocnemius muscles of the OZR compared to the LZR $(p<0.05)$. However, there was no difference in UCP3 protein expression in the soleus muscles of the OZR compared to the LZR $(p=0.34)$. Furthermore, aerobic exercise training did not significantly alter UCP3 protein expression in the soleus, plantaris, or gastrocnemius muscles of the LZR; however UCP3 protein expression levels decreased in the trained soleus and gastrocnemius muscles compared with controls. CONCLUSIONS: The decrease in UCP3 with aerobic exercise training was most notable in the soleus of the OZR. These data demonstrate that there are muscle specific effects of obesity and aerobic exercise training on UCP3 protein expression levels.

Key words: CITRATE SYNTHASE, AEROBIC TRAINING, UNCOUPLING PROTEIN 3, METABOLIC SYNDROME 


\section{INTRODUCTION}

Paragraph number 1. Uncoupling proteins are a family of mitochondrial inner membrane proteins, which are believed to be involved in the regulation of energy expenditure. Uncoupling protein 1 (UCP1), which is highly expressed in brown adipose tissue, has been clearly demonstrated to contribute to thermogenesis [see reviewed (1). Uncoupling protein 3 (UCP3) is a member of the uncoupling protein family that is highly expressed in skeletal muscle, and shares a $\sim 60$ homology to UCP1 (2). Although UCP3 was originally believed to have a similar function to UCP1, based on its homology, it has been established that UCP3 does not contribute to thermogenics or muscle proton leak [reviewed (3)]. A potential function of UCP3 is that UCP3 may serve as a mitochondrial mediator of fatty acid metabolism in the muscle It has been demonstrated that elevated circulating free fatty increases muscle UCP3 protein expression levels in both in human and animal models (4-7), perhaps as an attempt to prevent lipidinduced oxidative damage to muscle mitochondria. Furthermore, when free fatty acid levels are elevated during exercise there is an increase in UCP3 mRNA (8;9), and protein levels $(10 ; 11)$. On the other hand it has been proposed that UCP3 may play a protective role against reactive oxygen species (ROS) production $(3 ; 12 ; 13)$, although this may be directly related to preventing lipid peroxidation (3). Nevertheless, these data support the hypothesis that UCP3 is actively involved in free fatty acid metabolism and therefore, the increase in UCP3 with acute exercise may be a means of mitochondria protection under conditions of high fatty acids.

Paragraph number 2. In contrast to an acute bout of exercise, long-term aerobic exercise training may produce the opposite effect on UCP3. Boss et al. reported that 8-weeks of treadmill running resulted in a $76 \%$ and $59 \%$ decrease in UCP3 mRNA in the tibialis anterior and soleus muscles of rats, respectively (14), however, it is not known if the UCP3 protein levels were also decreased in this study. Similarly, in a cross-sectional study, the UCP3 protein levels in quadriceps muscles of endurance-trained men were 
significantly lower when compared with untrained controls (15). Furthermore, Fernstrom and colleagues (16) demonstrated that long-term aerobic training decreased UCP3 protein expression when normalized to mitochondrial activity. Combine these data provide evidence that the increase UCP3 protein expression is transient and that the UCP3 contributes to the acute adaptation to exercise (3). However, to our knowledge no study has examined the response of UCP3 protein expression levels to aerobic exercise training in primarily glycolytic muscles, like the plantaris, vs. a primarily oxidative muscle like the soleus.

Paragraph number 3. In addition to aerobic training, obesity, or any situation in which free fatty acid levels were elevated, could alter UCP3 protein expression levels. For example, in rodent models a high fat diet induced an increase in UCP3 protein expression in some $(5 ; 6 ; 17)$, although not all studies (18). For example, Chou and colleagues (6) determined that high fat diet (60\% of energy from fat, for 4 weeks) increased UCP3 content along with plasma free fatty acid levels. The obese Zucker (fa/fa) rat (OZR) is rodent model consistently used in the literature as a model of severe obesity. The OZR have a dysfunctional leptin receptor and therefore do not properly regulate their food intake (19). This results in rapid and severe obesity, skeletal muscle insulin resistance, hyperglycemia, and high levels of free fatty acids (20-22). Because of the high levels of plasma free fatty acids in the OZR it would be expected that the OZR would have increased UCP3 expression, compared to the lean zucker rat (LZR), similar to the high fat feeding model. However, previous work in the OZR has demonstrated that there is a decrease in the UCP3 mRNA expression in the soleus muscle compared to the LZR (23) whereas, in a separate study there was a significant increase in UCP3 protein expression in the quadriceps of the OZR compared to the LZR (20). However, neither of these studies examined UCP3 expression in multiple types of muscles (glycolytic or oxidative muscles). This is important because it is possible that the response of UCP3 to treatment (e.g., diet or exercise) could be muscle phenotype specific and vary between glycolytic compared to oxidative muscles (4;24-27). For example, Schrauwen and colleagues (24) demonstrated that the regulation of UCP3 protein expression, in response to a high fat diet, was related to muscle fiber 
type in healthy humans. Similarly, both glycolytic and oxidative skeletal muscles of the OZR are exposed to significantly higher levels of free fatty acids compared to the LZR (28). However, the regulation of UCP3 to either the severe obesity, as observed in the OZR, or aerobic exercise could be different depending on the muscle being examined. Together, these data demonstrate the need for further study of the interaction between obesity, aerobic exercise training, and UCP3 protein expression levels in both oxidative and glycolytic skeletal muscles.

Paragraph number 4. It has been demonstrated that aerobic exercise training increases the proteins responsible for fatty acids oxidation (29). Increased metabolism of fatty acids would reduce the need for UCP3 to remove non-metabolized fatty acids, which in turn could allow for the decrease in UCP3 protein expression in skeletal muscle with aerobic exercise training $(3 ; 8 ; 14 ; 30)$. However, there is a scarcity of data concerning the interactions of obesity, muscle oxidative capacity, and exercise on UCP3 content in skeletal muscle. Therefore, the purposes of this study were three-fold: (i) first to determine if basal UCP3 is elevated in both fast and slow hindlimb muscles of OZR compared to LZR; (ii) secondly, to determine whether aerobic exercise alters the content of UCP3 in the skeletal muscles of the OZR differently from the LZR; (iii) third, to determine if changes in UCP3 protein expression are dependent on the oxidative capacity of the muscle being examined. 


\section{METHODS}

Paragraph number 5. Animals. An equal number of 6 week old male OZR and LZR rats (Harlan, Indianapolis, IN) were randomly assigned to control $(\mathrm{C}, \mathrm{n}=16)$ or training $(\mathrm{ET}, \mathrm{n}=16)$ groups. Animals were housed in pathogen-free conditions, two per cage, at $20-22^{\circ} \mathrm{C}$ with a reversed $12: 12$-h light-dark cycle, and fed rat chow and water ad libitum throughout the study period. All animal procedures were conducted in accordance with institutional guidelines, and ethical approval was obtained from the Animal Care and Use Committee at the West Virginia University.

Paragraph number 6. Training protocol. Animals were trained by running on a level motorized rodent treadmill (Columbus Instruments, Columbus, $\mathrm{OH}$ ) 5 days weekly for 9 weeks. During the first 4 wk, the speed of the treadmill and duration of the training sessions were gradually increased from a speed of $10 \mathrm{~m} / \mathrm{min}$ for $10 \mathrm{~min}$ to a running speed of $20 \mathrm{~m} / \mathrm{min}$ for the OZR and $24 \mathrm{~m} / \mathrm{min}$ for the LZR. Different speeds were used to compensate for the increased intensity of exercise for the OZR due to increased body weight compared to LZR. Our pilot work suggested that the difference in body weight would vary around $40 \%$ and we used an estimation based on the formula of "work=1/2 mass * velocity squared $\left(\mathrm{W}=1 / 2 \mathrm{~m}^{*} \mathrm{~V}^{2}\right)$ " and the estimated final weights of 500 grams for the OZR and 350 grams for the LZR. This calculation estimates that at 20 and $24 \mathrm{~m} / \mathrm{min}$ for the OZR and LZR, respectively, they would have an estimated final work output of 0.028 joules. Furthermore, our pilot data demonstrated that these intensities would be able to be reliably maintained by the OZR and LZR, respectively, with minimal motivation by the investigators. Additionally, as demonstrated by the mitochondrial proteins examined in this study we saw similar increases in the trained groups of both the OZR and LZR. During weeks 5 through 9, a 5-min warm-up session at a speed of $15 \mathrm{~m} / \mathrm{min}$ was followed by the 55 -min training session. During the training sessions, mild electrical shock stimulation was applied, if necessary, to maintain the running motivation. Animals assigned to the control group were handled daily and exposed 
to the noise of the running treadmill by placing their cages next to the treadmill during the exercise session.

Paragraph number 7. Forty eight hours after the last training session and an overnight fast ( $\sim 16$ hours) animals were anesthetized with isoflurane and euthanized via cardiac puncture at which time the soleus, plantaris, and gastrocnemius muscles were quickly removed, frozen immediately in liquid nitrogen and stored at $-80^{\circ} \mathrm{C}$ until further analysis. These muscles were chosen to examine changes in UCP3 in response to aerobic training in the oxidative (soleus), glycolytic, (plantaris), and mixed oxidative and glycolic (gastrocnemius) muscles. Although it has been demonstrated that there is a reduction in percent of total fiber area occupied by the glycolytic fibers in the OZR compared to the LZR, the relative percentage of the glycolytic to oxidative fibers remained constant (31). Torgan et al. demonstrated that the OZR has $\sim 77 \%$ type I fibers in the soleus muscle compared to the LZR $(\sim 83 \%)$, with no difference in fiber type percentages in the plantaris muscle between the OZR and LZR ( $\sim 10 \%$ type I, $\sim 68 \%$ type IIa, and $\sim 22 \% \mathrm{IIb})$.

Paragraph number 8. Western Blot analyses. Protein extracts were obtained from hindlimb muscles as routinely performed in our lab (32). The protein contents of the solublized extracts were quantified in duplicate by using bicinchoninic acid reagents (Pierce, Rockford, IL, USA) and bovine serum albumin (BSA) standards. $40 \mu \mathrm{g}$ of soluble protein was boiled for $4 \mathrm{~min}$ at $100^{\circ} \mathrm{C}$ in Laemmli buffer and loaded on each lane of a $12 \%$ polyacrylamide gel. The proteins were separated by NuPage Bis-Tris gel (NP0303, Invitrogen, CA, USA) with NuPage Running Buffer MES-SDS (NP0002; Invitrogen, CA, USA) for 1.5 hours at $20^{\circ} \mathrm{C}$, and molecular weight was confirmed with SeeBlue2®Plus2 (LC5925, Invitrogen, CA, USA). The gels were blotted to nitrocellulose membranes (Bio-Rad, Hercules, CA, USA) and stained with Ponceau S red (Sigma Chemical Co, St Louis, MO, USA) to confirm equal loading and transferring of proteins to the membrane in each lane. 
Paragraph number 9. The membranes were then blocked in $4 \%$ non-fat milk in Tris buffered saline with $0.05 \%$ Tween 20 (TBS-T) and probed with an UCP3 antibody (AB3046; Chemicon, CA, USA), cytochrome c oxidase subunit I (COX I; Invitrogen, CA, USA) or beta-tubulin antibody (Abcam, MA, USA). Isolated skeletal muscle mitochondrial protein and rat liver homogenate were used as positive and negative controls, respectively, for UCP3. Secondary antibodies were conjugated to horseradish peroxidase (HRP) (Chemicon) and the signals were developed by chemiluminescence (Pierce, Rockford, IL, USA). The signals were visualized by exposing the membranes to X-ray films (BioMax MS-1, Eastman Kodak, Rochester, NY, USA), and digital records of the films were captured with a Kodak 290 camera. The resulting bands were quantified as optical density (OD) x band area by a onedimensional (1-D) image analysis system (Eastman Kodak, Rochester, NY, USA) and expressed in arbitrary units normalized to the OD of beta-tubulin. The sizes of the proteins were verified by using standard molecular-weight markers (Bio-Rad, Hercules, CA, USA).

Paragraph number 10. Citrate synthase activity assay. Approximately $20 \mathrm{mg}$ of soleus muscle samples were homogenized on ice in $0.1 \mathrm{M}$ Tris buffer containing $0.1 \%$ Triton $\mathrm{X}-100, \mathrm{pH}$ 8.35. Citrate synthase (CS) activity was determined spectrophotometrically according to the method of Srere et al (33) and as conducted routinely in our laboratory. The homogenates were frozen under liquid nitrogen and thawed four times to disrupt the mitochondria in order to release the CS. The assay system was in a total volume of $200 \mu \mathrm{l}: 100 \mathrm{mM}$ Tris buffer (pH 8.35), 5 mM 5,5-dithiobis (2-nitrobenzoate) (DTNB), $22.5 \mathrm{mM}$ acetylCoA, $25 \mathrm{mM}$ oxaloacetate (OAA), and $4 \mu \mathrm{l}$ of homogenate. The rate in change in color was monitored at a wavelength of $405 \mathrm{~nm} \mathrm{sec}$ intervals for a period of $3 \mathrm{~min}$ by using a Dynex MRX plate reader controlled through PC software (revelation, Dynatech Laboratories, CA, USA). All measurements were performed in duplicate, in the same setting at $20-22^{\circ} \mathrm{C}$. The solublized protein extracts of the homogenates were quantified in duplicate by using bicinchoninic acid reagents (Pierce, Rockford, IL, USA) and BSA standards. The CS activity was normalized to the total protein expression and was reported as nanomoles per milligram protein per minute. 
Paragraph number 11. Statistical analyses. Results are presented as means \pm SE. A One-way ANOVA was used to examine differences across groups. Tukey's Post hoc tests were used to determine differences between the means. Significance was set at $P<0.05$. 


\section{RESULTS}

Paragraph number 12. Characterization of animals. At the start of this study the OZR had significantly elevated body weights compared to the LZR $(224.6 \pm 16.6$ vs. $171.9 \pm 14.9 \mathrm{~g}, \mathrm{p}<0.05)$. No differences in starting body weight were observed between control and trained animals within phenotype. After training, the animals were 15-16 weeks old. Training significantly lowered the body weights of OZR ( $658 \pm 18$ vs. $502 \pm 21 \mathrm{~g}, \mathrm{p}<0.05)$ but not LZR $(358 \pm 11$ vs. $360 \pm 16 \mathrm{~g})$ animals as previously reported (22).

Paragraph number 13. UCP3 protein levels. The effects of obesity and/or exercise on the protein concentrations of UCP3 in the hindlimb muscles were dependent on the muscle being examined. In the fast contracting plantaris and medial gastrocnemius muscles, there was an 8-fold and 3-fold increase, respectively, in the basal level of UCP3 in the OZR compared to the LZR (Figure 1A \& 1B). However, this difference was not observed in the soleus muscles of the OZR compared to the LZR (Figure 1C). Exercise had no effect on UCP3 concentration in either the fast contracting plantaris or medial gastrocnemius muscles (Figure 1A \& 1B). Additionally, aerobic exercise had no effect on the UCP3 content in the slow contracting soleus muscles of the LZR. Conversely, in the soleus muscles of the OZR there was a $67 \%$ decrease with aerobic exercise (Figure 1C).

Paragraph number 14. COX I protein levels. COX I is an inner mitochondrial membranebound enzyme which has a role in the electron transport chain. COX I was examined as a marker for mitochondrial content (11). This measure was important to determine if the training protocol was effective in increasing the mitochondrial protein fraction, and secondly to help determine whether changes in UCP3 expression were consistent with or independent from mitochondrial biogenesis. COX I protein expression increased in both the plantaris and soleus muscles with training (Figure 2A). 
Furthermore, UCP3 normalized to COX I protein expression (UCP3/COX I) was also examined (Figure 2B). UCP3/COX I was reduced in both the medial gastrocnemius (42\%) and the soleus $(59 \%)$ muscles of the LZR animals, but there was no change in the plantaris muscles. In the OZR, UCP3/COX I was reduced in the plantaris and soleus muscles, by $30 \%$ and $81 \%$ respectively, with no change in the medial gastrocnemius muscles.

Paragraph number 15. Citrate Synthase activity. To further verify that the training protocol was effective, CS activity, shown in figure 3, was measured biochemically in the soleus muscles of all trained and control animals. Similarly, to past studies from our lab (32), CS activities increased by $\sim 30 \%$ in soleus muscles in trained muscles from both the OZR and LZR animals. 


\section{DISCUSSION}

Paragraph number 16. The primary novel findings from this study are that UCP3 protein expression is affected by obesity and muscle phenotype, in the OZR. In this study we show a significantly greater basal UCP3 protein expression in the fast contracting glycolytic muscles of the hindlimb (gastrocnemius and plantaris) of the OZR compared to the LZR; however, there was no affect of obesity on UCP3 protein expression in the slow contracting oxidative soleus muscles.

Paragraph number 17. Previous research has shown that the OZR has significantly elevated palmitate (the most common free fatty acids found in the body) uptake per gram of muscle tissue as compared with LZR (28). This increase in exposure to free fatty acids may partially explain the increased UCP3 protein expression in the plantaris and gastrocnemius muscles that we observed in the current study. However, it remains unclear why UCP3 protein expression is not different in the soleus muscles of the LZR and the OZR. One possible explanation is that UCP3 expression may be determined in part by the manner in which fatty acids are stored in glycolytic and aerobic muscles. For example, Turcotte and colleagues (28) reported that glycolytic muscles in the OZR have elevated diacylglycerol synthesis compared to the LZR, whereas the oxidative muscle have elevated triglyceride synthesis compared to the LZR. However, the interactions between UCP3 and di- or triglycerides have not been elucidated. Another possibility is that the mitochondria in highly oxidative soleus muscles have sufficient UCP3 to provide stabilization to the mitochondria under conditions of high fatty acids, whereas, mitochondria in fast contacting muscles have less UCP3 and respond to the exposure of fatty acids by elevating the expression of UCP3.

Paragraph number 18. In this study we report that 9 weeks of aerobic exercise training resulted in decreases in UCP3 protein expression, and UCP3 expression normalized to mitochondrial protein expression, in the hindlimb muscles. It is important to note that nine weeks of aerobic training at 
this intensity and duration were sufficient to increase the mitochondrial protein expression (COX I) in the plantaris and soleus muscles of both the LZR and OZR, and that these increases were not different between groups. This would indicate that the animals had achieved adaptations to the aerobic exercise, and that the different training speeds were appropriate to illicit similar increases in mitochondrial protein expression in both the LZR and OZR. Furthermore, the soleus muscles of both the LZR and the OZR had significant increases in mitochondrial protein (COX I) and mitochondrial activity (CS activity) with a relative decrease in UCP3 protein expression. It has been proposed that aerobic training increases metabolic efficiency, which decreases the expression of UCP3 in skeletal muscle $(14 ; 34 ; 35)$ perhaps because mitochondria are stabilized to prevent oxidative damage by elevation of other oxidative enzymes (e.g., MnSOD, GPx, GSH/GSSG) in muscle or blood (36-38). Recent data provide additional evidence that UCP3 may provide a protective role for mitochondria, because the enhanced $\mathrm{H}_{2} \mathrm{O}_{2}$ emitting potential of mitochondria is returned to resting levels when UCP3 is increased in vivo (39). Furthermore, Hellsten and colleagues (40) have recently shown that antioxidant supplementation increased UCP3 expression levels in muscle after acute exercise and this suggests a clear linkage of UCP3 and adaptations to oxidative stress. In addition, to regulation by oxidative stress, the decrease in UCP3 levels after aerobic training in the current study could also be indicative of adaptations in muscle mitochondria to exercise because UCP3 contributes to the rate of state 4 respiration in skeletal muscle mitochondria (41). In support of this hypothesis, other studies which have examined chronic aerobic exercise training models, have also demonstrated a decrease in UCP3 expression with training $(14 ; 15)$.

Paragraph number 19. Our findings, are in agreement with data from previous studies which found that protein expression of UCP3 does not increase in parallel with training-induced mitochondrial biogenesis $(14 ; 16 ; 42)$. However this is contrary to the findings of others who reported increased UCP3 protein concentration (11) or mRNA expression $(11 ; 35)$ during 10 or 14 days, respectively, of aerobic training. We cannot rule out the possibility that there was an initial increase in UCP3 protein levels during the first 2-weeks of exercise training, but if this occurred, then this was a transient increase. This possibility, 
would explain why Jones and colleagues (11) found a parallel increase in UCP3 concentration and mitochondrial biogenesis. Our data suggest that such acute increases in UCP3 would likely be transient, since decreased UCP3 protein concentration and mRNA expression are reported both with aerobic training $(14 ; 16)$ and in aerobic trained cross-sectional studies $(4 ; 15 ; 42)$. It is possible that if UCP3 protein concentration was examined within 24 hours of the last training bout an increased protein concentration would have been observed as in aforementioned studies.

Paragraph number 20. A novel finding of this study was that the reduction in UCP3 protein expression with aerobic exercise training was more evident in the soleus muscle of the OZR than in the soleus of the LZR, or in either of the glycolytic muscles. It has been demonstrated that muscles higher in type I fibers (like the soleus) are more susceptible to exercise induced changes in UCP3 content (27). This may partially explain why the soleus muscles, which is composed of $\sim 80 \%$ type I fibers $(43 ; 44)$, demonstrated the most notable decline in UCP3 protein expression. Although there are significant differences in skeletal muscle fiber type percentages in muscles of the OZR compared to the LZR, the general trend in fiber type distribution remains similar to other rodent models, with the soleus muscle being composed primarily of type I fibers $(\sim 80 \%)$, the plantaris with predominately type IIa fibers ( $\sim 60 \%)$, and the gastrocnemius representing both type I and type II fibers $(29 ; 43 ; 44)$. Furthermore, it was confirmed in this study that among the muscles examined UCP3 protein expression followed a similar pattern in the OZR and LZR with it being lowest in the soleus muscles and no difference between the plantaris and gastrocnemius muscles.

Paragraph number 21. OZR animals were heavier than LZR animals, so if the animals were to run at the same pace, the muscles of the OZR animals would have a greater total workload than the LZR. Although we attempted to match training intensities by allowing the LZR to run at a faster pace than the OZR, we cannot completely rule out the possibility that potential differences in the training intensity may explain, at least in part, why the changes in normalized UCP3 protein expression were different between 
phenotypes. Nevertheless, it is apparent that both animal phenotypes increased mitochondrial protein expression in the plantaris and soleus muscles similarly, but that decreases in normalized UCP3 protein expression were more pronounced in the OZR.

Paragraph number 22. In conclusion, this study demonstrated that there is an interaction effect of muscle type (glycolytic or aerobic) and obesity in regards to the effect on UCP3 protein expression. Although the OZR has a significantly elevated UCP3 protein expression in the glycolytic muscles (plantaris) there was no difference in the aerobic muscles (soleus) between the two animal groups. On the

other hand, aerobic exercise had a similar effect on lowering the protein expression of UCP3 relative to the mitochondrial protein COX I. These data indicate that although there are differences in between the LZR and OZR, aerobic exercise affects them similarly.

\section{Acknowledgement.}

This study supported by NIH: National Institute on Aging Grant R01 AG021530 to S.E. Alway. 


\section{Reference List}

1. Cannon B, Nedergaard J. Brown adipose tissue: function and physiological significance. Physiol Rev. 2004;277-359.

2. Boss $\mathrm{O}$, Hagen $\mathrm{T}$, Lowell BB. Uncoupling proteins 2 and 3: potential regulators of mitochondrial energy metabolism. Diabetes 2000;143-56.

3. Bezaire V, Seifert EL, Harper ME. Uncoupling protein-3: clues in an ongoing mitochondrial mystery. FASEB J. 2007;312-24.

4. Cline GW. Tough love: left out in the cold, but not abandoned, by UCP3. J.Appl.Physiol 2006;12-3.

5. Himms-Hagen J, Harper ME. Physiological role of UCP3 may be export of fatty acids from mitochondria when fatty acid oxidation predominates: an hypothesis. Exp.Biol.Med.(Maywood.) 2001;78-84.

6. Schrauwen P, Saris WH, Hesselink MK. An alternative function for human uncoupling protein 3: protection of mitochondria against accumulation of nonesterified fatty acids inside the mitochondrial matrix. FASEB J 2001;2497-502.

7. Schrauwen P. High-fat diet, muscular lipotoxicity and insulin resistance. Proc.Nutr.Soc. 2007;3341.

8. Hesselink MK, Keizer HA, Borghouts LB, Schaart G, Kornips CF, Slieker LJ, Sloop KW, Saris WH, Schrauwen P. Protein expression of UCP3 differs between human type 1, type 2a, and type 2b fibers. FASEB J 2001;1071-3.

9. Felipe F, Bonet ML, Ribot J, Palou A. Up-regulation of muscle uncoupling protein 3 gene expression in mice following high fat diet, dietary vitamin A supplementation and acute retinoic acid-treatment. Int.J Obes.Relat Metab Disord. 2003;60-9.

10. Chou CJ, Cha MC, Jung DW, Boozer CN, Hashim SA, Pi-Sunyer FX. High-fat diet feeding elevates skeletal muscle uncoupling protein 3 levels but not its activity in rats. Obes.Res. 2001;313-9.

11. Cadenas S, Buckingham JA, Samec S, Seydoux J, Din N, Dulloo AG, Brand MD. UCP2 and UCP3 rise in starved rat skeletal muscle but mitochondrial proton conductance is unchanged. FEBS Lett. 1999;257-60.

12. Schrauwen P, Hesselink MK, Vaartjes I, Kornips E, Saris WH, Giacobino JP, Russell A. Effect of acute exercise on uncoupling protein 3 is a fat metabolism-mediated effect. Am.J.Physiol Endocrinol.Metab 2002;E11-E17.

13. Zhou M, Lin BZ, Coughlin S, Vallega G, Pilch PF. UCP-3 expression in skeletal muscle: effects of exercise, hypoxia, and AMP-activated protein kinase. Am J Physiol Endocrinol Metab 2000;E622-E629. 
14. Schrauwen P, Russell AP, Moonen-Kornips E, Boon N, Hesselink MK. Effect of 2 weeks of endurance training on uncoupling protein 3 content in untrained human subjects. Acta Physiol Scand. 2005;273-80.

15. Jones TE, Baar K, Ojuka E, Chen M, Holloszy JO. Exercise induces an increase in muscle UCP3 as a component of the increase in mitochondrial biogenesis. Am.J.Physiol Endocrinol.Metab 2003;E96-101.

16. Echtay KS, Roussel D, St Pierre J, Jekabsons MB, Cadenas S, Stuart JA, Harper JA, Roebuck SJ, Morrison A, Pickering S, Clapham JC, Brand MD. Superoxide activates mitochondrial uncoupling proteins. Nature 2002;96-9.

17. Boss O, Samec S, Desplanches D, Mayet MH, Seydoux J, Muzzin P, Giacobino JP. Effect of endurance training on mRNA expression of uncoupling proteins 1,2 , and 3 in the rat. FASEB $J$ $1998 ; 335-9$.

18. Russell AP, Wadley G, Hesselink MK, Schaart G, Lo S, Leger B, Garnham A, Kornips E, Cameron-Smith D, Giacobino JP, Muzzin P, Snow R, Schrauwen P. UCP3 protein expression is lower in type I, IIa and IIx muscle fiber types of endurance-trained compared to untrained subjects. Pflugers Arch. 2003;563-9.

19. Fernstrom M, Tonkonogi M, Sahlin K. Effects of acute and chronic endurance exercise on mitochondrial uncoupling in human skeletal muscle. J Physiol 2004;755-63.

20. Fabris R, Nisoli E, Lombardi AM, Tonello C, Serra R, Granzotto M, Cusin I, Rohner-Jeanrenaud F, Federspil G, Carruba MO, Vettor R. Preferential channeling of energy fuels toward fat rather than muscle during high free fatty acid availability in rats. Diabetes 2001;601-8.

21. Corbalan MS, Margareto J, Martinez JA, Marti A. High-fat feeding reduced muscle uncoupling protein 3 expression in rats. J.Physiol Biochem. 1999;67-72.

22. Takaya K, Ogawa Y, Masuzaki H, Matsuoka N, Hosoda K, Nakao K. [Leptin Receptor]. Nippon Rinsho 1998;1925-30.

23. Turner N, Bruce CR, Beale SM, Hoehn KL, So T, Rolph MS, Cooney GJ. Excess lipid availability increases mitochondrial fatty acid oxidative capacity in muscle: evidence against a role for reduced fatty acid oxidation in lipid-induced insulin resistance in rodents. Diabetes 2007.

24. Zucker LM. Fat mobilization in vitro and in vivo in the genetically obese Zucker rat "fatty". J.Lipid Res. 1972;234-43.

25. Frisbee JC, Samora JB, Peterson J, Bryner R. Exercise training blunts microvascular rarefaction in the metabolic syndrome. Am.J.Physiol Heart Circ.Physiol 2006;H2483-H2492.

26. Boss O, Samec S, Kuhne F, Bijlenga P, Assimacopoulos-Jeannet F, Seydoux J, Giacobino JP, Muzzin P. Uncoupling protein-3 expression in rodent skeletal muscle is modulated by food intake but not by changes in environmental temperature. J.Biol.Chem. 1998;5-8.

27. Schrauwen P, Hoppeler H, Billeter R, Bakker AH, Pendergast DR. Fiber type dependent upregulation of human skeletal muscle UCP2 and UCP 3 mRNA expression by high-fat diet. Int.J.Obes.Relat Metab Disord. 2001;449-56. 
28. Mogensen M, Bagger M, Pedersen PK, Fernstrom M, Sahlin K. Cycling efficiency in humans is related to low UCP3 content and to type I fibres but not to mitochondrial efficiency. J.Physiol 2006;669-81.

29. Russell AP, Somm E, Debigare R, Hartley O, Richard D, Gastaldi G, Melotti A, Michaud A, Giacobino JP, Muzzin P, LeBlanc P, Maltais F. COPD results in a reduction in UCP3 long mRNA and UCP3 protein content in types I and IIa skeletal muscle fibers. J.Cardiopulm. Rehabil. 2004;332-9.

30. Russell AP, Somm E, Praz M, Crettenand A, Hartley O, Melotti A, Giacobino JP, Muzzin P, Gobelet C, Deriaz O. UCP3 protein regulation in human skeletal muscle fibre types I, IIa and IIx is dependent on exercise intensity. J.Physiol 2003;855-61.

31. Turcotte LP, Swenberger JR, Zavitz TM, Yee AJ. Increased fatty acid uptake and altered fatty acid metabolism in insulin-resistant muscle of obese Zucker rats. Diabetes 2001;1389-96.

32. Torgan CE, Brozinick JT, Jr., Kastello GM, Ivy JL. Muscle morphological and biochemical adaptations to training in obese Zucker rats. J.Appl.Physiol 1989;1807-13.

33. Tonkonogi M, Krook A, Walsh B, Sahlin K. Endurance training increases stimulation of uncoupling of skeletal muscle mitochondria in humans by non-esterified fatty acids: an uncoupling-protein-mediated effect? Biochem.J 2000;805-10.

34. Pujol A, Lefaucheur L, Ecolan P, Picon L, Penicaud L. Fiber type composition and enzyme activities of muscles in two models of obese rats. Comp Biochem.Physiol B 1993;269-72.

35. Siu PM, Donley DA, Bryner RW, Alway SE. Citrate synthase expression and enzyme activity after endurance training in cardiac and skeletal muscles. J Appl.Physiol 2003;555-60.

36. Srere PA, Foster DW. On the proposed relation of citrate enzymes to fatty acid synthesis and ketosis in starvation. Biochem.Biophys.Res.Commun. 1967;556-61.

37. Schrauwen P. Skeletal muscle uncoupling protein 3 (UCP3): mitochondrial uncoupling protein in search of a function. Curr.Opin.Clin.Nutr.Metab Care 2002;265-70.

38. Tsuboyama-Kasaoka N, Tsunoda N, Maruyama K, Takahashi M, Kim H, Ikemoto S, Ezaki O. Up-regulation of uncoupling protein 3 (UCP3) mRNA by exercise training and down-regulation of UCP3 by denervation in skeletal muscles. Biochem.Biophys.Res.Commun. 1998;498-503.

39. Knez WL, Jenkins DG, Coombes JS. Oxidative stress in half and full Ironman triathletes. Med.Sci.Sports Exerc. 2007;283-8.

40. Nikolaidis MG, Paschalis V, Giakas G, Fatouros IG, Koutedakis Y, Kouretas D, Jamurtas AZ. Decreased blood oxidative stress after repeated muscle-damaging exercise. Med.Sci.Sports Exerc. 2007;1080-9.

41. Vollaard NB, Cooper CE, Shearman JP. Exercise-induced oxidative stress in overload training and tapering. Med.Sci.Sports Exerc. 2006;1335-41. 
42. Anderson EJ, Yamazaki H, Neufer PD. Induction of endogenous uncoupling protein 3 suppresses mitochondrial oxidant emission during fatty acid-supported respiration. J.Biol.Chem. 2007;31257-66.

43. Hellsten Y, Nielsen JJ, Lykkesfeldt J, Bruhn M, Silveira L, Pilegaard H, Bangsbo J. Antioxidant supplementation enhances the exercise-induced increase in mitochondrial uncoupling protein 3 and endothelial nitric oxide synthase mRNA content in human skeletal muscle. Free Radic.Biol.Med. 2007;353-61.

44. Ljubicic V, Adhihetty PJ, Hood DA. Role of UCP3 in state 4 respiration during contractile activity-induced mitochondrial biogenesis. J.Appl.Physiol 2004;976-83.

45. Schrauwen P, Troost FJ, Xia J, Ravussin E, Saris WH. Skeletal muscle UCP2 and UCP3 expression in trained and untrained male subjects. Int.J.Obes.Relat Metab Disord. 1999;966-72.

46. Chen KD, Alway SE. Clenbuterol reduces soleus muscle fatigue during disuse in aged rats. Muscle Nerve 2001;211-22.

47. Chen KD, Alway SE. A physiological level of clenbuterol does not prevent atrophy or loss of force in skeletal muscle of old rats. J.Appl.Physiol 2000;606-12.

48. Garrabou G, Soriano A, Lopez S, Guallar JP, Giralt M, Villarroya F, Martinez JA, Casademont J, Cardellach F, Mensa J, Miro O. Reversible inhibition of mitochondrial protein synthesis during linezolid-related hyperlactatemia. Antimicrob.Agents Chemother. 2007;962-7. 


\section{FIGURE LEGENDS}

Figure 1 UCP3 content in hindlimb muscles. The UCP3 protein expression was examined by Western immunoblots in the plantaris (A), medial gastrocnemius (B), and soleus muscles (C). Male obese Zucker (OZR-ET), n=8) and lean Zucker (LZR-ET, n=8) were endurance trained (ET) on a motorized treadmill for 12 weeks. Control (LZR, $\mathrm{n}=8$; OZR, $n=8$ ) LZR and OZR animals were exposed to the similar environment (positioned next to the treadmill) but were not exercised. The insets show representative Western blots for UCP3 and $\beta$-tubulin. $\beta$-tubulin was used as the loading control for each sample. The data are expressed in arbitrary units with UCP3 normalized to the $\beta$-tubulin content of each lane, and presented as means $\pm \mathrm{SE} . * \mathrm{P}<0.05$, data from OZR animals was significant different from the LZR animals. ${ }^{*} \mathrm{P}<0.05$, significantly different from all other groups. The main effects of obesity (OZR or LZR) and exercise interaction (obesity $\mathrm{x}$ exercise) in these animals were analyzed by a $2 \times 2$ ANOVA. Data are presented as means $\pm \mathrm{SE}$.

Figure 2 The effects of endurance training on COX I protein expression. (A) The COX I protein expression was examined by immunoblot analysis. We recorded a band at $\sim 37$ $\mathrm{kDa}$ as known in previous studies (45). The insets show representative Western blots for COX I and $\beta$-tubulin, which was used as the loading control for each sample. The data are expressed in arbitrary units with COX I normalized to the $\beta$-tubulin content of each lane. (B) UCP3 protein expression normalized to COX I protein expression. Data are presented as means $\pm \mathrm{SE} .{ }^{*} \mathrm{P}<0.05$, data significantly different from the LZR control animals. ${ }^{* *} \mathrm{P}<0.05$, significantly different from control OZR. The main effects of obesity (OZR or LZR) and exercise interaction (obesity x exercise) in these animals were 
analyzed by a $2 \times 2$ ANOVA. Data are presented as means \pm SE. Other abbreviations are identical to Figure 1.

Figure 3 The effects of endurance training on citrate synthase (CS) activity in soleus muscles. CS activity was determined in the soleus muscle of control and aerobically trained LZR and OZR rats. CS activity is normalized to the total protein expression of the sample used in the assay. Data are normalized to the protein expression of the sample and expressed as units $\cdot \mathrm{mg} \operatorname{prot}^{-1} \cdot \mathrm{min}^{-1} . * \mathrm{P}<0.05$, data significantly different from the LZR control animals. ${ }^{* *} \mathrm{P}<0.05$, significantly different from control OZR. Data are presented as means \pm SE. Other abbreviations are identical to Figure 1. 


\section{Figure 1}

A)

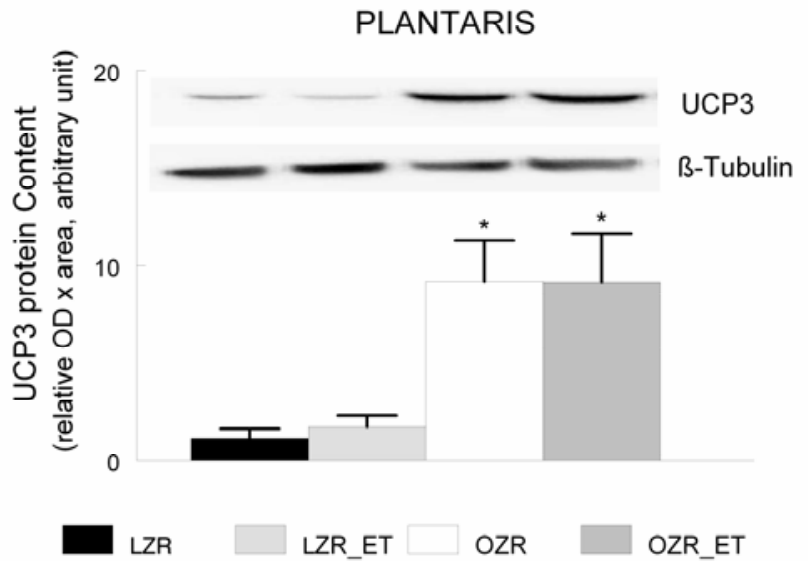

B)

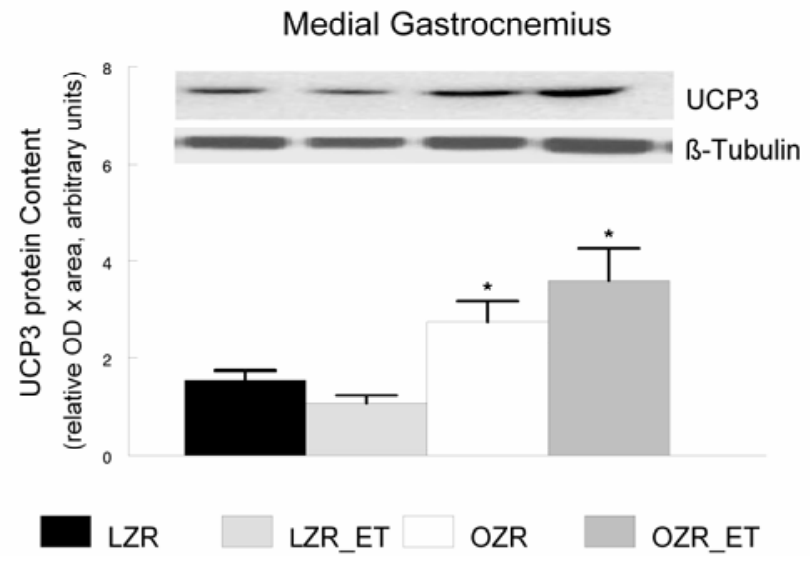


C)

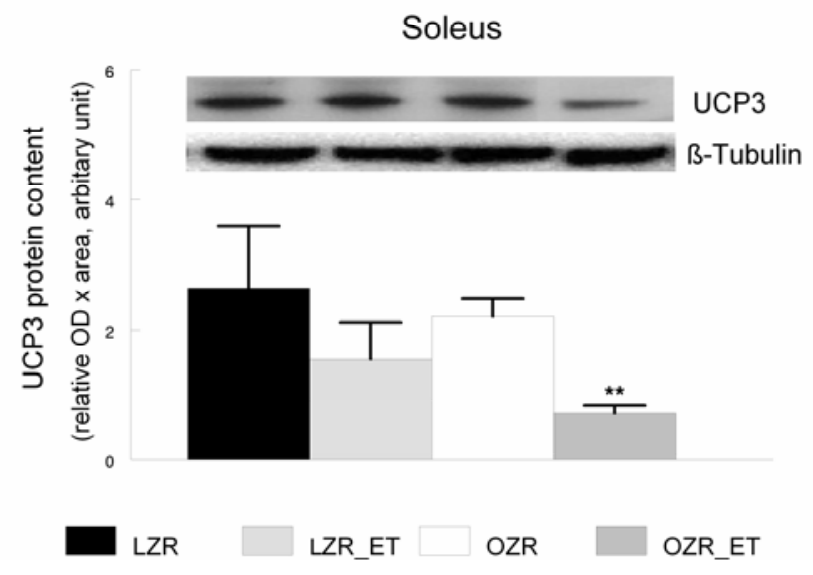




\section{Figure 2}

A)

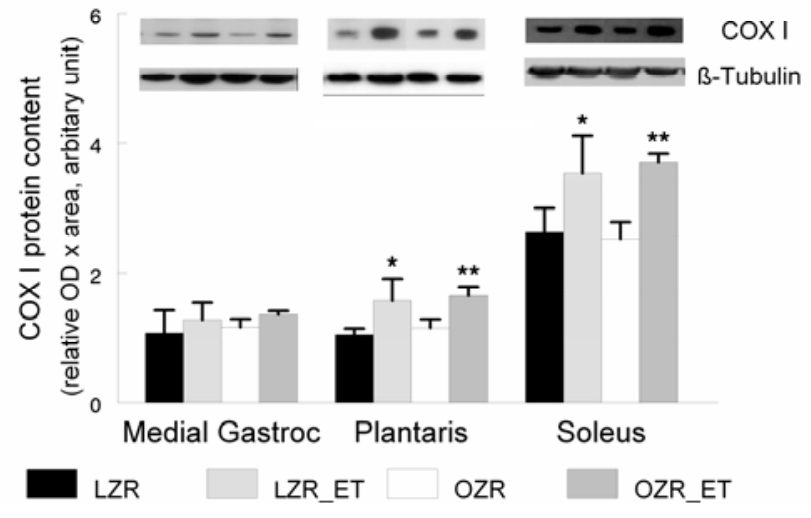

B)

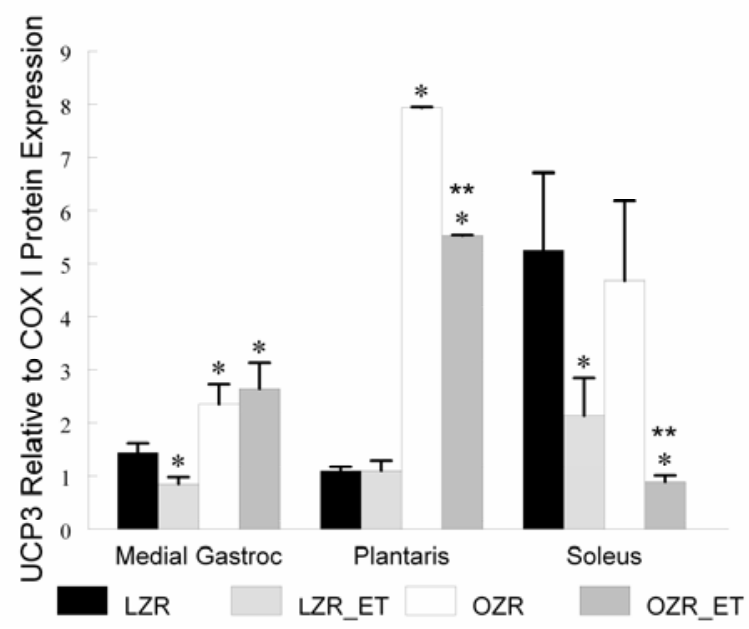


Figure 3

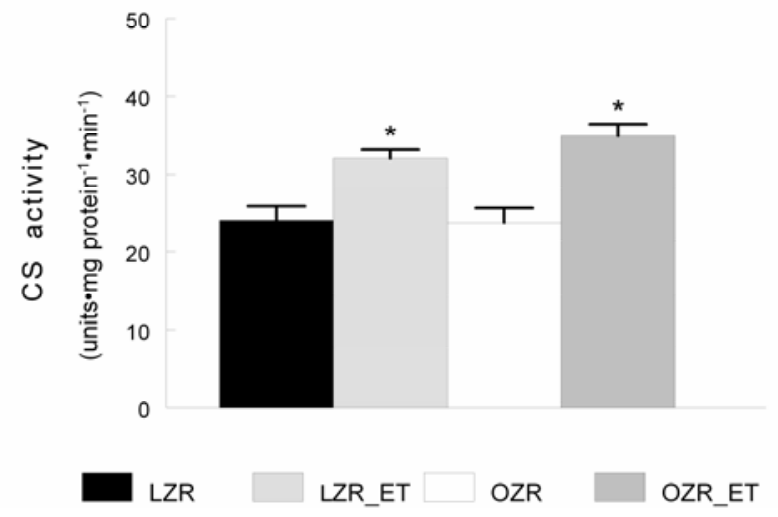




\section{Dissertation Methods}

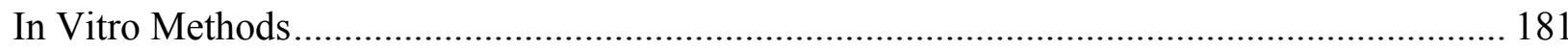

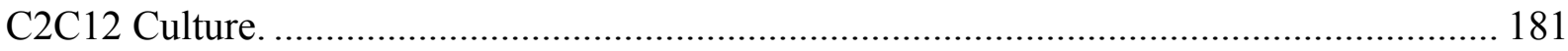

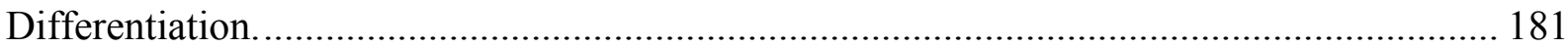

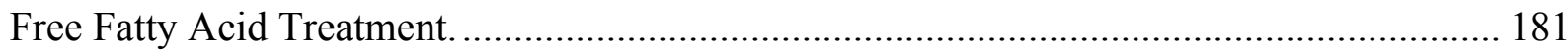

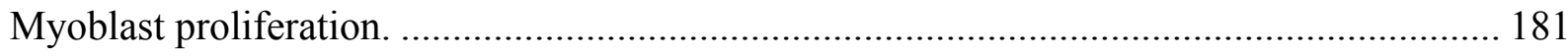

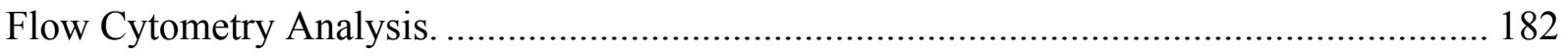

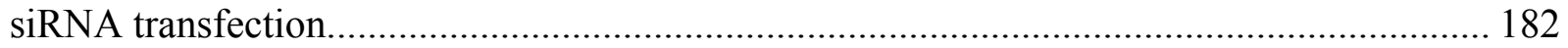

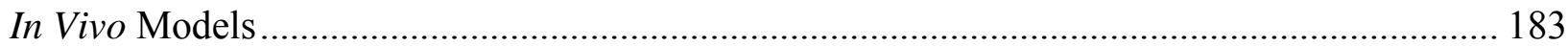

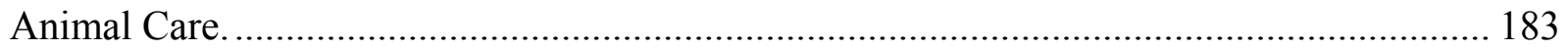

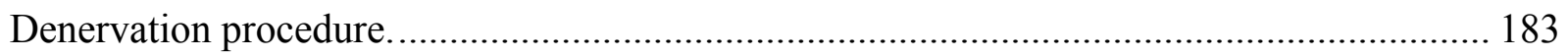

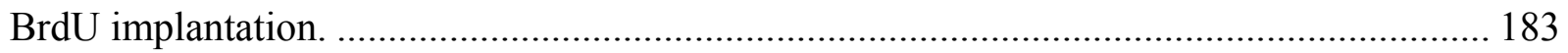

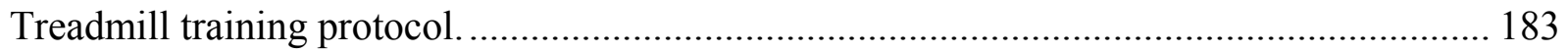

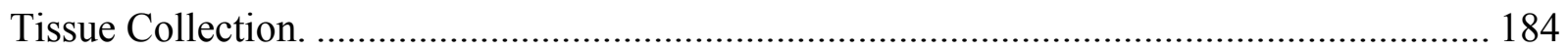

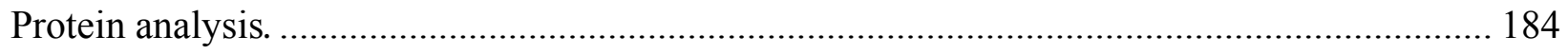

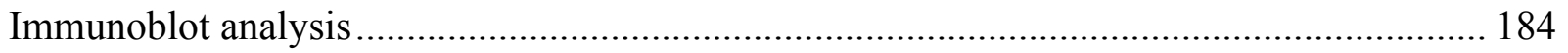

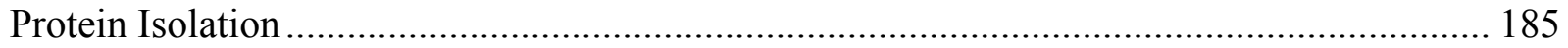

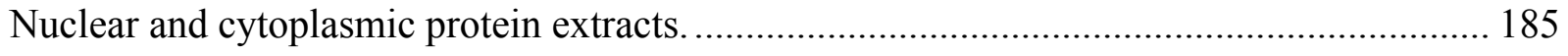

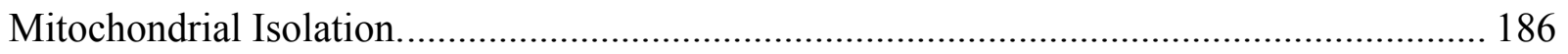

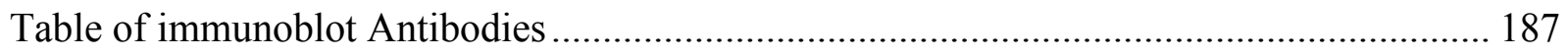




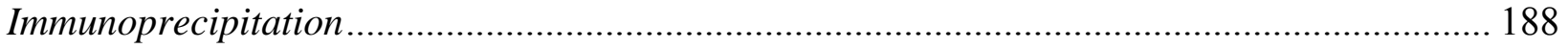

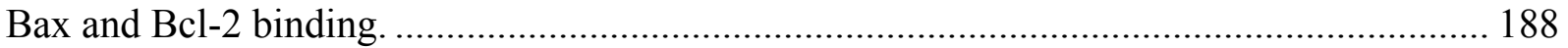

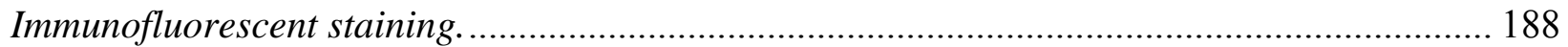

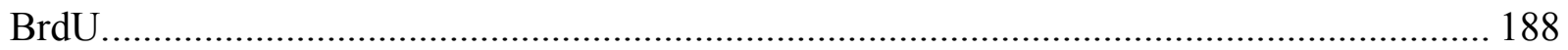

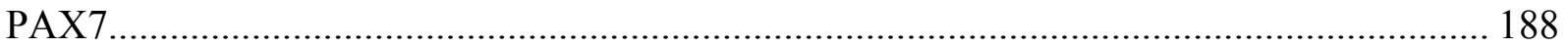

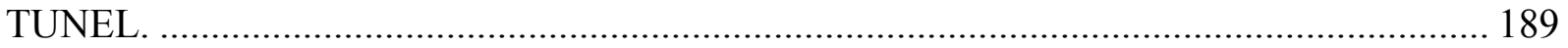

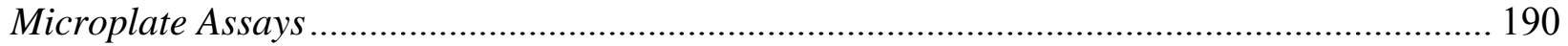

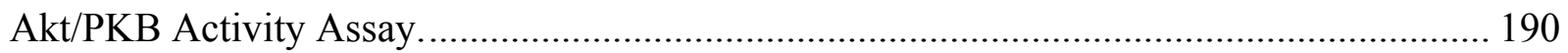

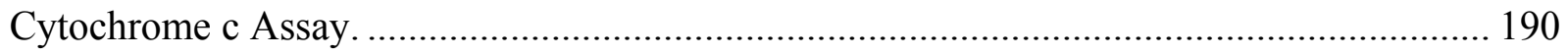

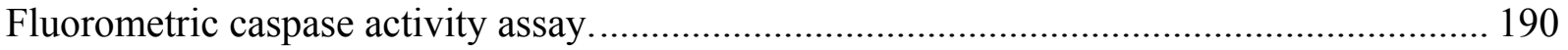

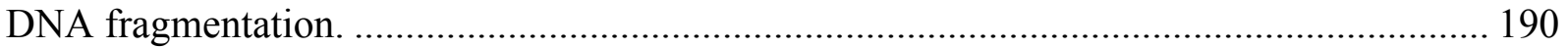

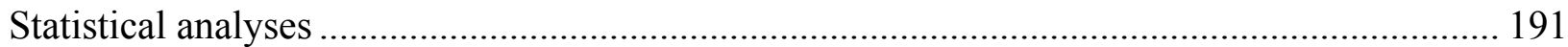




\section{IN VITRO METHODS}

\section{C2C12 Culture.}

C2C12 myoblasts were purchased from American Type Culture Collection (ATCC, Manassas, VA). The cells were cultured in $100 \mathrm{~mm}$ polystyrene culture dishes in Dulbecco Modified Eagle's Medium (Invitrogen, USA) supplemented with 10\% FBS and 1\% antibiotic antimycotic mixture and passaged in $0.25 \%$ trypsin. The cells were maintained in a humidified incubator under an atmosphere of $5 \% \mathrm{CO} 2$ at $37^{\circ} \mathrm{C}$. Fresh medium was supplied every 24-36 hours unless otherwise noted.

\section{Differentiation.}

For differentiation into myotubes, the myoblasts were grown to confluency and transferred to DMEM containing ITS liquid media (Sigma-Aldrich, St. Louis, MO). Myotubes were used for experiments following 4 days of differentiation, unless otherwise noted. All experiments were performed in triplicate.

\section{Free Fatty Acid Treatment.}

Palmitate (Sigma Chemicals; St. Louis, MO) was administered to cells as described by Chavez and Summers $(46 ; 47)$ with dodecanoic acid (laurate) used as a short chain free fatty acid (FFA) to differentiate the effects of FFAs alone and FFAs which interfere with Akt signaling. Briefly, palmitate was dissolved in ethanol and diluted in DMEM containing 2\% BSA. C2C12 myotubes were incubated with the FFAs $(0.75 \mathrm{mM}$ final concentration) in $1 \%$ FBS-DMEM for $16 \mathrm{~h}$, washed with DHANKS, and then incubated with the FFA in serum free DMEM for 2 hours. $1 \%$ FBS was reintroduced to the media 10 minutes prior to collection, except where indicated. C2C12 myoblast were incubated with FFAs $(0.25 \mathrm{mM}$ final concentration) in $10 \%$ FBS for $12-24$ hours and harvested immediately, except where indicated. Control experiments were performed with $2 \%$ BSA in the absence of FFAs.

\section{Myoblast proliferation.}

The first experiment performed was to determine if palmitate treatment inhibited myoblast proliferation. For this experiment $\mathrm{C} 2 \mathrm{C} 12$ myoblasts were suspended in trypsin, centrifuged at $20^{\circ} \mathrm{C}$ for 5 minutes at $1500 \mathrm{rpm}$ and then resuspended in PBS. Next $10 \mu \mathrm{M}$ carboxyfluorescein diacetate, succinimidyl ester (CFSE) was added to the cells and then the staining was immediately quenched with the addition of an equal volume of $10 \%$ FBS. An aliquot was fixed in $1 \%$ paraformaldehyde, to determine initial staining intensity. The cells were then plated into $35 \mathrm{~mm}$ plates in $10 \%$ FBS and allowed to grow for 24 hours. At this point the myoblasts were treated with palmitate, laurate, Akt-inhibitor (124005, Calbiochem, Germany) or BSA only and allowed to grow for an additional 24 hours. Next, the myoblasts were washed twice with PBS, harvested in $0.25 \%$ trypsin, and fixed with $1 \%$ paraformaldehyde, and examined using the FACSCalibur ${ }^{\mathrm{TM}}$ Flow Cytometer.

An additional proliferation assay was performed in a separated experiment in which the $\mathrm{C} 2 \mathrm{C} 12$ myoblasts were grown to $\sim 50$ percent confluency, treated with or without FFAs, pulsed 
for $20 \mathrm{~min}$ with $30 \mu \mathrm{g} / \mathrm{ml} \mathrm{BrdU}$ (550891, BD Biosciences Pharmingen, USA), harvested in trypsin, and fixed in ice cold $70 \%$ EOTH for 24 hours. The myoblast were then resuspended in $0.1 \%$ triton-X/0.1 M HCL for $1 \mathrm{~min}$, centrifuged at $2000 \mathrm{rpm}$ for $5 \mathrm{~min}$, then resuspended in DNA Denaturing Buffer $\left(0.15 \mu \mathrm{M} \mathrm{NaCl}, 15 \mu \mathrm{M}\right.$ Trissodium citrate dihydrate) at $95^{\circ} \mathrm{C}$ for $5 \mathrm{~min}$, followed by incubation at $4^{\circ} \mathrm{C}$ for $5 \mathrm{~min}$, and centrifuged $2000 \mathrm{rpm} 5 \mathrm{~min}$. Next the pellet was washed in 1\% BSA in PBS and then resuspended in Mouse anti-BrdU $(1: 50 ; 555627$; BD Pharmingen ${ }^{\mathrm{TM}}$, USA) for $30 \mathrm{~min}$ at room temperature. Next the cell were washed twice in PBS and then incubated with Anti-mouse Alexa-488 secondary antibody (1:400; A11029; Invitrogen, USA). Lastly, the myoblasts were wash twice with PBS and then resuspended in Propidium Iodide (10 $\mu \mathrm{g} / \mathrm{ml}$; P3566, Invitrogen, USA), RNAse (100 $\mu \mathrm{g} / \mathrm{ml} ; 10109169001$; Roche, USA) in PBS and analyzed a FACSCalibur ${ }^{\mathrm{TM}}$ Flow Cytometer.

\section{Flow Cytometry Analysis.}

The cells were transferred to $5 \mathrm{ml}$ polstytrene round bottom tubes for data acquisition and analysis on a FACSCalibur ${ }^{\mathrm{TM}}$ Flow Cytometer using CellQuest Pro software (BD Biosciences). All data are represented as mean fluorescence intensity (MFI). Additional cell cycle modeling was performed using Modfit LT software (Verity Software house, Inc).

\section{SiRNA transfection.}

The myotubes were transfected with scrambled, nonspecific siRNA without mammalian homology, or Bax siRNA (Santa Cruz Biotechnology, Santa Cruz, CA) using Lipofectamine 2000 (Invitrogen Carlsbad, CA). Individual siRNAs ( $80 \mathrm{pmols} /$ transfection) were transfected using Lipofectamine in serum-free DMEM for 6 hours. A $2 \mathrm{x}$ concentration $(2 \% \mathrm{FBS}, 4 \% \mathrm{BSA}$, and $1.25 \mathrm{mM}$ of palmitate) of media was then added to each well and the samples were incubated for an additional 12 hours. 


\section{IN VIVO MODELS}

\section{Animal Care.}

Obese and Lean zucker rats were purchased from Harlan labs (Harlan, Indianapolis, IN). Animals were housed in pathogen-free conditions, at $20-22^{\circ} \mathrm{C}$, and fed rat chow and water ad libitum throughout the study period. The animal care standards were followed by adhering to the recommendations for the care of laboratory animals, as advocated by the American Association for Accreditation of Laboratory Animal Care, which fully conformed to the Animal Welfare Act of the US Department of Health and Human Services. All animal procedures were conducted in accordance with institutional guidelines and ethical approval was obtained from the Animal Care and Use Committee at the West Virginia University prior to carrying out tests.

\section{Denervation procedure.}

To achieve compensatory hypertrophy, synergist denervation was employed. Briefly, the animals were placed under a general anesthesia using $2 \%$ isoflurane, and after cessation of reflex activity, the medial and lateral branches of the tibial nerve that innervate the plantar flexor muscles (i.e. gastrocnemius and soleus) were cut, and the cut nerve ends were sutured into the biceps femoris muscle to ensure that the nerve stumps did not reinnervate the gastrocnemius muscle. Care was taken to avoid any damage to the nerves, blood vessels and connective tissues. Innervation to the plantaris and the deep toe flexor muscles were left intact so that the animals ambulated normally around the cage after the surgical denervation. Following the surgery, the hamstring muscle layers were closed with reabsorbable suture, and the skin incisions were closed with wound clips. The incision sites were covered with an antibacterial cream to prevent infection. This resulted in removing the enervation to both heads of the gastrocnemius muscle and soleus muscles and placing a compensatory load on the plantaris muscle according to our previously published methods (48).

The contralateral limb received a sham surgery in which the branches of the tibial nerve were examined but not severed, and this served as an internal control for each animal. All procedures were performed under aseptic conditions. The animals recovered quickly and were alert and walking within $\sim 45$ min after surgery. Loading occurred for 7 or 21 days. In addition to placing a compensatory load on the plantaris muscle withdrawal of innervations to the medial gastrocnemius results in an highly-favorable apoptotic environment for this muscle (49).

\section{BrdU implantation.}

A time-released bromodeoxyuridine (BrdU) pellet (21-day release, $0.22 \mu \mathrm{g}$ BrdU.g body mass1-day-1; Innovative Research, Sarasota, FL) was placed subcutaneously on the dorsum. BrdU is a thymidine analog and is incorporated in nuclei during DNA synthesis. Therefore, it was used to identify activated satellite cells/muscle precursor cells during the 7- or 21-day period of muscle loading-induced hypertrophy.

\section{Treadmill training protocol.}

Animals were trained by running on a level motorized rodent treadmill (Columbus Instruments, Columbus, OH) 5 days weekly for 9 weeks. During the first 4 wk, the speed of the treadmill and 
duration of the training sessions were gradually increased from a speed of $10 \mathrm{~m} / \mathrm{min}$ for $10 \mathrm{~min}$ to a running speed of $20 \mathrm{~m} / \mathrm{min}$ for the OZR and $24 \mathrm{~m} / \mathrm{min}$ for the LZR. Different speeds were used to compensate for the increased intensity of exercise for the OZR due to increased body weight compared to LZR. Our pilot work suggested that the difference in body weight would vary around $40 \%$ and we used an estimation based on the formula of "work $=1 / 2$ mass * velocity squared $\left(\mathrm{W}=1 / 2 \mathrm{~m} * \mathrm{~V}^{2}\right)$ " and the estimated final weights of 500 grams for the OZR and 350 grams for the LZR. This calculation estimates that at 20 and $24 \mathrm{~m} / \mathrm{min}$ for the OZR and LZR, respectively, they would have an estimated final work output of 0.028 joules. Furthermore, our pilot data demonstrated that these intensities would be able to be reliably maintained by the OZR and LZR, respectively, with minimal motivation by the investigators. Additionally, as demonstrated by the mitochondrial proteins examined in this study we saw similar increases in the trained groups of both the OZR and LZR. During weeks 5 through 9, a 5-min warm-up session at a speed of $15 \mathrm{~m} / \mathrm{min}$ was followed by the 55 -min training session. During the training sessions, mild electrical shock stimulation was applied, if necessary, to maintain the running motivation. Animals assigned to the control group were handled daily and exposed to the noise of the running treadmill by placing their cages next to the treadmill during the exercise session.

\section{Tissue Collection.}

Animals were anaesthetized with ketamine hydrochloride, (9 mg x $100 \mathrm{~g}$ body weight $^{-1}$ ) and xylazine hydrochloride ( $1 \mathrm{mg} \mathrm{x} 100 \mathrm{~g}$ body weight $^{-1}$ ), I.P. and the hindlimb muscles from each limb were removed and frozen in isopentane, cooled to the temperature of liquid nitrogen, and stored at $-80^{\circ} \mathrm{C}$ until further analysis. Additionally, a mid-belly section of each muscle was fixed in $10 \%$ formalin and was embedded in paraffin.

For examination of the muscles that underwent compensatory loading or denervation. The hindlimb muscles were collected seven $(n=6$ LZR-7 and $n=6$ OZR-7) and 21 days $(n=6$ LZR-2 1 and $n=6$ OZR-21) after the surgical denervation. The animals were all 12 weeks old at time of tissue collection. The hindlimb muscles from the treadmill trained animals were harvested forty eight hours after the last training session and an overnight fast ( $\sim 16$ hours).

These muscles were chosen to examine changes in in the oxidative (soleus), glycolytic, (plantaris), and mixed oxidative and glycolic (gastrocnemius) muscles. Although it has been demonstrated that there is a reduction in percent of total fiber area occupied by the glycolytic fibers in the OZR compared to the LZR, the relative percentage of the glycolytic to oxidative fibers remained constant (31). Torgan et al. demonstrated that the OZR has $\sim 77 \%$ type I fibers in the soleus muscle compared to the LZR $(\sim 83 \%)$, with no difference in fiber type percentages in the plantaris muscle between the OZR and LZR ( $\sim 10 \%$ type I, $\sim 68 \%$ type IIa, and $\sim 22 \%$ IIb).

\section{PROTEIN ANALYSIS.}

\section{Immunoblot analysis}

The protein contents of the solublized extracts were quantified in duplicate by using bicinchoninic acid reagents (Pierce, Rockford, IL, USA) and bovine serum albumin (BSA) standards. $60 \mu \mathrm{g}$ of soluble protein was boiled for $4 \mathrm{~min}$ at $100^{\circ} \mathrm{C}$ in Laemmli buffer and loaded on each lane of a $12 \%$ polyacrylamide gel. The proteins were separated by routine SDS-PAGE for 1.5 hours at $20^{\circ} \mathrm{C}$. The gels were blotted to nitrocellulose membranes (Bio-Rad, Hercules, 
CA, USA) and stained with Ponceau S red (Sigma Chemical Co, St Louis, MO, USA) to confirm equal loading and transferring of proteins to the membrane in each lane.

The membranes were then blocked in 5\% non-fat milk in Tris buffered saline with $0.05 \%$ Tween 20 (TBS-T) and then probed with appropriate primary antibody (see table 1). Goat anti-rabbit secondary antibodies were conjugated to horseradish peroxidase (HRP) (Chemicon, CA, USA) and the signals were developed by chemiluminescence (Pierce, Rockford, IL, USA). The signals were visualized by exposing the membranes to X-ray films (BioMax MS-1, Eastman Kodak, Rochester, NY, USA), and digital records of the films were captured with a Kodak 290 camera. The resulting bands were quantified as optical density (OD) $\mathrm{x}$ band area by a one-dimensional (1-D) image analysis system (Eastman Kodak, Rochester, NY, USA) and expressed in arbitrary units nits normalized to $ß$-Tublin. The sizes of the proteins were verified by using standard molecular-weight markers (Bio-Rad, Hercules, CA, USA). To reduce the day-to-day variability between blots all comparisons were performed on samples run on the same membrane.

\section{Protein Isolation}

Total Protein homogenates of whole muscle sections were prepared in lysis buffer $(20 \mathrm{mM}$ Tris pH 7.5, $150 \mathrm{mM} \mathrm{NaCl}, 1 \%$ Nonidet P-40, 0.5\% Sodium Deoxycholate, $1 \mathrm{mM}$ EDTA, 0.1\% SDS) with the addition of Protease inhibitor cocktail (PIC; Sigma). Separate mitochondrial and mitochondria free protein fractions were also prepared according to methods as previously performed in our lab (50). Briefly, samples were homogenized in mitochondrial isolation buffer (20 mM HEPES pH 7.5, 10 mM KCl, 1.5 mM MgCl2, 1 mM EGTA, 1 mM EDTA, $1 \mathrm{mM}$ dithiothreitol, $250 \mathrm{mM}$ sucrose) with protease inhibitor cocktail (Sigma-Aldrich, St Louis, MO, USA). The homogenates were centrifuged at $800 \mathrm{x} g$ to remove nuclei and cell debris followed by centrifugation at $16,000 \mathrm{x}$ g for $20 \mathrm{~min}$ at $4^{\circ} \mathrm{C}$ to pellet the mitochondria. The supernatants were used as mitochondria-free cystosol. The mitochondrial pellet was washed twice then resuspended in total protein lysis buffer for analysis of Bax associated with the mitochondrial membrane.

Total protein homogenates of $\mathrm{C} 2 \mathrm{C} 12$ myoblast and Myotubes were obtained by washing 3 times in ice-cold PBS then the cells were lysed in 1x SDS sample buffer (50 mM Tris-HCl, $\mathrm{pH}$ $6.8,2 \%$ SDS, $6 \%$ glycerol, $1 \% \beta$-mercaptolethanol, $0.02 \%$ bromophenol blue) was added directly to the myotubes. $2 x$ SDS lysis buffer was added to an equal volume of the subcellular fractions obtained below. Samples were then lysed with a 25 gauge needle and boiled for 5 min at $100^{\circ} \mathrm{C}$ and separated on a $4-12 \%$ gradient polyacrylamide gel (Invitrogen, USA). Gels were blotted to nitrocellulose membranes (Bio-Rad, Hercules, CA) and stained with Ponceau red (Sigma Chemical Co, St Louis, MO, USA) to confirm equal loading.

\section{Nuclear and cytoplasmic protein extracts.}

The nuclear and cytoplasmic protein extracts were obtained using the method described by Rothermel et al. (51) and performed routinely in our lab. For in vitro experiments cells were washed 3 times in ice-cold phosphate buffered saline (PBS) then incubated in lysis buffer (10 $\mathrm{mM} \mathrm{NaCl}, 1.5 \mathrm{mM} \mathrm{MgCl}$, $20 \mathrm{mM}$ HEPES, $\mathrm{pH} 7.4,20 \%$ glycerol, 0.1\% Triton X-100, and 1 $\mathrm{mM}$ dithiothreitol) for 5 minutes at $4^{\circ} \mathrm{C}$. The cells were gently homogenized in a small glass 
homogenizer with Teflon pestle. For the in vivo experiments muscle samples were homogenized in 1:10 ice-cold lysis buffer (10 mM NaCl, $1.5 \mathrm{mM} \mathrm{MgCl}_{2}, 20 \mathrm{mM}$ HEPES at $\mathrm{pH} 7.4,20 \%$ glycerol, $0.1 \%$ Triton X-100, and $1 \mathrm{mM}$ dithioreitol) with a mechanical homogenizer. Muscle homogenates were transferred to $1.5 \mathrm{ml}$ Eppendorf tubes and centrifuged at $300 \mathrm{rpm}$ for 5minutes at $4^{\circ} \mathrm{C}$.

The homogenates were centrifuged at $1,000 \mathrm{rpm}$ for $1 \mathrm{~min}$ at $4^{\circ} \mathrm{C}$. The supernatants were spun twice more at 2,000 RPM and the final supernant contained the cytoplasmic protein fraction. The initial pellet contained the nuclear protein fraction. The nuclear pellet was washed twice in lysis buffer and then resuspended in lysis buffer containing $0.6 \mathrm{M} \mathrm{NaCl}$. The mixture was incubated for $1 \mathrm{~h}$ at $4^{\circ} \mathrm{C}$ and centrifuged at $14,000 \mathrm{rpm}$ for $15 \mathrm{~min}$ at $4^{\circ} \mathrm{C}$. The supernatants contained the nuclear protein fraction. A portion of the cytosolic extract (without addition of protease inhibitors) was stored and used for fluorometric caspase activity assays, while protease inhibitor cocktail (PIC, Sigma-Aldrich, St Louis, MO) was added to the nuclear and remaining cytosolic portion for further analysis.

\section{Mitochondrial Isolation.}

For the isolation of the mitochondrial and nuclear fraction from the cytoplasmic protein fraction the samples were incubated in ice-cold Mito-buffer $(20 \mathrm{mM}$ HEPES pH 7.5, $10 \mathrm{mM} \mathrm{KCl,} 1.5$ $\mathrm{mM} \mathrm{MgCl} 2,1 \mathrm{mM}$ EGTA, $1 \mathrm{mM}$ EDTA, $1 \mathrm{mM}$ dithiothreitol, $250 \mathrm{mM}$ sucrose, and $0.1 \mathrm{mM}$ phenylmethylsulfonyl fluoride) for 15 minutes. The samples were homogenized by homogenization in a small glass homogenizer with Teflon pestle. For the in vivo experiments the samples were initially minced with scissors before homogenization. The homogenates were centrifuged at $800 \mathrm{~g}$ to remove nuclei and cell debris and then centrifuged at $16,000 \mathrm{~g}$ for $20 \mathrm{~min}$ at $4{ }^{\circ} \mathrm{C}$ to pellet the mitochondria. The supernatant contained the mitochondrial-free cytosolic protein fraction and this used for analysis. 


\section{Table of immunoblot Antibodies}

\begin{tabular}{l|lll}
\hline Protein & Product number & Company & Dilution \\
\hline & & & $1: 2000$ \\
Total Akt & 9272 & Cell Signaling Technology & $1: 1000$ \\
Akt1 & 2967 & Cell Signaling Technology & $1: 500-1000$ \\
Akt2 & 2964 & Cell Signaling Technology & $1: 10000$ \\
Myosin Heavy Chain & MF20 & Hybridoma Bank & $1: 400$ \\
MyoD & Sc-304 & Santa Cruz & $1: 400$ \\
Myogenin & Sc-576 & Santa Cruz & $1: 1000$ \\
Cyclin D & 2946 & Cell Signaling Technology & $1: 2000$ \\
Cyclin B1 & 4135 & Cell Signaling Technology & $1: 1000$ \\
Phosph-Cyclin B1 & 41315 & Cell Signaling Technology & $1: 1000$ \\
p27 & 610243 & BD Biosciences & $1: 1000$ \\
p21 & 2946 & Cell Signaling Technology & $1: 400$ \\
p21 & Sc-6246 & Santa Cruz & $1: 400$ \\
p53 & Sc-99 & Santa Cruz & $1: 2000$ \\
Mn SOD & $06-984$ & Upstate & $1: 1000$ \\
Cu/Zn SOD & $07-403$ & Millipore & $1: 1000$ \\
COX I & A6403 & Invitrogen & $1: 2000$ \\
Beta-tubulin & Ab6046 & Abcam & $1: 500$ \\
Smac/Diablo & 612244 & BD Biosciences & $1: 1000$ \\
AIF & 4642 & Cell Signaling Technology & $1: 1000$ \\
UCP3 & UCP32-A & Alpha Diagnostics & $1: 400$ \\
Bax & Sc-493 & Santa Cruz & $1: 400$ \\
Bcl-2 & sc-7382 & Santa Cruz & $1: 400$ \\
BAD & 9467 & Santa Cruz & $1: 1000$ \\
FoxO3a & $9454 S$ & Cell Signaling Technology & $1: 1000$ \\
FoxO1 & 9472 & Cell Signaling Technology & $1: 1000$ \\
FoxO4 & $07-371$ & Cell Signaling Technology & $1: 3000$ \\
Histone & & Upsate & \\
\hline & & & \\
\hline
\end{tabular}




\section{IMMUNOPRECIPITATION}

\section{Bax and Bcl-2 binding.}

To determine if Bax to Bcl-2 binding corresponded to Akt Ser ${ }^{473}$ phosphorylation, FFA treated myotubes were serum starved for two hours with or without the addition FFAs or a commercially available Akt inhibitor (124005, Calbiochem, Germany). 1\% FBS was reintroduced to the media 10 minutes before collection of the myotubes. Similarly, to determine if the binding of Bax to Bcl-2 was altered with palmitate treatment, Bcl-2 was immunoprecipitated and the binding of Bax was determined through immunoblot analysis.

After treatment, myotubes were harvested in CHAPS buffer (40 mM HEPES, pH 7.5, 120 $\mathrm{mM} \mathrm{NaCl}, 1 \mathrm{mM}$ EDTA, $10 \mathrm{mM}$ pyrophosphate, $10 \mathrm{mM}$ P-glycerolphosphate, $40 \mathrm{mM} \mathrm{NaF}, 1.5$ $\mathrm{mM}$ sodium vanadate, $0.3 \%$ CHAPS, $0.1 \mathrm{mM}$ PMSF, $1 \mathrm{mM}$ benzamidine, and $1 \mathrm{mM}$ DTT), rocked for $20 \mathrm{~min}$ at $4^{\circ} \mathrm{C}$ and then centrifuged at $1,000 \mathrm{~g}$ for $10 \mathrm{~min}$ at $4{ }^{\circ} \mathrm{C}$. An aliquot from the resulting supernatant was preserved as total protein. The remaining supernatant was incubated with anti-Bcl-2 (0.2 $\mu \mathrm{g} / 100 \mu \mathrm{l}$; Santa Cruz), and incubated overnight at $4^{\circ} \mathrm{C}$. Prior to analysis, the immune complexes were collected for $1 \mathrm{~h}$ at $4^{\circ} \mathrm{C}$ with a goat anti-mouse BioMag IgG (Quigen, 310004 ) beads, blocked with $0.1 \%$ nonfat dry milk in CHAPS buffer. The beads were collected using a magnetic stand and washed with $200 \mathrm{mM}$ CHAPS and $60 \mathrm{mM}$ HEPES. The precipitates were eluted in 5x SDS sample buffer $(250 \mathrm{mM}$ Tris-HCl pH 6.8, 10\% SDS, 30\% Glycerol, 5\% $\beta$-mercaptoethanol and $0.02 \%$ bromophenol blue) and then boiled for $5 \mathrm{~min}$. The beads were collected with a magnetic stand, and the supernatant was collected and subjected to SDS-PAGE.

\section{IMMUNOFLUORESCENT STAINING.}

\section{BrdU.}

Parafin embedded, 7- $\mu \mathrm{m}$-thick, muscle cross sections from the loaded and control plantaris muscles were de-paraffinized in xylene, followed by rehydration in graded ethanol washes, and then rinsed in distilled $\mathrm{H}_{2} \mathrm{O}$. The tissues sections were incubated in an antigen retrieval buffer ( $10 \mathrm{mM}$ sodium citrate, $0.05 \%$ Tween-20, ph 6.0 ) for 30 minutes at $95^{\circ} \mathrm{C}$, washed in phosphate buffered saline (PBS) and then blocked in $1.5 \%$ goat serum in PBS at $37^{\circ} \mathrm{C}$ for $30 \mathrm{~min}$. Sections were then incubated with an anti-BrdU mouse monoclonal antibody (1:20 dilution, 555627; BD Pharmingen, San Diego, CA) followed by an anti-mouse Alexa 488 (A21463; Invitrogen, CA). Negative control experiments were done by omitting the BrdU antibody from the tissue sections. The basal lamina was identified with primary antibodies to anti-Laminin mouse IgG2a (D18; Hybridoma Bank) followed by goat anti-mouse IgG2a-R (Santa Cruz Biotechnology, CA). Only the BrdU positive nuclei within the basal lamina were quantified. The BrdU labeling index were calculated as: the number of BrdU labeled nuclei total nuclei ${ }^{-\mathbf{1}} 100$. This provided an index of satellite cell activation.

\section{PAX7}

Pax7 antibody (PAX7; Developmental Studies, Hybridoma Bank, U. Iowa) was used to determine the number of satellite cells in the control muscles (52). Since the formalin fixation 
interfered with the Pax7 antibody, $7 \mu \mathrm{m}$ cross-sections were obtained from frozen mid-belly sections of the muscle as previously performed in our laboratory (53). Briefly, the sections were air dried at room temperature, fixed in ice-cold methanol-acetone (1:1) for 10 minutes, rinsed in PBS, and permeablized in $0.2 \%$ triton- $\mathrm{X}$ in $0.1 \%$ sodium citrate. Next the sections were incubated for 30 minutes in $1.5 \%$ goat serum at $37^{\circ} \mathrm{C}$ in before incubation with Pax 7 primary antibodies, followed by an anti-mouse Alexa 488. The samples were then probed with antiLaminin mouse IgG2a (2E8; Hybridoma Bank) followed by goat anti-mouse IgG2a-R (Santa Cruz Biotechnology, CA).

D18, developed by Dr. Joshua Sanes, PAX7 antibody, developed by Dr. Atsushi Kawakami, and 2E8, developed by Dr. Eva Engvall, antibodies were obtained from the Developmental Studies Hybridoma Bank developed under the auspices of the NICHD and maintained by The University of Iowa, Department of Biological Sciences, Iowa City, IA 52242.

\section{TUNEL.}

In situ TdT-mediated dUTP nick end labeling (TUNEL) staining. The nuclei with DNA strand breaks were assessed using a fluorometric TUNEL detection kit according to the manufacturer's instructions for both $\mathrm{C} 2 \mathrm{C} 12$ cells and muscle cross sections (1684795; Roche Applied Science, Indianapolis, IN). For muscle cross sections, $10-\mu \mathrm{m}$-thick frozen medial gastrocnemius muscle cross sections from were cut in a freezing cryostat at $-20^{\circ} \mathrm{C}$. Tissue sections were air dried at room temperature, fixed in $4 \%$ paraformaldehyde in PBS, $\mathrm{pH} 7.4$, at room temperature for 20 min, permeabilized with $0.2 \%$ Triton $\mathrm{X}-100$ in $0.1 \%$ sodium citrate at $4^{\circ} \mathrm{C}$ for $2 \mathrm{~min}$, and incubated with fluorescein-conjugated TUNEL reaction mixture in a humidified chamber at $37^{\circ} \mathrm{C}$ for $1 \mathrm{~h}$ in the dark. Negative control experiments were done by omitting the TdT enzyme in the TUNEL reaction mixture on the tissue sections. After TUNEL labeling, the muscle sections were incubated with an anti-chick laminin mouse monoclonal antibody (for visualizing the basal lamina, $20 \mu \mathrm{g} / \mathrm{ml}$, clone 31-2) followed by an anti-mouse (1:200 dilution, C2181) and mounted with DAPI Vectashield mounting medium. TUNEL- and DAPI-positive nuclei and laminin staining were examined under a fluorescence microscope, and the captured images were stacked using a SPOT RT camera (Diagnostic Instruments, Sterling Heights, MI), and SPOT RT software (Universal Imaging, Downingtown, PA). The numbers of TUNEL and DAPI-positive nuclei were counted from six random, nonoverlapping fields at an objective magnification of $\mathrm{x} 40$. Only the labeled nuclei that were under the laminin staining were counted, to exclude any non-muscle nuclei in the sections. Data were expressed as number of TUNEL-positive nuclei per 100 nuclei counted. 


\section{MICROPLATE ASSAYS}

\section{Akt/PKB Activity Assay.}

To confirm changes to Akt/PKB activity another group of $\mathrm{C} 2 \mathrm{C} 12$ myotubes from each treatment condition were incubated in serum free DMEM for 2 hours with the addition of 100 $\mathrm{nM}$ insulin for 10 minutes before collection (46;47). Akt/PKB activity was assessed via Akt/PKB Kinase Activity Kit (Stressgen, EKS-400A). The change in color was measured at a wavelength of $405 \mathrm{~nm}$ by using a Dynex MRX plate reader controlled through PC software (Revelation; Dynatech Laboratories, CA, USA). Measurements were performed in duplicate, with all samples analyzed at the same time. The $\mathrm{OD}_{405}$ reading was then normalized to the milligrams of protein used in the assay.

\section{Cytochrome c Assay.}

The mitochondria free cytoplasmic fraction protein obtained as described previously was used for analysis of the cytochrome-c released from the mitochondria according to the manufacture's instructions (\#5265, Medical and Biological Laborotories). The change in color were monitored at a wavelength of $450 \mathrm{~nm}$ using a Dynex MRX plate reader. Measurements were performed in duplicate with all comparisons performed with the same assay. The cytochrome $c$ content were expressed as $\mathrm{OD}_{450}$ per milligram of protein.

\section{Fluorometric caspase activity assay.}

Activity of the caspase-9, 3 , and 8 were analyzed by a commercial caspase assay kit (APO54A-019-KI01, Apotech, Switzerland) according to the manufacturer's procedure and as previously performed in our laboratory (54). Caspase- 3 and caspase- 9 were measured as indices of mitochondrial induced apoptosis, whereas caspase 8 is a non-mitochondrial dependent caspase. Briefly, $50 \mu \mathrm{l}$ of the nuclei-free cytosolic extract (without protease inhibitors) were incubated in $50 \mu \mathrm{l}$ of assay buffer (50 mM PIPES, $0.1 \mathrm{mM}$ EDTA, 10\% glycerol, $10 \mathrm{mM}$ DTT, $\mathrm{pH}$ 7.2) with $100 \mu \mathrm{M}$ of the fluorogenic 7-amino-4-trifluoromethyl coumarin (AFC)-conjugated substrate (Ac-DEVD-AFC, Alexis Corp., San Diego, CA, USA) at $37^{\circ} \mathrm{C}$ for $2 \mathrm{~h}$. Caspase activity were accessed using a fluorescent microplate reader at the following wavelengths: caspase- 8 excitation 380nm and emission 460nm; caspase-3 \& 9 excitation 400nm and emission 505nm. The microplate were incubated at $37^{\circ} \mathrm{C}$ for 2-hours with caspase activity determined by subtracting OD readings at time 2 -hour from the initial reading at time 0 -hour. Optical density were normalized to the protein concentration of each muscle sample to provide a caspase activity index $\left(\mathrm{OD} \cdot \mathrm{mg}\right.$ protein $\left.^{-1}\right)$. Measurements were performed in duplicate.

\section{DNA fragmentation.}

A cell death detection ELISA kit (Roche Applied Science, Indianapolis, IN, USA) was used to quantitatively determine the apoptotic DNA fragmentation by measuring the cytosolic histone- 
associated mono- and oligonucleosomes. The change in optical density (OD) was measured at a wavelength of $450 \mathrm{~nm}$ by using a Dynex MRX plate reader controlled through PC software (Revelation; Dynatech Laboratories, CA, USA). Measurements were performed in duplicate, with samples from OZR and LZR analyzed at the same time. The $\mathrm{OD}_{450}$ reading was then normalized control samples. Measurements were performed in triplicate.

\section{STATISTICAL ANALYSES}

Statistical analyses were performed using the SYSTAT 11.0 software package. A one way Analysis of variance (ANOVA) was performed on the difference in all measured variables. Statistical significance was accepted at $P<0.05$. All data are given as means \pm standard error. 


\section{Reference List}

1. Cannon B, Nedergaard J. Brown adipose tissue: function and physiological significance. Physiol Rev. 2004;277-359.

2. Boss $\mathrm{O}$, Hagen T, Lowell BB. Uncoupling proteins 2 and 3: potential regulators of mitochondrial energy metabolism. Diabetes 2000;143-56.

3. Bezaire V, Seifert EL, Harper ME. Uncoupling protein-3: clues in an ongoing mitochondrial mystery. FASEB J. 2007;312-24.

4. Hesselink MK, Keizer HA, Borghouts LB, Schaart G, Kornips CF, Slieker LJ, Sloop KW, Saris WH, Schrauwen P. Protein expression of UCP3 differs between human type 1, type 2a, and type 2b fibers. FASEB J 2001;1071-3.

5. Felipe F, Bonet ML, Ribot J, Palou A. Up-regulation of muscle uncoupling protein 3 gene expression in mice following high fat diet, dietary vitamin A supplementation and acute retinoic acid-treatment. Int.J Obes.Relat Metab Disord. 2003;60-9.

6. Chou CJ, Cha MC, Jung DW, Boozer CN, Hashim SA, Pi-Sunyer FX. High-fat diet feeding elevates skeletal muscle uncoupling protein 3 levels but not its activity in rats. Obes.Res. 2001;313-9.

7. Cadenas S, Buckingham JA, Samec S, Seydoux J, Din N, Dulloo AG, Brand MD. UCP2 and UCP3 rise in starved rat skeletal muscle but mitochondrial proton conductance is unchanged. FEBS Lett. 1999;257-60.

8. Schrauwen P, Hesselink MK, Vaartjes I, Kornips E, Saris WH, Giacobino JP, Russell A. Effect of acute exercise on uncoupling protein 3 is a fat metabolism-mediated effect. Am.J.Physiol Endocrinol.Metab 2002;E11-E17.

9. Zhou M, Lin BZ, Coughlin S, Vallega G, Pilch PF. UCP-3 expression in skeletal muscle: effects of exercise, hypoxia, and AMP-activated protein kinase. Am J Physiol Endocrinol Metab 2000;E622-E629.

10. Schrauwen P, Russell AP, Moonen-Kornips E, Boon N, Hesselink MK. Effect of 2 weeks of endurance training on uncoupling protein 3 content in untrained human subjects. Acta Physiol Scand. 2005;273-80.

11. Jones TE, Baar K, Ojuka E, Chen M, Holloszy JO. Exercise induces an increase in muscle UCP3 as a component of the increase in mitochondrial biogenesis. Am.J.Physiol Endocrinol.Metab 2003;E96-101.

12. Echtay KS, Roussel D, St Pierre J, Jekabsons MB, Cadenas S, Stuart JA, Harper JA, Roebuck SJ, Morrison A, Pickering S, Clapham JC, Brand MD. Superoxide activates mitochondrial uncoupling proteins. Nature 2002;96-9.

13. Schrauwen P. High-fat diet, muscular lipotoxicity and insulin resistance. Proc.Nutr.Soc. 2007;3341. 
14. Boss O, Samec S, Desplanches D, Mayet MH, Seydoux J, Muzzin P, Giacobino JP. Effect of endurance training on mRNA expression of uncoupling proteins 1,2 , and 3 in the rat. FASEB $J$ 1998;335-9.

15. Russell AP, Wadley G, Hesselink MK, Schaart G, Lo S, Leger B, Garnham A, Kornips E, Cameron-Smith D, Giacobino JP, Muzzin P, Snow R, Schrauwen P. UCP3 protein expression is lower in type I, IIa and IIx muscle fiber types of endurance-trained compared to untrained subjects. Pflugers Arch. 2003;563-9.

16. Fernstrom M, Tonkonogi M, Sahlin K. Effects of acute and chronic endurance exercise on mitochondrial uncoupling in human skeletal muscle. J Physiol 2004;755-63.

17. Fabris R, Nisoli E, Lombardi AM, Tonello C, Serra R, Granzotto M, Cusin I, Rohner-Jeanrenaud F, Federspil G, Carruba MO, Vettor R. Preferential channeling of energy fuels toward fat rather than muscle during high free fatty acid availability in rats. Diabetes 2001;601-8.

18. Corbalan MS, Margareto J, Martinez JA, Marti A. High-fat feeding reduced muscle uncoupling protein 3 expression in rats. J.Physiol Biochem. 1999;67-72.

19. Takaya K, Ogawa Y, Masuzaki H, Matsuoka N, Hosoda K, Nakao K. [Leptin Receptor]. Nippon Rinsho 1998;1925-30.

20. Turner N, Bruce CR, Beale SM, Hoehn KL, So T, Rolph MS, Cooney GJ. Excess lipid availability increases mitochondrial fatty acid oxidative capacity in muscle: evidence against a role for reduced fatty acid oxidation in lipid-induced insulin resistance in rodents. Diabetes 2007.

21. Zucker LM. Fat mobilization in vitro and in vivo in the genetically obese Zucker rat "fatty". J.Lipid Res. 1972;234-43.

22. Frisbee JC, Samora JB, Peterson J, Bryner R. Exercise training blunts microvascular rarefaction in the metabolic syndrome. Am.J.Physiol Heart Circ.Physiol 2006;H2483-H2492.

23. Boss O, Samec S, Kuhne F, Bijlenga P, Assimacopoulos-Jeannet F, Seydoux J, Giacobino JP, Muzzin P. Uncoupling protein-3 expression in rodent skeletal muscle is modulated by food intake but not by changes in environmental temperature. J.Biol.Chem. 1998;5-8.

24. Schrauwen P, Hoppeler H, Billeter R, Bakker AH, Pendergast DR. Fiber type dependent upregulation of human skeletal muscle UCP2 and UCP3 mRNA expression by high-fat diet. Int.J.Obes.Relat Metab Disord. 2001;449-56.

25. Mogensen M, Bagger M, Pedersen PK, Fernstrom M, Sahlin K. Cycling efficiency in humans is related to low UCP3 content and to type I fibres but not to mitochondrial efficiency. J.Physiol 2006;669-81.

26. Russell AP, Somm E, Debigare R, Hartley O, Richard D, Gastaldi G, Melotti A, Michaud A, Giacobino JP, Muzzin P, LeBlanc P, Maltais F. COPD results in a reduction in UCP3 long mRNA and UCP3 protein content in types I and IIa skeletal muscle fibers. J.Cardiopulm.Rehabil. 2004;332-9. 
27. Russell AP, Somm E, Praz M, Crettenand A, Hartley O, Melotti A, Giacobino JP, Muzzin P, Gobelet C, Deriaz O. UCP3 protein regulation in human skeletal muscle fibre types I, IIa and IIx is dependent on exercise intensity. J.Physiol 2003;855-61.

28. Turcotte LP, Swenberger JR, Zavitz TM, Yee AJ. Increased fatty acid uptake and altered fatty acid metabolism in insulin-resistant muscle of obese Zucker rats. Diabetes 2001;1389-96.

29. Torgan CE, Brozinick JT, Jr., Kastello GM, Ivy JL. Muscle morphological and biochemical adaptations to training in obese Zucker rats. J.Appl.Physiol 1989;1807-13.

30. Tonkonogi M, Krook A, Walsh B, Sahlin K. Endurance training increases stimulation of uncoupling of skeletal muscle mitochondria in humans by non-esterified fatty acids: an uncoupling-protein-mediated effect? Biochem.J 2000;805-10.

31. Pujol A, Lefaucheur L, Ecolan P, Picon L, Penicaud L. Fiber type composition and enzyme activities of muscles in two models of obese rats. Comp Biochem.Physiol B 1993;269-72.

32. Siu PM, Donley DA, Bryner RW, Alway SE. Citrate synthase expression and enzyme activity after endurance training in cardiac and skeletal muscles. J Appl.Physiol 2003;555-60.

33. Srere PA, Foster DW. On the proposed relation of citrate enzymes to fatty acid synthesis and ketosis in starvation. Biochem.Biophys.Res.Commun. 1967;556-61.

34. Schrauwen P. Skeletal muscle uncoupling protein 3 (UCP3): mitochondrial uncoupling protein in search of a function. Curr.Opin.Clin.Nutr.Metab Care 2002;265-70.

35. Tsuboyama-Kasaoka N, Tsunoda N, Maruyama K, Takahashi M, Kim H, Ikemoto S, Ezaki O. Up-regulation of uncoupling protein 3 (UCP3) mRNA by exercise training and down-regulation of UCP3 by denervation in skeletal muscles. Biochem.Biophys.Res.Commun. 1998;498-503.

36. Knez WL, Jenkins DG, Coombes JS. Oxidative stress in half and full Ironman triathletes. Med.Sci.Sports Exerc. 2007;283-8.

37. Nikolaidis MG, Paschalis V, Giakas G, Fatouros IG, Koutedakis Y, Kouretas D, Jamurtas AZ. Decreased blood oxidative stress after repeated muscle-damaging exercise. Med.Sci.Sports Exerc. 2007;1080-9.

38. Vollaard NB, Cooper CE, Shearman JP. Exercise-induced oxidative stress in overload training and tapering. Med.Sci.Sports Exerc. 2006;1335-41.

39. Anderson EJ, Yamazaki H, Neufer PD. Induction of endogenous uncoupling protein 3 suppresses mitochondrial oxidant emission during fatty acid-supported respiration. J.Biol.Chem. 2007;31257-66.

40. Hellsten Y, Nielsen JJ, Lykkesfeldt J, Bruhn M, Silveira L, Pilegaard H, Bangsbo J. Antioxidant supplementation enhances the exercise-induced increase in mitochondrial uncoupling protein 3 and endothelial nitric oxide synthase mRNA content in human skeletal muscle. Free Radic.Biol.Med. 2007;353-61.

41. Ljubicic V, Adhihetty PJ, Hood DA. Role of UCP3 in state 4 respiration during contractile activity-induced mitochondrial biogenesis. J.Appl.Physiol 2004;976-83. 
42. Schrauwen P, Troost FJ, Xia J, Ravussin E, Saris WH. Skeletal muscle UCP2 and UCP3 expression in trained and untrained male subjects. Int.J.Obes.Relat Metab Disord. 1999;966-72.

43. Chen KD, Alway SE. Clenbuterol reduces soleus muscle fatigue during disuse in aged rats. Muscle Nerve 2001;211-22.

44. Chen KD, Alway SE. A physiological level of clenbuterol does not prevent atrophy or loss of force in skeletal muscle of old rats. J.Appl.Physiol 2000;606-12.

45. Garrabou G, Soriano A, Lopez S, Guallar JP, Giralt M, Villarroya F, Martinez JA, Casademont J, Cardellach F, Mensa J, Miro O. Reversible inhibition of mitochondrial protein synthesis during linezolid-related hyperlactatemia. Antimicrob.Agents Chemother. 2007;962-7.

46. Chavez JA, Summers SA. Characterizing the effects of saturated fatty acids on insulin signaling and ceramide and diacylglycerol accumulation in 3T3-L1 adipocytes and C2C12 myotubes. Arch.Biochem.Biophys. 2003;101-9.

47. Chavez JA, Knotts TA, Wang LP, Li G, Dobrowsky RT, Florant GL, Summers SA. A role for ceramide, but not diacylglycerol, in the antagonism of insulin signal transduction by saturated fatty acids. J.Biol.Chem. 2003;10297-303.

48. Degens H, Alway SE. Skeletal muscle function and hypertrophy are diminished in old age. Muscle Nerve 2003;339-47.

49. Siu PM, Alway SE. Mitochondria-associated apoptotic signaling in denervated rat skeletal muscle. J.Physiol 2005;309-23.

50. Siu PM, Alway SE. Mitochondria-associated apoptotic signaling in denervated rat skeletal muscle. J.Physiol 2005;309-23.

51. Rothermel B, Vega RB, Yang J, Wu H, Bassel-Duby R, Williams RS. A protein encoded within the Down syndrome critical region is enriched in striated muscles and inhibits calcineurin signaling. J.Biol.Chem. 2000;8719-25.

52. Zammit PS, Relaix F, Nagata Y, Ruiz AP, Collins CA, Partridge TA, Beauchamp JR. Pax7 and myogenic progression in skeletal muscle satellite cells. J.Cell Sci. 2006;1824-32.

53. Siu PM, Alway SE. Mitochondria-associated apoptotic signaling in denervated rat skeletal muscle. J.Physiol 2005;309-23.

54. Siu PM, Alway SE. Mitochondria-associated apoptotic signaling in denervated rat skeletal muscle. J.Physiol 2005;309-23. 